\title{
Cascading Trade Protection: Evidence from the US*
}

\author{
Aksel Erbahar ${ }^{\dagger}$ and Yuan $\mathrm{Zi}^{\ddagger}$ \\ April 2017 \\ [Previous version: October 2016]
}

\begin{abstract}
In a world with increasingly integrated global supply chains, trade policy targeting upstream products has unintended consequences on their downstream industries. In this paper, we examine whether protection granted to intermediate manufacturers leads to petition for protection by their downstream users. We first provide a simple model based on the quantitative framework of Ossa (2014) which identifies the key factors and their interactions that cause cascading protection to motivate our empirical analysis. Then, we test our model by identifying the input-output relationships among the time-varying temporary trade barriers of the US using its detailed input-output tables. As predicted by the theory, we find that measures on imported inputs increase the likelihood of their downstream users' subsequent trade remedy petition over the 1988-2013 period. Moreover, our simulation exercise shows that cascading protection can cause additional welfare losses, and hence we propose that trade policy investigations should take vertical linkages into account.
\end{abstract}

JEL codes: F1, F13, F14, F68

Keywords: trade policy, protectionism, trade barriers, global supply chains, input-output, anti-dumping

\footnotetext{
${ }^{*}$ We are grateful to Richard Baldwin, Nicolas Berman, Maarten Bosker, Chad Bown, Theresa Carpenter, Paola Conconi, Arnaud Costinot, Beata Javorcik, Marcelo Olarreaga, Ugo Panizza, and participants at several seminars for helpful comments at various stages of the development of this work. We thank the editor and the referees for insightful suggestions that helped improve this paper. Aksel Erbahar acknowledges funding provided by the project 'Dispute Settlement in Trade: Training in Law and Economics' (DISSETTLE), a Marie Curie Initial Training Networks (ITN) funded under the EU's Seventh Framework Programme, Grant Agreement No FP7-PEOPLE-2010-ITN_264633. Yuan Zi thanks additionally to the faculty of the Massachusetts Institute of Technology (MIT) for their hospitality during her visit as a doctoral researcher.

${ }^{\dagger}$ Erasmus School of Economics (ESE), Erasmus University Rotterdam, the Netherlands, and Tinbergen Institute, email: erbahar@ese.eur.nl

${ }^{\ddagger}$ The Graduate Institute of International and Development Studies (IHEID), Geneva, Switzerland, email: yuan.zi@graduateinstitute.ch
} 


\section{Introduction}

The US President Barack Obama, moments before signing The Manufacturing Enhancement Act of 2010, stated in his speech that "...[manufacturers] often have to import certain materials from countries and pay tariffs on those materials. This legislation will reduce or eliminate some of those tariffs, which will significantly lower costs for American companies across the manufacturing landscape..." (Obama, 2010). Input trade liberalization certainly has benefits. Amiti and Konings (2007), for example, show that a 10 percentage point fall in input tariffs results in a 12 percent gain in productivity for Indonesian firms that import these goods. Similarly, Goldberg et al. (2009) find that the Indian trade liberalization in 1991 enabled domestic firms to import new varieties and thus produce new products. Research in this area is mostly focused on liberalization and not on protection. However, following the rationale of the input liberalization literature, increasing import duties on key intermediates is clearly detrimental to the domestic manufacturing firms that use these inputs. One way for these downstream firms to pass on the losses to final consumers is to gain import protection for their own products. This type of protection, fittingly coined "cascading protection" by Hoekman and Leidy (1992), is the subject of this paper.

In this paper, we examine whether protection granted to intermediate manufacturers leads to petition for protection by their downstream users. We were motivated by the use of temporary trade barriers (TTBs) in the US, which include anti-dumping (AD), countervailing duties (CVD), and safeguards (SG), on vertically-linked products. For example, the World Bank's detailed Temporary Trade Barriers Database (Bown, 2014) shows that, in 1998, several US manufacturers of hot-rolled carbon steel applied for anti-dumping protection and the Department of Commerce imposed measures in 1999 on these products coming from Japan and Russia 11 In 2001, the US initiated a massive safeguard investigation covering 611 10-digit Harmonized Tariff Schedule (HTS) products that are heavy downstream users of hot-rolled carbon steel. Measures were imposed on a majority these products in $20022^{2}$ In another example, in 2001, the US applied anti-dumping duties on polyethylene terephthalate (PET) imported from India and Taiwan, after a petition by Dupont Teijin Films, Tsubishi Polyester Film, and Toray Plastics Incorporated. In 2003, five US producers of polyethylene retail carrier bags, a user industry of PET, requested anti-dumping duties on their products imported from China, Malaysia, and Thailand. Final measures were imposed in 20043

In order to guide our empirical analysis, we follow the quantitative framework developed by Ossa (2014) and extend it to provide a simple model of vertically-linked industries to identify the key factors and their interactions that cause cascading protection to occur. In this model, upstream protection increases the input price of downstream firms and this, assuming price-taking behavior, leads to an increase in import penetration for the downstream industry and thus a higher likelihood to petition

\footnotetext{
${ }^{1}$ These products were investigated once again in 2000, this time targeting 11 additional countries, with final measures imposed in 2001.

${ }^{2}$ See Durling and Prusa $(2003,2006)$ for a closer look at trade protection in the US steel industry, with focus on the crucial hot-rolled steel market.

${ }^{3}$ See Appendix Table A.2 for additional examples.
} 
for protection, which is the model's main empirically testable implication 4 The model also predicts that the existence of cascading protection creates an additional incentive for upstream industries to petition, leading to "too many" filings by intermediate manufacturers.

We test our main prediction by first identifying the input-output relationships among the timevarying TTBs of the US using its detailed input-output (IO) tables provided by the Bureau of Economic Analysis (BEA) $!^{5}$ We get the trade barrier data from the World Bank's Temporary Trade Barriers Database (Bown, 2014) and combine it with additional industry-level data from the BEA. Our identification relies on the fact that US TTB proceedings do not give legal voice to downstream firms during an investigation on one of their inputs. This affirms that upstream protection acts as an exogenous shock to the downstream firm. In fact, our empirical results show that protection on imported inputs increases the likelihood of their downstream users' subsequent trade remedy petition by 3 percentage points on average. This represents about 23 percent of the mean initiation rate (13 percent) in 19972013. The effect depends not only on the importance of the input in terms of its cost share but also on upstream and downstream industry characteristics such as import penetration, demand elasticity, and market size. In contrast, when we replicate the analysis for the EU, where TTB investigations do take downstream effects into account, we find no evidence for cascading protection. Next, we turn to our second prediction and investigate whether upstream industries that have "cascading-protection prone downstream structure" are more likely to file for protection and find positive and statistically significant results. In the last analytical part, we do a simulation exercise and find that the welfare loss for the importing country is 1.04 percent when cascading protection exists, much larger than the loss of 0.55 percent without it. Our counterfactual analyses show that these losses are exacerbated in a world with deeper global supply chains, and thus we argue that trade policy investigations should take vertical linkages into account.

Our findings relate mostly to the literature on vertically-linked trade policy schemes. Cascading trade protection, which is the main focus of this paper, was first identified by Feinberg and Kaplan (1993) who show that AD petitions that target downstream goods tend to follow AD initiations by upstream industries in the US chemicals and metals industries during 1980-86. However, they do not match upstream/downstream pairs and thus do not establish causality between upstream TTB measures and subsequent demand for TTBs by their downstream counterparts ${ }^{6}$ Hoekman and Leidy (1992) present a theoretical model, based on their earlier work on rent-seeking (Leidy and Hoekman, 1991) that explains how a downstream industry will follow its upstream counterpart in petitioning for $\mathrm{AD}$ duties due to depressed profits. Their model also explains why downstream users will not necessarily object to trade protection on their intermediate goods as long as they will also

\footnotetext{
${ }^{4}$ Note that this structure can be applied to all types of trade policy, and not just TTBs. We use TTBs to proxy for trade policy changes because they are the most transparent and frequently used type of time-varying trade policy in the US during 1995-2013.

${ }^{5}$ Ideally, we would test our prediction for all TTB user countries but no country except for the US has such a highly disaggregated IO table that is necessary for our analysis.

${ }^{6}$ They do employ the non-parametric Mann-Whitney $U$-test and show suggestive evidence that there is a tendency for downstream petitions to occur after upstream petitions.
} 
obtain protection. Their paper offers a neat cost-benefit analysis of cascading protection but does not discuss the role of market structure. Sleuwaegen et al. (1998) extend Hoekman and Leidy (1992) by incorporating market structure and predict that cascading protection is more likely to occur when the upstream industry is concentrated and has high import penetration, and the downstream industry is less concentrated. These two papers help illuminate the channel for cascading protection, but both work with only two industries (one upstream and one downstream), with limiting assumptions on vertical specialization patterns $7^{7}$ Hence, it is difficult to bring those models to data and inform their empirical and quantitative implications. Even though our paper's contribution is mostly empirical, we marginally contribute to this strand of literature by instead focusing on a vertically-linked multiindustry setting, and show that cascading protection exists in one of the most widely used models in international trade, namely the "new" trade model of Krugman (1980).

In the empirical literature, Blonigen (2015) uses subsidy and trade protection data and finds that industrial policy that promotes the steel sector has adverse effects on the export performance of steel-using industries. Konings and Vandenbussche (2013) use French firm-level data and find that AD duties depress sales and exports of export-oriented firms. Another paper that depicts the costs of input protection is by Vandenbussche and Viegelahn (2016), who use detailed Indian firm-level data to find that importing firms lower their purchases of protected inputs, and hence reduce their sales of outputs that use those inputs. The study that is closest to our paper in its approach and goal is Krupp and Skeath (2002), who examine certain upstream/downstream product pairs that were affected by US AD in 1977-92, and show that duties on upstream products negatively affect the quantity of downstream production. They find no evidence of an effect on the value of downstream production, which indicates that prices might play a role. They do not, however, look at the incidence of cascading protection. Interestingly, while examples are abundant, there is no rigorous empirical examination of cascading protection in the international trade literature 8 Hence, this paper provides the first systematic look at how trade barriers on imported inputs increase the likelihood of their downstream users' trade remedy petition. This is crucial in understanding the relationship between the increasingly integrated global supply chains and the amplification of welfare distortions due to trade protection.

Finally, our results are related to an extensive literature on anti-dumping use in the US, one of the most prominent users of contingent trade protection. Takacs (1981) and Finger et al. (1982) were among the first studies that look at US AD and safeguard use in the pre-1980 period. Initially created to combat predatory pricing, AD has become a tool for trade protectionism that aims to limit foreign competition, especially to help out declining industries 9 Staiger and Wolak (1994), Prusa (1996, 2011), and Irwin (2005) are among the important studies on AD use in the US. The literature then began to focus on the proliferation of AD in the world, as described in detail by Prusa (2001),

\footnotetext{
${ }^{7}$ For instance, Sleuwaegen et al. (1998) assume that upstream firms in both countries serve the home country only.

${ }^{8}$ There is, however, related research on the effective rates of protection which looks at countries' tariff structures in a static way.

${ }^{9}$ See, for example, Boltuck and Litan (1991) who examine the lax application of AD criteria. For in-depth analyses on declining industries and trade protection, see Hillman (1982), Brainard and Verdier (1997), and Magee (2002).
} 
Vandenbussche and Zanardi (2008), and Bown (2011). None of these papers, however, have looked at vertical linkages between $\mathrm{AD}$ measures as we do in this paper 10

The rest of the paper proceeds as follows. Section 2 presents a model of cascading protection based on Ossa (2014) with vertical linkages and tailored for anti-dumping procedures that guides our empirical analysis. Section 3 describes the data in detail. Section 4 has our empirical analysis with robustness checks. In Section 5, we do a simulation exercise with counterfactuals and calculate welfare effects. Section 6 concludes.

\section{A Model of Cascading Trade Protection}

This section presents the basic theoretical framework that guides our empirical and quantitative analyses. Our framework is standard and borrows significantly from older contributions in the literature. Notably, we build on the quantitative framework of Ossa (2014) and extend it to incorporate vertical industry linkages in a setting where industries have access to anti-dumping. As we go through the model in steps, we explain how each assumption can be linked to the US AD proceedings 11 Our specific assumptions with regards to the AD procedure in the US are based on an extensive literature that includes but not limited to works by Hoekman and Leidy (1992), Sleuwaegen et al. (1998), Blonigen and Haynes (2002, 2010), and Blonigen and Prusa (forthcoming). We characterize the protection granting decision by a government with a welfare function that exhibits loss aversion as the ones developed by Freund and Özden (2008) and Tovar (2009).

\subsection{Basic Environment}

We consider a world with two countries, each having $S$ downstream industries indexed by $s$ and $W$ upstream industries indexed by $w \mathbb{1 2}$ Consumers have access to a continuum of differentiated manufactured goods from each downstream industry and a homogeneous non-manufactured good. Preferences over these goods are identical across countries and are given by the following CES utility

\footnotetext{
${ }^{10}$ Although not directly related to our paper, recent work by Blanchard et al. (2016) do take into account supply chain linkages in trade policy determination. In that paper, the authors find that discretionary tariffs are decreasing in the domestic content of imported final goods.

${ }^{11}$ Note that even though the model aims to mimic AD proceedings, our empirical analysis includes other TTBs, namely CVDs and SGs, as well. Stand-alone CVDs (most CVDs are applied simultaneously with AD duties in the US) and SGs are used infrequently by the US.

${ }^{12}$ In Appendix Section A.4.1, we provide a multi-country extension to show that the existence of cascading protection does not depend on our two-country assumption. Note that a two-country model implies that a trade barrier covers the entire imports of the targeted product(s). In reality, majority of TTBs are applied bilaterally, covering on average 45 percent of import values (c.i.f.) and 50 percent of import volumes. However, our extension shows that this does not necessarily hinder cascading protection. An important reason for us to have a two-country setting is that typical quantitative works with multiple countries can only work with about 40 industries due to data limitations. Given that our main focus is on the interplay between domestic industries, and the fact that contingent trade protection is often applied at the product-level, we find it more reasonable to choose a two-country setting so that we can directly calibrate the model using the US IO table (343 manufacturing industries).
} 
function:

$$
U_{i}=\prod_{s}\left(\sum_{j \in\{1,2\}} \int_{0}^{N_{j s}} x_{j i s}\left(u_{j s}\right)^{\frac{\sigma_{s-1}}{\sigma_{s}}} d u_{j s}\right)^{\frac{\mu_{s} \sigma_{s}}{\sigma_{s-1}}} Y_{i}^{\mu_{Y}}
$$

where $x_{j i s}$ is the quantity of a variety from industry $s$ country $j$ that is consumed in country $i, Y_{i}$ is the quantity of the non-manufacturing good consumed in country $i, N_{j s}$ is the mass of industry $s$ varieties produced in country $j, \sigma_{s}>1$ is the elasticity of substitution, and $\mu_{s}$ is the fraction of income spent on downstream industry $s$, with $\sum_{s} \mu_{s}+\mu_{Y}=1$.

Downstream industries use upstream intermediates to produce final goods. Their technologies are given by:

$$
x_{i s}=\phi_{i s} \prod_{w}\left(\sum_{j \in\{1,2\}} \int_{0}^{N_{j w}} x_{j i w s}\left(\nu_{j w}\right)^{\frac{\sigma_{w-1}}{\sigma_{w}}} d \nu_{j w}\right)^{\frac{\beta_{w s} \sigma_{w}}{\sigma_{w}-1}},
$$

where $x_{i s}$ is the quantity produced by downstream industry $s$ in country $i, N_{j w}$ is the mass of upstream industry $w$ varieties produced in country $j, x_{j i w s}$ is the quantity of an input variety produced by industry $w$ in country $j$, used by industry $s$ in country $i, \phi_{i s}$ is the productivity parameter, and $\beta_{w s}$ is the fraction of costs that industry $s$ spends on purchasing inputs $w$. The non-manufacturing good market is perfectly competitive and freely traded whereas the upstream and downstream manufacturing industries are monopolistically competitive. Also, since we are analyzing temporary trade protection, we assume that the number of firms is given exogenously 13

Next we describe the AD process ${ }^{14}$ Upon experiencing a negative trade shock, an industry decides whether to petition for protection. Filing a petition includes organizing the industry, and collecting and presenting evidence of injury, the total cost of which we denote as $C_{i s} \sqrt{15}$ When a petition is filed, the government determines whether there is "dumping" and whether this has caused injury to the relevant domestic industry. We assume the government grants protection with a fixed probability $\theta$. Protection takes the form of an ad-valorem duty, which we denote as $t$, whose ex-ante value raises domestic industry profits back to their pre-shock level. For model tractability we also assume that the applied duty is in the form of an iceberg trade cost and hence it does not accrue to revenue.

\footnotetext{
${ }^{13}$ We assume a fixed number of firms for three reasons. First, because it features positive profits and therefore lends itself naturally to an analysis of temporary trade protection. As petition for protection is costly, allowing free entry implies zero profits and hence no incentives for incumbents to petition for protection in the first place. Second, TTBs are unlikely to provide incentives for firm entry since the WTO mandates that AD measures expire in five years with a (costly) possibility of extension, hence we can view TTBs as providing $5+$ years of protection with duration uncertainty. In fact, recent literature has shown that trade policy uncertainty significantly deters trade and trade-induced structural change (see Handley (2014), Handley and Limao (2015), and Pierce and Schott (2016)). Lastly, TTBs are most often applied in declining industries which should discourage firm entry in the first place, especially if entry costs are large.

${ }^{14}$ As mentioned before, the model aims to mimic the US AD system - countries have some flexibility in administering contingent trade protection. Additional details of the US AD investigation procedure can be find at the Antidumping and Countervailing Duty Handbook (ITC, 2008).

${ }^{15}$ In US AD investigations, the petition is deemed admissible if it is filed on behalf of a domestic industry: "( $\left.i\right)$ the domestic producers or workers who support the petition account for at least 25 percent of the total production of the domestic like product, and (ii) the domestic producers or workers who support the petition account for more than 50 percent of the production of the domestic like product produced by that portion of the industry expressing support for or opposition to the petition" (ITC, 2005). We follow the previous literature and assume that such internalization problems are solved (with costs).
} 
Our assumption of a fixed protection granting probability lies upon the fact that the Commerce Department's International Trade Administration (ITA) finds dumping in the large majority of investigations (more than 90 percent), and formal establishment of causality between "dumping" and "injury," which is the responsibility of the International Trade Commission (ITC), is almost never required ${ }^{16}$ As a consequence, the verdict on injury often determines whether protection measures are imposed. This implies that industries would not petition without some form of injury in the first place (they are requested to provide formal proofs). However, if all petitioning industries are able to pass the injury test, then protection should be automatically granted in each case, which clearly contradicts reality. Finding no convincing empirical evidence on the determinants of $\theta$, we simply assume that it is fixed. This can be interpreted as the ITC determinations being prone to random exogenous shocks making the granting probability less than one 17 In Appendix Section A.5, we discuss this assumption and its empirical relevance in detail.

Our formulation of a profit-restoring government can be reconciled with a political contribution model where government preferences display loss aversion and preference dependence as in Freund and Özden (2008) and Tovar (2009). In their models, the government perceives a decline in welfare when profits fall below a reference profit $\bar{\Pi}_{i s}$ for industry $s$ but derives no (or less) additional utility for profits above it. Applied to our context, suppose the government grants trade protection without taking into account its impact on other industries 18 If the protection structure before $\mathrm{AD}$ is the optimal policy (taking into account lobbying) and the risk-averse government takes industry profits with optimal policy tariffs as the reference point, a slight decline in foreign prices would induce the government to raise tariffs to bring the domestic industry profits back to the reference level. In particular, Freund and Özden (2008) argue that protection patterns predicted by this type of model exhibits remarkable overlap with actual AD charges in the US. They also find empirical evidence for this pattern in the hot-rolled steel industry of the US. Tovar (2009) uses non-tariff trade barrier data and finds that models with loss aversion match trade protection data better than standard political economy models.

Since the main objective of this paper is to understand the domestic contagion of trade policy along a country's supply chain, we assume that only country 1 can file for protection. Overall, given the complex and obscure nature of the actual TTB investigations, we inevitably make several simplifying assumptions. Nevertheless, in Appendix we provide various model extensions as sensitivity analyses: we extend the model to a multi-country setting in Section A.4.1, drop our CES assumption and allow endogenous markups in Section A.4.2, and allow both countries to be active policymakers in Section A.4.3 to examine how relaxing specific assumptions of the model affects the existence of cascading

\footnotetext{
${ }^{16}$ In the US, AD investigations are conducted jointly by the quasi-judicial ITC which examines whether there is injury to the domestic industry, and the ITA which determines the existence of dumping; injury is classified into three categories: material injury, threat of material injury and material retardation of the establishment of an industry. Dumping occurs if the price of the subject imports is "less than fair value" (ITC, 2005).

${ }^{17}$ Another trivial possibility for negative injury determinations is the inability of petitioning industries to prove injury.

${ }^{18}$ Crucially, the US investigations do not have a "public interest clause" that would mandate the authorities to consider the downstream effects of protection. The EU, another large AD user, does provide a legal standing for downstream users and consumers. See Section 4.2 for our falsification test using EU data.
} 
protection.

\subsection{Equilibrium for Given Trade Protection}

To facilitate the discussion on the cascading mechanism and quantitative exercises in later sections, we first present the equilibrium of the economy taking the petition and protection status as given. Cost minimization of the downstream implies that firms in upstream industry $w$ of country $j$ face the following demand:

$$
x_{j i w}=\frac{\left(p_{j w} \tau_{j i w}\right)^{-\sigma_{w}}}{P_{i w}^{1-\sigma_{w}}} \sum_{s} \beta_{w s} Q_{i s}
$$

where $p_{j w}$ is the ex-factory price of a variety from industry $w$ in country $j$, and $P_{i w}$ is the price index of industry $w$ varieties in country $i ; \tau_{j i w} \equiv 1+t_{j i w} \mathbb{P}_{i w}$, where $t_{j i w}$ is the duty country $i$ imposes on imports of $w$ from country $j$ and $\mathbb{P}_{i w}$ is the indicator variable which equals 1 when industry $w$ is granted protection; and $Q_{i s}$ is the total input expenditure of downstream industry $s$ in country $i$. The aggregated price index $P_{i w}$ is given by:

$$
P_{i w}=\left(\sum_{j \in\{1,2\}} N_{j w}\left(p_{j w} \tau_{j i w}\right)^{1-\sigma_{w}}\right)^{\frac{1}{1-\sigma_{w}}} .
$$

The profit-maximizing firm charges a constant markup over marginal cost. We choose the price of the non-manufacturing good as the numeraire, which implies that wages are equal to one in both countries. Hence, $p_{i w}=\frac{\sigma_{w}}{\left(\sigma_{w-1}\right) \phi_{i w}}$. The unit cost of downstream firms in industry $s$, country $i$ is therefore:

$$
c_{i s}=\frac{A_{s}}{\phi_{i s}} \prod_{w} P_{i w}^{\beta_{w s}}
$$

where $A_{s}=\prod_{w} \beta_{w s}^{-\beta_{w s}}$. Similarly, utility maximization implies that firms in downstream industry $s$ of country $j$ face the following demand in country $i$ :

$$
x_{j i s}=\frac{\left(p_{j s} \tau_{j i s}\right)^{-\sigma_{s}}}{P_{i s}^{1-\sigma_{s}}} \mu_{s} E_{i},
$$

where $p_{j s}, P_{i s}$ and $\tau_{j i s}$ are defined analogously to the upstream case, and $E_{i}$ is the income of country $i$. For simplicity, we assume that $E_{i}$ is fixed for both countries. Assuming a fixed $E_{i}$ is equivalent to assuming that in an economy with many industries, the net change due to protection is negligible in changing consumer income ${ }^{19}$ This assumption should be rather innocuous given that TTB protection is a rare event (the mean industry initiation rate is 6 percent in 1988-2013). The aggregated price

\footnotetext{
${ }^{19}$ If we assume that industry profits accrue to consumer income, protection increases industry profits, which translates to higher domestic income and thus greater consumption which benefits all industries; on the other hand, costly petitioning has the opposite income effect as it generates lump-sum losses.
} 
index $P_{i s}$ is given by:

$$
P_{i s}=\left(\sum_{j \in\{1,2\}} N_{j s}\left(p_{j s} \tau_{j i s}\right)^{1-\sigma_{s}}\right)^{\frac{1}{1-\sigma_{s}}},
$$

where $p_{j s}=\frac{\sigma_{s}}{\sigma_{s-1}} c_{j s}$. As a result, the operating profit of industry $s$ in country $i$ can be written as:

$$
\Pi_{i s}=\frac{1}{\sigma_{s}} \sum_{j \in\{1,2\}} N_{i s}\left(\frac{p_{i s} \tau_{i j s}}{P_{j s}}\right)^{1-\sigma_{s}} \mu_{s} E_{j} .
$$

The net profit of industry $s$ therefore equals $\Pi_{i s}-C_{i s} \mathbb{F}_{i s}$, where $\mathbb{F}_{i s}$ is an indicator variable which equals 1 when industry $s$ of country $i$ files for protection. With the CES production function, downstream firms always spend proportional to their revenue on their input purchases: $Q_{i s}=\left(\sigma_{s}-1\right) \Pi_{i s}$. This yields the operating profit of upstream industry $w$ :

$$
\Pi_{i w}=\frac{1}{\sigma_{w}} \sum_{j \in\{1,2\}} N_{i w}\left(\frac{\tau_{i j w} p_{i w}}{P_{j w}}\right)^{1-\sigma_{w}}\left(\sum_{s}\left(\sigma_{s}-1\right) \beta_{w s} \Pi_{j s}\right) .
$$

The net profit of industry $w$ therefore equals $\Pi_{i w}-C_{i w} \mathbb{F}_{i w}$, with $\mathbb{F}_{i w}$ being defined analogously to $\mathbb{F}_{i s}$.

Taking the protection status $\mathbb{P}$ and the tariff level $\tau$ as given, conditions (1)-(5) present a system of $2(2 W+3 S)$ equations with $2(2 W+3 S)$ unknowns, and thus $P_{i w}, P_{i s}, c_{i s}, \Pi_{i w}$ and $\Pi_{i s}$ can be solved given a numeraire. With information on petition $\operatorname{cost} C$ and granting probability $\theta$, we can therefore calculate industries' expected net gains/losses from petitioning.

\subsection{Cascading Protection, Market Structure and Upstream Incentives}

We define cascading protection as the case when the protection of an upstream industry increases the likelihood of its downstream counterpart's petition for protection 20 From a sequential game perspective, upstream firms make their petition decisions first, perfectly accounting for their impact on the decisions of downstream firms. Then, conditional on upstream's eventual protection status, downstream firms make their petition decisions. However, instead of searching for all possible subgame perfect Nash equilibria, we are interested in the second stage of the game, where downstream firms take upstream protection as given and react to it. For interested readers, the complete game is presented in Appendix Section A.3.

The profits of downstream industry $\Pi_{1 s}$ is a function of $\mathbb{P}_{s}$ and $\left\{\mathbb{P}_{w}\right\}$, where $\left\{\mathbb{P}_{w}\right\}$ is a $W \times 1$ vector with its $w^{t h}$ element being $\mathbb{P}_{w}{ }^{21}$ The downstream industry $s$ in country 1 chooses to file for protection $\left(\mathbb{F}_{s}=1\right)$ if and only if the expected gain exceeds the petition cost:

$$
\theta\left(\Pi_{1 s}\left(\left\{\mathbb{P}_{w}\right\}, \mathbb{P}_{s}=1\right)-\Pi_{1 s}\left(\left\{\mathbb{P}_{w}\right\}, \mathbb{P}_{s}=0\right)\right)-C_{s}>0
$$

\footnotetext{
${ }^{20}$ The existing literature typically defines cascading protection as "both intermediate and final good industries petition for protection" (Sleuwaegen et al., 1998).

${ }^{21}$ As only industries in country 1 can file for protection, we henceforth suppress the country subscripts for $\mathbb{F}, \mathbb{P}$, and $C$.
} 
Assume that $C_{s}=\bar{C}_{s}+e$, where $\bar{C}_{s}$ is a positive constant and $e$ is a random, independent disturbance term with mean zero ${ }^{22}$ Then the likelihood that the downstream industry petitions is positively correlated with potential rises in profits. Thus, defining $\frac{\Delta \Pi_{1 s}\left(\left\{\mathbb{P}_{w}\right\}\right)}{\Delta \mathbb{P}_{s}} \equiv \Pi_{1 s}\left(\left\{\mathbb{P}_{w}\right\}, 1\right)-\Pi_{1 s}\left(\left\{\mathbb{P}_{w}\right\}, 0\right)$, cascading protection happens if and only if the downstream industry's operating profit is supermodular in upstream and downstream protections 23

$$
\frac{\Delta^{2} \Pi_{1 s}}{\Delta \mathbb{P}_{s} \Delta \mathbb{P}_{w}} \equiv \frac{\Delta \Pi_{1 s}\left(\mathbb{P}_{w}=1\right)}{\Delta \mathbb{P}_{s}}-\frac{\Delta \Pi_{1 s}\left(\mathbb{P}_{w}=0\right)}{\Delta \mathbb{P}_{s}}>0
$$

In other words, the expected downstream profit gains from petitioning are larger with existing upstream protection. Substituting equations (4) and (2) into (7), we show in Appendix Section A.1 that $\frac{\Delta^{2} \Pi_{1 s}}{\Delta \mathbb{P}_{s} \Delta \mathbb{P}_{w}}$ can be rewritten as:

$$
\frac{\Delta^{2} \Pi_{1 s}}{\Delta \mathbb{P}_{s} \Delta \mathbb{P}_{w}}=\frac{\mu_{s} E_{1}}{\sigma_{s}}\left(M_{s}^{\prime}-M_{s}\right)
$$

where $M_{s}^{\prime}=1-\frac{N_{1 s} p_{1 s}^{1-\sigma_{s}}}{N_{1 s} p_{1 s}^{1-\sigma_{s}}+N_{2 s} p_{2 s}{ }^{1-\sigma_{s}}}$ and $M_{s}=1-\frac{N_{1 s} p_{1 s}^{1-\sigma_{s}}}{N_{1 s} p_{1 s}^{1-\sigma_{s}}+N_{2 s} p_{2 s}{ }^{1-\sigma_{s}}}$ are the import penetration rates of industry $s$ with and without upstream protection (and without downstream protection in both cases), with $p_{1 s}^{\prime}$ and $p_{1 s}$ being the corresponding prices charged by domestic firms. Given the fixed number of firms and income levels, the petition decision of downstream firms depends only on domestic market profits. Because the government grants protection to restore firms' domestic profits, motivation for cascading protection lies on the adverse effect of upstream protection on downstream profits. Using the expression of $M_{s}$ and unit cost equation $(2)$, it is easy to verify that $\frac{\Delta^{2} \Pi_{1 s}}{\Delta \mathbb{P}_{s} \Delta \mathbb{P}_{w}}>0$ trivially holds - cascading protection naturally emerges given our setting ${ }^{24}$

Both Hoekman and Leidy (1992) and Sleuwaegen et al. (1998) emphasize that upstream protection will increase the probability that protection will be granted $(\theta)$ if sought by the downstream industry. However, it is not clear whether the administering authority's decision is affected by the cause of the injury. In fact, the ITC has been criticized heavily for not establishing a causal relationship between dumping and injury as necessitated by the WTO. Therefore it is more natural to assume that conditional on petitioning, whether injury is caused by upstream protection or not should have zero predictive power in granting probability ${ }^{25}$ Our result suggests that the existence of cascading protection does not rely on the assumption of granting probability as the previous literature argues. Instead, it rises naturally from a vertical market structure whose building blocks are widely used in the trade literature.

\footnotetext{
${ }^{22}$ And $\min e>-\bar{C}_{s}$ so that $C_{s}>0$.

23 As all upstream industries are isomorphic, it is sufficient to analyze one; here we also slightly abuse notation as $\frac{\Delta \Pi_{1 s}\left(\mathbb{P}_{w}\right)}{\Delta \mathbb{P}_{s}}$ should be formally written as $\frac{\Delta \Pi_{1 s}\left(\mathbb{P}_{w}, \mathbb{P}_{-w}\right)}{\Delta \mathbb{P}_{s}}$.

${ }^{24}$ Notice that injury transmission is the key mechanism: cascading protection emerges in many classes of models as long as upstream protection decreases downstream profits. Those include, but not limited to, models with multiple countries, variable markups, or imperfect tariff pass-through. Nevertheless, this result hinges upon our assumption of a profit-restoring government. In Appendix sections A.4.1, A.4.2, and A.4.3 we also relax this particular assumption to see if cascading protection still holds in various model extensions. For an empirical discussion of how TTBs increase overall price levels, see Appendix Section A.6.

${ }^{25}$ Indeed, we were not able to find a relationship empirically between upstream protection and the probability of obtaining downstream protection given petition. Appendix Section A.5 shows our results.
} 
A higher $\frac{\Delta^{2} \Pi_{1 s}}{\Delta \mathbb{P}_{s} \Delta \mathbb{P}_{w}}$ implies a relatively larger gain from petitioning for the downstream industry with upstream protection. In other words, cascading protection is more likely to happen when $\frac{\Delta^{2} \Pi_{1 s}}{\Delta \mathbb{P}_{s} \Delta \mathbb{P}_{w}}$ is large. Performing the first-order Taylor approximation of equation (8) around $t_{21 w}=0$, we get:

$$
\frac{\Delta^{2} \Pi_{1 s}}{\Delta \mathbb{P}_{s} \Delta \mathbb{P}_{w}} \approx \frac{\left(\sigma_{s}-1\right) \mu_{s} E_{1}}{\sigma_{s}}\left(1-M_{s}\right) M_{s} \beta_{w s} M_{w} t_{21 w}
$$

Detailed derivation of Equation (9) is given in Appendix Section A.1. If the newly protected imported input is heavily used (high $\beta_{w s}$ and $M_{w}$ ), and the downstream industry faces an elastic demand (high $\left.\sigma_{s}\right)$, the injury transmitted to the downstream industry is more likely to be severe - this will increase the likelihood of cascading protection. Import penetration of the downstream industry $\left(M_{s}\right)$ affects the likelihood of cascading protection non-monotonically. When import penetration is very high or very low, the downstream profit loss caused by upstream protection is small, hence the marginal increase of the petition likelihood induced by upstream protection is small as well[ ${ }^{26}$

The points discussed above can be summarized in the following proposition, which sheds light on how market structure influences the likelihood of cascading protection.

PROPOSITION 1. Cascading protection is more likely to happen if the protected upstream industry has high import penetration and/or is heavily used by its downstream industry; it is also more likely to happen if the affected downstream industry has a large domestic market and/or a high demand elasticity. When the import penetration rate of the downstream industry rises, it first increases and then decreases the likelihood of cascading protection.

In their seminal paper, Hoekman and Leidy (1992) propose that when an upstream industry seeks protection that stands to severely harm its domestic downstream customers, the motivation must lie in the expectation that the transmission of injury will make downstream protection more likely. Thus, we now examine whether potential cascading protection creates incentives for upstream industries to pursue protection in the first place. Taking into account that its eventual protection will increase its downstream industries' petition likelihood, the upstream industry $w$ will file for protection if and only if:

$$
\theta\left[E\left(\Pi_{1 w}\left(\mathbb{P}_{w}=1\right)\right)-E\left(\Pi_{1 w}\left(\mathbb{P}_{w}=0\right)\right)\right]-C_{w}>0,
$$

where $E\left(\Pi_{1 w}\left(\mathbb{P}_{w}=1\right)\right)$ is the expected payoff of the upstream industry when it receives protection. Upstream firms' decision to petition would take into account world profits: an increase in upstream protection shifts the domestic demand for upstream goods towards domestic producers, but also increases the price of domestic downstream goods. As a result, foreign downstream production expands and hence its demand for those domestic upstream goods increases as well.

\footnotetext{
${ }^{26}$ To further illustrate the point, think of a case where a certain downstream industry has import penetration close to zero. In this case, domestic downstream firms are so competitive that given an increase in costs (due to upstream protection), profits are not too much affected. In another extreme case where a downstream industry has import penetration close to 100 percent, then the industry's marginal decline in competitiveness due to upstream protection is not sufficient to prompt a petition.
} 
Protection granted to the upstream industry increases the likelihood of downstream industries' petition, which in turn affects the expected profits of the upstream industry. Denoting the downstream protection outcomes by an $s \times 1$ vector $\left\{\mathbb{P}_{s}\right\}$, and the probability of its realization by $\operatorname{Pr}\left(\left\{\mathbb{P}_{s}\right\} \mid \mathbb{P}_{w}\right)$, $E\left(\Pi_{1 w}\left(\mathbb{P}_{w}=1\right)\right)$ can be written as:

$$
E\left(\Pi_{1 w}\left(\mathbb{P}_{w}=1\right)\right)=\sum_{\left\{\mathbb{P}_{s}\right\}} \Pi_{1 w}\left(\mathbb{P}_{w}=1,\left\{\mathbb{P}_{s}\right\}\right) \operatorname{Pr}\left(\left\{\mathbb{P}_{s}\right\} \mid \mathbb{P}_{w}=1\right)
$$

If the upstream industry does not consider the impact of its behavior on its downstream industries' protection likelihood, then it perceives $\operatorname{Pr}\left(\left\{\mathbb{P}_{s}\right\} \mid \mathbb{P}_{w}=1\right)=\operatorname{Pr}\left(\left\{\mathbb{P}_{s}\right\} \mid \mathbb{P}_{w}=0\right)$. In this case, its expected payoff from getting protected becomes:

$$
E_{0}\left(\Pi_{1 w}\left(\mathbb{P}_{w}=1\right)\right)=\sum_{\left\{\mathbb{P}_{s}\right\}} \Pi_{1 w}\left(\mathbb{P}_{w}=1,\left\{\mathbb{P}_{s}\right\}\right) \operatorname{Pr}\left(\left\{\mathbb{P}_{s}\right\} \mid \mathbb{P}_{w}=0\right)
$$

If the existence of cascading protection increases the upstream industry's petition incentive, we expect that $E\left(\Pi_{1 w}\left(\mathbb{P}_{w}=1\right)\right)>E_{0}\left(\Pi_{1 w}\left(\mathbb{P}_{w}=1\right)\right)$. We prove that this is indeed the case in Appendix Section A.2. The intuition is as follows. As income is fixed, consumers spend a fixed proportion on purchasing downstream goods. From an upstream industry perspective, downstream protection acts as a shift of foreign demand to domestic demand. With the presence of protection, upstream firms are relatively more competitive domestically and hence benefit from this shift. Therefore, knowing that its own protection increases the likelihood of downstream protection provides an additional incentive for the upstream industry to file for protection. This result is summarized in the following proposition:

PROPOSITION 2. The existence of cascading protection increases the likelihood of upstream industries to file for protection.

The key insight of Proposition 2 is that when industries are vertically linked, the upstream industry may file "too many" petitions at the expense of its downstream users and final consumers. A duty imposed on upstream goods directly decreases the domestic consumer's welfare by making domestic downstream products more expensive. Due to the possibility of cascading protection, these duties might have an additional negative impact on consumer welfare by triggering downstream protection. Moreover, Proposition 2 indicates that these effects can be even larger as upstream industries are more likely to file for protection when they know that their downstream counterparts can also obtain protection. As is well-known, TTBs are often imposed for import relief rather than welfare maximization, and this often hurts the final consumers. Our theoretical exercise indicates that welfare losses associated with trade protection may be larger than one conventionally thinks when vertical linkages are taken into account. 


\section{Specification and Data}

\subsection{Empirical Specification}

To get our main empirical specification, we perform a first-order Taylor expansion around $\mathbb{P}_{w}=0$ for all $w$, and thus approximate the downstream petition condition (6) as:

$$
\mathbb{F}_{s}=1 \text { iff } \theta \underbrace{\frac{\left(\sigma_{s}-1\right) \mu_{s} E_{1}}{\sigma_{s}}\left(1-M_{s}\right) M_{s}}_{\stackrel{\text { def }}{=} Z s} \underbrace{\sum_{w} \beta_{w s} M_{w} t_{21 w} \mathbb{P}_{w}}_{\stackrel{\text { def }}{=}(\text { affected share })_{s}}+f_{s}>0
$$

where $f_{s} \equiv \frac{\theta \mu_{s} E_{1}}{\sigma_{s}}\left(M_{s}-M_{s}^{1}\right)-C_{s}$. Note that here $M_{s}$ denotes the downstream import penetration without downstream nor upstream protection, and $M_{s}^{1}$ is import penetration with downstream but without upstream protection. The first term in $f_{s}$ is the expected gain from petition without upstream protection, and together with petition cost $C_{s}$, it captures the inherent motivation of an industry to petition for TTBs. For clarity, we separate our independent variable into two parts and call the first part that summarizes the downstream industry's market structure as $Z_{s}$, and call the second part that generates the input price shock as (affected share) $s$.

We assume that the error term follows a logistical distribution, and we add a time dimension as there is a time-lag between the protection of the upstream good and the initiation of a new investigation by the downstream user. Thus, we lag our time-varying right-hand side variable, (affected share $)_{s, t-k}$, where $t$ is year and $k$ denotes the lag. We use one-, two-, and three-year lags, and take the mean of these for each downstream industry at time $t$ in our main specification. The reason we do this is because in US TTB investigations, the ITC requests that the petitioner(s) present data on economic factors such as profits for "the three most recent complete calendar years as well as the year-to-date period of the current year and the like period of the previous year" (ITC, 2005) ${ }^{27}$ Finally, we proceed to estimate the following empirical specification using conditional logit:

$$
\operatorname{Pr}\left(\mathbb{F}_{s t}=1 \mid Z_{s}, \frac{1}{3} \sum_{k=1}^{3}\left(\text { affected share }_{s, t-k}\right), f_{s}, f_{t}\right)=\Lambda\left(\theta Z_{s} \frac{1}{3} \sum_{k=1}^{3}\left(\text { affected share }_{s, t-k}\right)+f_{s}+f_{t}\right),
$$

where industry fixed effects $f_{s}$ control for the inherent ability of an industry to petition, and time fixed effects $f_{t}$ control for overall macroeconomic shocks. We also cluster standard errors at the downstream industry level for arbitrary within-industry correlations. If cascading protection indeed exists in the data, we expect to find a statistically significant positive estimate of $\theta{ }^{28}$ As a robustness check we use the linear probability model and results hold qualitatively.

Crucially, our identification strategy relies on the plausible assumption that upstream protection is an exogenous shock for the downstream industries. This is due to downstream industries not having a legal standing in AD investigations in the US. As a quasi-falsification exercise, we replicate our results

\footnotetext{
${ }^{27}$ As a robustness check, we use the maximum instead of the mean and results do not change.

${ }^{28}$ We are slightly abusing language here as we can only estimate $\theta$ up to a constant with the logit estimator.
} 
for the EU, where downstream effects are explicitly considered through a "community interest test," to examine whether cascading protection still exists.

To estimate equation $(10)$, we get $\mathbb{F}_{s}$ (the indicator variable for downstream petition), $\mathbb{P}_{w}$ (the indicator variable for upstream protection), and $t_{21 w}$ (the duty imposed on upstream industry) from the Temporary Trade Barriers Database (Bown, 2014); $\beta_{w s}$ (the direct requirement coefficient) and $\mu_{s} E_{1}$ (the market size of downstream industry) are from the $\mathrm{BEA}$ (1997); $M_{s}$ and $M_{w}$ (import penetration rates for downstream and upstream industries respectively) are from Bernard et al. (2006) for 1987 and from BEA (1997) for 1997; and $\sigma_{s}$ is based on Broda and Weinstein (2006). We describe the data in more detail in the following section.

\subsection{Data Description}

Our empirical analysis uses data mainly from two sources. First, we get temporary trade barrier (TTB) data from the World Bank's Temporary Trade Barriers Database (Bown, 2014) that has detailed information on anti-dumping (AD), countervailing duty (CVD), and safeguard (SG) investigations by all user countries with each investigation mapped to the targeted Harmonized System (HS) codes. For the US, products are often identified at the 10-digit Harmonized Tariff Schedule (HTS) level which enables us to identify the subject products at a very disaggregated level.

Between 1988 and 2013 ${ }^{29}$ the US initiated 1,167 TTB cases and imposed 567 measures (51 percent affirmative) ${ }^{30}$ targeting 69 different countries and 928 distinct 6 -digit HS products ${ }^{31}$ The majority of these TTBs were AD (77 percent), with the rest consisting of CVDs (22 percent) and SGs (1 percent) 32 According to Bown (2014), US TTBs in stock as of end-2013 covered 3 percent of its imports in 2013, a staggering figure which makes US the second-largest TTB user after India. Figure 1 shows the annual counts of US TTB initiations and measures. Note that there are spikes in certain years due mostly to macroeconomic conditions such as recessions and currency appreciations 33 This reveals the need to control for macroeconomic factors in our empirical specification. Moreover, the number of measures seems to follow the number of initiations almost proportionally with a lag - this gives support to the fixed likelihood of protection assumption in our model.

Investigations cover a large variety of products, mainly in the manufacturing sector. Table 1 shows the 3-digit North American Industry Classification System (NAICS) composition of US TTBs in 1988-2013 counted by the number of "unique" investigations, where "unique" refers to a product (which might include multiple HTS10 lines), not a product-country as illustrated in Figure $1{ }^{34}$ As

\footnotetext{
${ }^{29}$ We use the 1988-2013 period since the HTS system, which we use to concord with the BEA's input-output tables, was introduced in 1988 even though the US TTB data is available from 1979.

${ }^{30}$ There were 54 cases under investigation as of January 2014.

${ }^{31}$ Here, in line with the previous literature, a case refers to an official petition, which targets a product-country combination. Note that the investigated "product" can include multiple HTS lines.

${ }^{32}$ These SGs include the transitional China-specific safeguards as well. Note that global-SGs are underrepresented here since an SG is counted as a single case even though it targets all countries.

${ }^{33}$ See Knetter and Prusa (2003) and Bown and Crowley (2013) for the macroeconomic determinants of TTB investigations.

${ }^{34}$ We also count simultaneous $\mathrm{AD}$ and CVD petitions as a single unique investigation in Table 1
} 
can be seen from Table 1, the Primary Metals and the Fabricated Metals sectors together make up 36 percent of all investigations - two closely related sectors where the cost share of Primary Metals in Fabricated Metals is 32 percent. The figure also shows that TTBs affect a wide range of industries as Other sectors, which include 15 distinct NAICS3, make up 17 percent of all investigations. Table A.1 in Appendix shows all the affected industries, ordered by how frequently they were targeted by US TTBs, and their summary statistics.

The second major component of the data we use is the Bureau of Economic Analysis' (BEA) 1997 Input-Output (IO) tables that enable us to link US TTBs to each other based on cost shares. These IO tables cover 486 industries (343 manufacturing) at the 6-digit BEA industry level based on NAICS codes. We use the BEA's direct requirement coefficients as cost shares in our analysis to focus on a minimum degree of separation between inputs and outputs and avoid overemphasizing IO relationships. Furthermore, in order to avoid circularities, we drop IO pairs where input and output are the same 6-digit BEA industry. The most crucial foundation of our empirical analysis is the matching of US TTBs, which are at the 10-digit HTS level, to the IO tables, which are at the 6-digit BEA industry level. To do this we use Schott/s (2008) US import data at HTS level and Pierce and Schott's (2009) methodology to convert HS codes from US TTB data to 10-digits and then concord them over time to achieve maximum number of matches to the HTS-BEA concordance tables provided by the BEA. See Appendix Section A.7 that explains this matching procedure in detail.

Note that the ideal input-output data for our analysis would be at the product level. There is a small but growing literature that tries to identify input-output linkages at the firm level. Closely related to our work is a paper by Vandenbussche and Viegelahn (2016), who use a unique firm-level dataset (Prowess) which includes information on Indian firms' outputs and inputs. Using this dataset, the authors are able to identify firms who are affected by AD measures on their inputs, and show that these firms skew their sales towards outputs that use non-protected inputs. Other papers that focus on input cost shocks at the firm level are: Barrot and Sauvagnat (2016), who examine how suppliers affected by natural disasters in the US impose substantial costs to their customers; and Boehm et al. (2016) and Carvalho et al. (2016) who use the Japanese earthquake in 2011 as a natural experiment and find that input-output linkages are crucial in transmitting shocks to (i) US-based Japanese affiliates in the former, and (ii) vertically-linked Japanese firms in the latter ${ }^{35}$ Even though a highly detailed firm-level dataset would be advantageous in our case as well, working with cost shares at the industry level implies that we encounter considerable random measurement error, which should bias our results towards zero 36 Despite this, our results are positive and statistically significant, so they could be considered as lower bound estimates.

Combining the TTB data with the IO tables allows us to find out the targeted products' relative

\footnotetext{
${ }^{35}$ This literature is also tied to work such as by Bernard et al. (2017) who examine buyer-seller relationships at the firm level.

${ }^{36}$ For example, the cost share of polyethylene terephthalate (PET) in polyethylene retail carrier bags is proxied by the direct requirement coefficient of 0.02 between the input industry Plastics Packaging Materials, Film and Sheet and the output industry Coated and Uncoated Paper Bags. This proxy might under- or over-estimate the true cost share.
} 
position in the value chain. Figure 2 shows the evolution of the "upstreamness" of targeted products in US TTB investigations in 1988-2013. We apply the methodology developed by Antràs et al. (2012) to the BEA's 1997 IO tables and obtain upstreamness figures by industry, larger figures indicating higher upstreamness ${ }^{37}$ For example, the industry Automobile and Light Trucks has an upstreamness of 1.00 (the minimum), whereas the industry Petrochemicals has an upstreamness of 4.65 (the maximum). The graph shows that TTB investigations, on average, have targeted relatively more upstream products as the solid line is always higher than the dashed line which is the trade-weighted upstreamness of US imports. This is not to say, however, that TTBs do not target downstream products - only the average product is further upstream. In fact, 23 percent of investigations had upstreamness lower than the dashed line. One can also see from the figure that there is no clear trend; US TTB investigations cover very upstream products in some years (e.g. 1993 and 2013) and more downstream products in others (e.g. 1989 and 2012). See Appendix Table A.1 for the upstreamness of all targeted industries.

With the data at hand, we can also visualize the connections between NAICS3 manufacturing sectors to reveal whether petitioning sectors are structurally clustered. Figure 3, which has sectors colored by whether they are heavily targeted by TTBs (dark gray: heavy TTB target, light gray: light TTB target) demonstrates that sectors that use TTBs are closely linked in terms of cost share. Note the cluster of heavily targeted sectors on the left side of the figure, especially the connection between the Primary Metals and the Fabricated Metals sector emphasized by the thick arrow indicating a high cost share. The relationship between Chemicals and Plastics and Rubber is also worth mentioning. The size of the nodes specifies how self-reliant a sector is (e.g. 42 percent of Computer and Electronics' cost comes from Computer and Electronics, while 2 percent of Furniture's cost comes from Furniture) - notice how the heavily targeted sectors are relatively more self-reliant which might indicate cascading protection within a sector (i.e. between industries) ${ }^{38}$

Additional data we use include import penetration ratios for 1987 (pre-sample period) based on Bernard et al. (2006) and import penetration rates and market size for 1997 (mid-sample) from the BEA 39 We calculate industry-level import demand elasticities using data from Broda and Weinstein $(2006) 40$

\footnotetext{
37 Antràs et al. (2012) use the BEA's 2002 IO tables to calculate the "average distance from final use" of an industry, and call this "upstreamness."

${ }^{38}$ In this paper, we refer to NAICS3 codes as sectors, and NAICS6 as industries. All of our empirical and numerical analyses are done at the industry level.

${ }^{39}$ We concord the import penetration rates in Bernard et al. (2006) from Standard Industrial Classification (SIC) codes to BEA industry codes using SIC87-NAICS97 and NAICS97-BEA concordance tables provided by the US Census Bureau.

${ }^{40}$ For each industry, we take the mean of the HTS10 elasticities provided by Broda and Weinstein (2006) using HTS10BEA industry concordance tables.
} 


\section{Results}

\subsection{Main Results: Test of Proposition 1}

Before directly estimating equation (11), we run simpler conditional logit regressions to get a sense of the relationship between downstream petitions and upstream protection. Table 2 has our results which report average marginal effects ${ }^{41}$ In column (1), we use a simple independent variable by summing the multiplication of cost share and the upstream protection dummy for each downstream industry (i.e. without taking the level of duty nor import penetration into account), and find that the effect is positive and statistically significant. Column (2) incorporates the level of duty and the marginal effect is more precisely estimated. In column (3), we use (affected share) as our independent variable ignoring market characteristics and find that a one standard deviation (0.008) increase in mean (affected share) increases the probability of petitioning by 3.66 percentage points ${ }^{42}$ In column (4), as a sensitivity check, we weight (affected share) by the imposed measure's industry coverage ratio, defined as $\frac{\text { no. of HTS10 targeted by measures }}{w t}$, and find that results are robust. We do this since TTB measures rarely cover an entire industry, creating measurement error 43

In column (5) of Table 2, we interact (affected share) with a dummy that indicates whether the downstream industry has a high elasticity of demand by dividing our sample to two based on the mean value of elasticity (10.05). As hinted by our theory, the marginal effect of a one unit change in the independent variable is positive and significant only for industries that have high demand elasticity. These preliminary results indicate that there is a positive relationship between downstream petitions and upstream protection, and this relationship is stronger for downstream industries that have higher demand elasticity. Note that using the maximum instead of the mean of the independent variable, or estimating using the linear probability model do not change the results qualitatively 44 For additional results using a reduced-form approach, see Appendix Section A.8.

We now turn to estimating equation (11) to get our main results in Table 3 . Note that since we are using conditional logit, the sample is reduced substantially as the calculation of the minimum sufficient statistic drops groups without variation in the dependent variable (i.e. industries that never petitioned for a TTB in the sample period). Out of the 331 downstream industries, only 153 have petitioned at least once in the sample period and thus 178 industries are dropped from the estimation. A further 12 industries do not have 1987 (pre-sample period) import penetration ratios so they are dropped as well in our full sample (1988-2013) estimations (the industry Cattle Ranching and Farming is also dropped since it lacks elasticity of substitution data). Columns (1) and (2) show that the marginal effect is statistically significant and has the predicted positive sign for both the mean and the maximum of the independent variable respectively. More precisely, a one standard deviation (0.135) increase in the

\footnotetext{
${ }^{41}$ Marginal effects calculated at the median are similar.

${ }^{42}$ This is calculated as $4.573 * 0.008 * 100=3.66$.

${ }^{43}$ The average measure covers 22 percent (median: 9 percent) of an industry with standard deviation 29 percent.

${ }^{44}$ These results are available on request.
} 
mean affected share increases the likelihood of downstream petition by 0.7 percentage points 45 Given that the mean initiation rate is 10 percent in the 1988-2013 conditional logit sample, this represents 7 percent of the average industry's petition probability.

Note that we use 1997 domestic market size data $\left(\mu_{s} E_{1}\right)$ and cost shares $\left(\beta_{w s}\right)$ in constructing our independent variable and these might be endogenous in the first half of the sample. For instance, a duty imposed on an industry can increase the size of a market and this might create reverse causality, biasing the coefficient upwards. Similarly, a duty imposed on an upstream industry might cause its downstream industry to switch to another input and thus alter its cost shares. Thus, our benchmark results correspond to Table 3 columns (3) and (4), which include only the second half of the sample (19972013) to address potential endogeneity concerns. Column (3) shows that a one standard deviation (0.040) increase in the mean affected share increases the petition likelihood by 3.5 percentage points on average 46 This effect represents about 27 percent of the mean initiation rate (13 percent) in the 1997-2013 conditional logit sample, and it varies substantially depending on the downstream industry.

Before quantifying the importance of these marginal effects, we do several sensitivity analyses to make sure that our result is robust. Table 4 has these results for the full 1988-2013 sample in panel (a) and the 1997-2013 sample in panel (b). Column (1) restricts the sample to manufacturing industries only as other sectors such as agriculture rarely use TTBs and have distinct political economy channels to obtain trade protection. Marginal effects remain positive and significant for both sample periods. In column (2), we exclude the biggest TTB user, the Primary Metals sector (NAICS3: 331), from our analysis to understand whether our results are driven by this sector. As results show the marginal effect is not statistically significant at the conventional levels anymore, albeit retaining its positive sign. This reveals the importance of the upstream sector Primary Metals in driving cascading protection. Column (3) excludes observations for each downstream industry that already has a measure in stock (i.e. unbalances the dataset), since this would eliminate any incentives for the downstream industry to petition for protection 47 We find that the results are robust for the full sample but not for the 1997-2013 period, likely due to the small sample size.

Table 4 column (4) divides the industries into two distinct downstream and upstream categories based on the median upstreamness of 2.11. This makes sure that there is no overlap between the two per our theory, and even though the sample is reduced dramatically, the coefficient stays positive and significant for the full sample period in panel (a). Column (4) of panel (b), on the other hand, shows a positive but imprecisely estimated marginal effect, probably due to the reduced sample size. In column (5), we change our dependent variable to successful petitions (measures) to infer whether input cost shocks have a differential effect on successful versus unsuccessful petitions and find that results are robust 48 In column (6), in order to verify that our results are not due to spurious correlation, we do

\footnotetext{
${ }^{45}$ This is calculated as $0.052 * 0.135 * 100=0.702$.

${ }^{46}$ Calculated as $0.865 * 0.04 * 100=3.46$.

${ }^{47}$ There might still be an incentive as investigations rarely cover an entire industry. Nevertheless, we do this robustness check to be more in line with the structure of our model.

${ }^{48}$ We do an additional robustness check by estimating the reduced-form of our structural equation using a multinomial logit specification following Blonigen and Park (2004) and Konings and Vandenbussche (2008), and thus examine differ-
} 
a falsification analysis where we replace the mean of the last three years' affected share with the mean of the next three years' affected share, and find that the coefficient turns statistically insignificant in both sample periods. In column (7), we use the linear probability model which enables us to include all industries and find that the coefficients are positive and statistically significant 49

\subsection{Cascading Protection in the EU?}

Note that our identification strategy relies on the assumption that the upstream and downstream industries do not interact in protection decisions, making upstream protection exogenous to downstream industries. We think this is a reasonable assumption as US TTB investigations do not consider (legally) the downstream effects of import protection 50 Theoretically, if there was internalization, then we should not be seeing any cascading protection. The EU, another large AD user, does legally consider downstream industries through its "community interest test." If our assumption is valid, then we should not observe cascading protecting using EU data. Therefore, in this subsection, we do the same empirical exercise for the EU as a quasi-falsification exercise.

We get EU TTB data from Bown (2014), we calculate absorption (domestic market size) and import penetration ratios using data classified at the PRODCOM product level from EUROSTAT, which we concord to Combined Nomenclature (CN) product codes using 1997 concordance tables provided by EUROSTAT. Note that we use US cost shares since the EU does not have a disaggregated IO table, and we use Broda and Weinstein (2006) elasticities which were calculated using US import data. Also, we concord EU's TTB investigations to BEA codes using the first 6-digits of the EU's CN codes in order to switch to the internationally harmonized HS level. With these caveats in mind, which are likely to create some measurement error, we replicate our main results in Table 3 with the EU data.

Table 5 presents the results for the entire EU sample period (1988-2012) in columns (1) and (2), and the second half of the sample period (1997-2012) in columns (3) and (4), with columns (2) and (4) using the maximum instead of the mean affected share for sensitivity analysis. The coefficients show that we consistently get a statistically insignificant odd ratio of 1 for all four columns. Comparing the EU results with that of the US reveals that unlike in the US, cascading protection might not be at play in the EU, possibly due to having a "community interest test" in AD investigations. This result gives support to our assumption that upstream protection acts as an exogenous shock to downstream industries in the US, causing cascading protection.

\footnotetext{
ential effects on petitions and measures. Appendix Section A.8.2 shows that the input cost shock coefficient is significant and similar in magnitude for both successful and unsuccessful petitions, revealing that the shocks do not change the outcome of an investigation but merely cause its petition as predicted by the theory.

${ }^{49}$ These LPM regressions exclude three outlier observations where the independent variable is above the $99^{t h}$ percentile.

${ }^{50}$ See Ikenson's (2011) policy brief for a rigorous argument for giving downstream industries legal standing in AD investigations in the US.
} 


\subsection{Heterogeneous Effects}

To get an idea of how much an upstream industry's protection contributes to the petition of its downstream industry we evaluate the marginal effects from our benchmark specification in Table 3 columns (1) and (3) for a sample of upstream-downstream dyads at their respective values for our independent variable. In order to save space, we restrict the sample to manufacturing dyads that are "close" (i.e. cost share larger then 10 percent) and that have at least initiated one TTB investigation in 1988-2013. Table 6 columns (1) and (2) identify the upstream and downstream industries respectively. The last two columns of the table show the mean initiation rates for the downstream industry in 19882013 and 1997-2013 respectively. Note how these rates differ markedly between industries: while the unconditional likelihood of initiation for Steel Wire Drawing is 67 percent, it is only 8 percent for the median downstream industry.

Table 6 column (3) shows the percentage point increase in the downstream industry's petition likelihood attributed to a measure imposed in the upstream industry. These are calculated by multiplying the marginal effect when the downstream industry is not affected by any upstream measure with $Z_{s} *(\text { affected share })_{s w}$ where the (affected share) $)_{s w}$ is IO-specific and the duty levels are evaluated at the observed mean value. Figures that are in bold indicate that a corresponding output initiation within three years of the input measure has occurred in the data. Note that the effects are usually less than a percentage point but some IO combinations stand out. For instance, the most heavily targeted upstream industry, Iron and Steel Mills, affects a minimum of 11 downstream industries, and according to our predictions, a measure on this industry most directly affects Steel Wire Drawing by increasing its likelihood of initiation by 9.7 percentage points in the 1997-2013 period, mostly because Steel Wire Drawing is the industry that relies the most on Iron and Steel Mills, with a cost share of 32 percent. Other industries that are relatively prone to initiation (i.e. higher than a percentage point increase) due to a measure on Iron and Steel Mills in order are Industrial Truck, Trailer and Stacker, Motorcycle, Bicycle, and Parts, and Electric Power and Specialty Transformer.

A measure on the most upstream industry Petrochemicals increases its close downstream industries' petition likelihood by 0.6 to 7.2 percentage points in 1997-2013. Note that these affected downstream industries also act as upstream industries to further downstream users, and this can exacerbate cascading protection as the supply chain gets further broken down. An upstream industry that stands out is Other Basic Organic Chemicals - a measure imposed on this industry increases the petition likelihood of its "close" downstream industries by 1.1 to 11.8 percentage points in 1997-2013, which can explain more than 80 percent of the mean initiation likelihood of Plastics Material and Resin. Note how Plastics Material and Resin in turn can affect its own downstream industries by increasing their likelihood of initiation by 3.0 to 5.8 percentage points - an upstream-midstream-downstream effect with Plastics Material and Resin being the midstream industry.

The largest effect is caused by a measure in Semiconductors and Related Device which increases the petition likelihood of All Other Electronic Components and Electronic Computer by 59.4 and 21.3 percentage points respectively, explaining these industries' entire mean initiation probabilities. In 
addition to high cost shares (larger than 10 percent), this is mostly due to the high import penetration rate in Semiconductors and Related Device (36 percent). Also, note the powerful effects of Primary Aluminum on Aluminum Sheet, Plate, and Foil due mostly to a high cost share (36 percent), of Primary Smelting and Refining of Copper on Copper Rolling, Drawing, and Extruding again due to a strong vertical relationship (38 percent cost share), of Nonferrous Metal on Jewelry and Silverware caused mostly by the highly import penetrated upstream industry at 60 percent, of Electron Tubes on Audio and Video Equipment due mostly to the 35 percent import penetration ratio in the upstream industry, and of All Other Electronic Components on both its close downstream industries due to its own import penetration ratio (47 percent) as well as the large domestic market size of its two close downstream industries ( $\$ 94$ billion in 1997) 51

Overall, the estimated effects are economically important when compared to the low average initiation rates. Furthermore, most often there are measures imposed on multiple upstream industries, which, if they are important for their downstream users, can exacerbate cascading protection. These evaluations help to anticipate which downstream industries will initiate new petitions after seeing higher duties on key inputs.

\subsection{Additional Results: Test of Proposition 2}

In this subsection, we follow Proposition 2, and test whether upstream industries that have a "cascadingprotection prone downstream structure" are more likely to petition for protection. For this test, we create the following upstream-specific index that measures "downstream structure":

$$
D S_{w} \equiv \sum_{s} \delta_{w s}\left(Z_{s} \beta_{w s} M_{w} t_{21 w}^{*}\right)
$$

where $Z_{s}, \beta_{w s}, M_{w}$ are as before, $t_{21 w}^{*}$ is the expected duty the industry will receive if it petitions and gets protection, and $\delta_{w s}$ is the IO-specific usage share that we use to weight each downstream industry's importance for the upstream industry 52 We adopt a "hybrid" approach to construct the potential duty or dumping margin $t_{21 w}^{*}$. For the industry-year combinations that did get protection, we use the actual dumping margins reported in the Temporary Trade Barriers Database. To fill in the other industry-year observations, we compute the difference between the unit value of US exports and imports ${ }^{53}$ and project that this margin will be the duty an upstream industry will obtain if it gets protected. When the projected margin is less than zero, we set it equal to zero. Also, to get a sense of how good our unit value approach is in proxying dumping margins, we calculate potential margins for protected industries and compare them to observed duties, and find a positive correlation of 0.33 .

We run the number of petitions by each upstream industry over the sample period on $D S_{w}$ and find a positive relationship 54 Note that here we use 291 upstream industries that have at least one

\footnotetext{
${ }^{51}$ The mean (median) domestic market size for a downstream industry was $\$ 13$ billion (\$6 billion) in 1997 .

${ }^{52}$ These usage shares are calculated from the BEA's 1997 IO tables.

${ }^{53}$ Unit values are trade-weighted averages of HS6 products based on UN Comtrade (WITS) data.

${ }^{54}$ We rescale $D S_{w}$ by multiplying it by 1,000 to make the interpretation of coefficients easier.
} 
manufacturing downstream counterpart (and have the necessary data), and the number of petitions by an upstream industry over 1988-2013 ranges from 0 to 21 , with median 0 , mean 1.1, and standard deviation 2.155 This reveals the over-dispersed (and count) nature of our dependent variable and suggests using the negative binomial regression model $[56$ We also include an industry-specific import penetration rate to control for an industry's inherent motivation to petition. Table 7 shows the results with both the negative binomial and linear specifications. Column (1) shows that there is a positive and significant relationship between an upstream industry's number of petitions and its "cascadingprotection prone downstream structure." More specifically, the incidence rate ratio (IRR) in column (1) explains that a one-unit increase in $D S_{w}$ is expected to increase the rate for petitions by a factor of 1.01. Column (2) uses the second half of the sample only (1997-2013) and finds that results are robust. Similarly, using a linear specification instead of count as in columns (3) and (4) does not change the results qualitatively. Note also that the coefficient on import penetration $\left(M_{w}\right)$ is always positive and significant as expected. These results show that frequent petitioning by an industry such as Motor Vehicle Parts could partly be explained by its "cascading-protection prone downstream structure" that creates an additional incentive to petition 57

The observation that there are "too many" TTB measures on relatively more upstream goods was hitherto puzzling since downstream industries would be expected to somehow stop these measures from being implemented. Our model showed that one reason why these downstream users do not "scream harder" is because they also have access to TTBs, and an upstream measure increases the level of duty the downstream industry can obtain given a successful petition, which creates an additional incentive resulting in cascading protection 58 Our results in this section show that upstream suppliers that are most frequent TTB-users tend to have downstream buyers that would be likely to ask for protection as well. Note, however, that the downstream industries would be better off without any upstream measure to begin with. This will be clearer in our welfare analyses in the next section.

\section{Simulation Exercise}

Now that we have established the existence of cascading protection empirically, the next question arises naturally: what are its welfare consequences? Moreover, we want to know, if the US modifies its TTB procedures and internalizes the impact of upstream protection on downstream users, such as by implementing a "public interest clause" like in the EU, what will be the consequences on industries' petition frequency and consumer welfare? Also, how would the results change as the world gets increasingly integrated via supply chains? To answer these questions, we calibrate the model proposed in Section 2 .

\footnotetext{
${ }^{55}$ We have 323 industries for the second half of the sample but we cannot use 32 of them for the full sample regressions since they lack pre-1997 import penetration data.

${ }^{56}$ Using a Poisson specification instead does not change the results qualitatively.

${ }^{57}$ Motor Vehicle Parts has the highest $D S_{w}$ in our sample, and was the seventh most active TTB-using industry in the US during 1988-2013.

${ }^{58} \mathrm{We}$ thank one of the referees for pointing this out.
} 
In Section 2.2 we showed that the equilibrium of the economy, taking the petition and protection conditions as given, can be represented by a system of $2(2 W+3 S)$ equations (equations (1)-(5)) with $2(2 W+3 S)$ unknowns $\left(P_{i w}, P_{i s}, c_{i s}, \Pi_{i w}\right.$ and $\Pi_{i s}$ for $\left.i \in\{1,2\}\right)$. Denoting the counterfactual value of $\Pi_{i s}$ by $\Pi_{i s}^{\prime}$ and counterfactual changes as $\hat{\Pi}_{i s}$ and so forth, one can verify by using the technique of Dekle et al. (2007) that equations (1)-(5) can be rewritten in changes as:

$$
\begin{gathered}
\hat{P}_{i w}=\left(\sum_{j \in\{1,2\}} \delta_{j i w} \hat{\tau}_{j i w}^{1-\sigma_{w}}\right)^{\frac{1}{1-\sigma_{w}}}, \\
\hat{c}_{i s}=\prod_{w} \hat{P}_{i w}^{\beta_{w s}}, \\
\hat{P}_{i s}=\left(\sum_{j \in\{1,2\}} \delta_{j i s}\left(\hat{c}_{j s} \hat{\tau}_{j i s}\right)^{1-\sigma_{s}}\right)^{\frac{1}{1-\sigma_{s}}}, \\
\hat{\Pi}_{i s}=\sum_{j \in\{1,2\}} \alpha_{i j s} \hat{\tau}_{i j s}^{1-\sigma_{s}} \hat{c}_{i s}^{1-\sigma_{s}} \hat{P}_{j s}^{\sigma_{s}-1}, \\
\hat{\Pi}_{i w}=\sum_{j \in\{1,2\}} \sum_{s} \alpha_{i j w s} \hat{\tau}_{i j w}^{1-\sigma_{w}} \hat{P}_{j w}^{\sigma_{w}-1} \hat{\Pi}_{j s},
\end{gathered}
$$

where $\alpha_{i j s}, \alpha_{i j w s}, \delta_{j i w}$, and $\delta_{j i s}$ are functions of $\beta, \sigma$, and trade flows $T$. In particular, $\alpha_{i j s} \equiv$ $\frac{T_{i j s}}{\sum_{j} T_{i j s}}, \alpha_{i j w s} \equiv \frac{T_{i j w s}}{\sum_{j} \sum_{s} T_{i j w s}} \equiv \frac{T_{i j w}}{\sum_{j} T_{i j w}} \frac{\left(\sigma_{s}-1\right) \beta_{w s} \Pi_{j s}}{\sum_{s}\left(\sigma_{s}-1\right) \beta_{w s} \Pi_{j s}}, \delta_{j i w} \equiv \frac{T_{j i w}}{\sum_{j} T_{j i w}}$, and $\delta_{j i s} \equiv \frac{T_{j i s}}{\sum_{j} T_{j i s}}$. Here, $T_{i j w}$ is the exports of country $i$ industry $w$ to country $j$ evaluated at world prices 59 Given $\sigma, \beta, T$, and the potential dumping margin $t$ for all industries, equations $(12)-(16)$ can be used to compute the counterfactual changes in upstream operating profit $\Pi_{i w}$, downstream operating profit $\Pi_{i s}$, downstream production cost $c_{i s}$, and industry price indices $P_{i s}$ and $P_{i w}$. Counterfactual welfare change can then be calculated from $\hat{W}_{i s}=\prod_{s} \hat{P}_{i s}^{-\mu_{s}} 60$

To determine a downstream industry's petition decision, we need to compare its expected operating profit gain with filing costs. Specifically, downstream industry $s$ will pursue protection when $\theta \hat{\Pi}_{i s} \Pi_{i s}>$ $C_{i s}$, where $\Pi_{i s}=\frac{1}{\sigma_{s}} \sum_{j} T_{i j s}$ according to our model. We assume that $C_{i s}$ is drawn from a logistic distribution with dispersion parameter $\lambda_{\text {disp }}$ and a scale parameter $\lambda_{c}+\lambda_{h} H_{\text {sector }}+\lambda_{h 2} H_{\text {sector }}^{2}+$ $\lambda_{g} \Delta G D P_{t}$, where $H_{\text {sector }}$ is the Herfindahl index measuring industry concentration 61 and $\Delta G D P_{t}$ is the real GDP growth of the US in year $t 62$ The parameters are: $\sigma, \beta, \mu, T, H_{\text {sector }}, \Delta G D P_{t}, t$, and $\lambda=\left\{\lambda_{c}, \lambda_{h}, \lambda_{h 2}, \lambda_{g}, \lambda_{\text {disp }}\right\}$. We treat country 1 as the US and country 2 as the rest of the world

\footnotetext{
${ }^{59}$ We obtain trade data $\left(T_{j i}\right)$ from UN Comtrade (WITS), and proxy for $T_{i i}$ (consumption of domestic production) by subtracting the export value of an industry from its production value, which we get from the BEA. Due to data unavailability for many industries' $T_{i i}$ for earlier years and 2012-13, we are able to do the numerical exercise for the 1998-2011 period.

${ }^{60}$ Indirect utility is given by $W_{i s}=\mu_{Y}{ }^{\mu_{Y}} \prod_{s}\left(\mu_{s}^{\mu_{s}} P_{i s}^{-\mu_{s}}\right)$.

${ }^{61}$ The Herfindahl indices, which are rescaled by multiplying by 100, are from the US Census Bureau and are for the year 2002, the earliest year of data availability by NAICS.

${ }^{62}$ Real GDP growth data is from the World Bank's World Development Indicators.
} 
(ROW). Also, in line with our empirical analysis, we assume that it takes three years for upstream protection to affect downstream industries.

As the ROW is passive, we set $t_{11}, t_{12}$, and $t_{22}$ equal to zero. Next, we compute the expected dumping margin $t_{21}$ like we did in Section 4.4. For downstream industries, the potential duty conditional on upstream protection can then be computed endogenously from the equation system (12)-(16). Then, we merge data on $\sigma, \beta, \mu, T, H_{\text {sector }}, \Delta G D P_{t}, t$ with the TTB data for simulation. Unfortunately, many industries are missing Herfindahl indices, which leaves us with only 156 industries for simulation. We divide the industries into two sub-samples. In particular, we assign industries that never been used directly for final consumption to upstream, and divide all remaining industries based on Antras' upstreamness index (the cut-off value now becomes 2.96). Then we normalize $\beta$ and $\mu$, setting $\mu_{Y}$ equal to 0.03 , the yearly average direct consumption share of agricultural products. We present the summary statistics of these variables in Table 8 .

We choose petition cost parameters $\lambda$ via simulated method of moments. In particular, we simulate 100 observations for each industry-year by drawing its petition cost shock from the logistic distribution 63 We treat upstream protection as given to simulate downstream industries' petition incidence by comparing simulated $\theta \hat{\Pi}_{i s} \Pi_{i s}$ with the petition cost $C_{i s}$ for each industry. We use the simulated data to construct the average petition incidence of each downstream industry, $\hat{m}_{s}$, and select parameters to match the actual petition incidence observed in the data. Formally, we describe the difference between the moments in the data and in simulated model by $\Delta m(\lambda)$ :

$$
\Delta m(\lambda)=m(\lambda)-\hat{m}(\lambda)=\left[\begin{array}{c}
m_{1}(\lambda)-\hat{m}_{1}(\lambda) \\
\ldots \\
m_{S}(\lambda)-\hat{m}_{S}(\lambda)
\end{array}\right] .
$$

The following moment condition is assumed to hold at the true parameter value $\lambda_{0}$ :

$$
E\left[\Delta m\left(\lambda_{0}\right)\right]=0
$$

and we select model parameters that minimize the following objective function:

$$
\hat{\lambda}=\underset{\lambda}{\arg \min }\left[\Delta m\left(\lambda_{0}\right)\right]^{T} \mathbf{W}\left[\Delta m\left(\lambda_{0}\right)\right]=0 .
$$

We choose the identity matrix as the weighting matrix $\mathbf{W}$. The resulting parameters are: $\lambda_{c}=1074.33$, $\lambda_{h}=-15.94, \lambda_{h 2}=13.37, \lambda_{g}=243.17$, and $\lambda_{\text {disp }}=0.95$. The calibrated parameters have the expected signs. In particular, the negative $\lambda_{h}$ implies that industry concentration makes petitioning costs lower due to organizational ease, at least until high concentration rates since $\lambda_{h 2}>0$; also, $\lambda_{g}>0$ is consistent with Figure 1 which shows that petitions are more likely to happen during recessions. The simulated downstream petition data matches 89 percent of the actual petition decisions observed in

\footnotetext{
${ }^{63}$ We choose 100 mainly for computational limitations. Depending on the choice of initial value, it takes about three days to run the estimation algorithm in a computer with 16 GB RAM and 4 Core $3.10 \mathrm{GHz}$ CPU.
} 
the data. In terms of average petitions per year, our model delivers a slightly underestimated value of 4.09 versus 5.18 in the actual data.

Given the estimates of $\lambda$, we can compute changes in industry profits, costs, and consumer welfare due to TTBs and perform counterfactual analyses. Column (1) of Table 9 presents the change caused by upstream (actual) and downstream (simulated) protection for the benchmark case. Here, $\Delta \Pi_{1 w}$ refers to the simple average change in operating profits of US upstream industries, and so forth. The average operating profit of US upstream industries increases by 1.67 percent as both upstream and downstream protection help boost their profit. The expansion of US intermediate suppliers costs their foreign competitors, whose profits decline by 0.26 percent. On the other hand, US downstream industries' profits decline slightly due to two opposing forces: upstream protection increases their marginal costs hence decrease profitability - we can see this from the average 0.89 percent $\left(\Delta c_{i s}\right)$ rise in downstream marginal costs, and the subsequent increase in profits due to obtained protection. The two forces largely cancel out and leave a 0.26 percent loss for downstream industries. The cost disadvantage of downstream industries translates into a 0.41 percent increase in profits for foreign downstream producers. Consumers in the US and the ROW face welfare losses of 1.04 and 0.05 percent respectively.

The welfare decline makes us wonder whether an adjustment in US TTB policy to internalize the impact of upstream protection via a "public interest clause" can mitigate the losses. To keep the analysis simple, we assume that any upstream petition that might harm a domestic downstream industry will be rejected by the US administering authority, and compute downstream behavior with associated profit, cost, and welfare changes. The results are presented in Table 9, column (2). Naturally, the upstream industries stop seeking protection as they know that their petition will get rejected. In this case, simulated downstream petition frequency decreases, confirming the existence of cascading protection. The average upstream profit increases, as the majority of industries that are not protected will not get hurt due to the loss in competitiveness of their domestic downstream users. Without an upstream cost pressure, the downstream average profit increases by 1.81 percent due to protection, while the opposite is true for foreign downstream profits. The US welfare loss falls to 0.55 percent, meaning that a mechanism such as a "public interest test" in TTB investigations can eliminate up to 47.38 percent of the welfare loss.

What about the effects of cascading protection in a world with deeper global value chains (GVCs)? We hypothesize that, in this case, due to increased transmission of injury from upstream protection, downstream industries will be more likely to pursue protection. To test this, we reallocate 50 and 90 percent of US usage of domestically produced upstream goods to foreign producers, while holding total production in both US and the ROW unchanged (i.e. US downstream industries use more intermediates from the ROW and the ROW downstream industries use more US intermediates). We treat this as counterfactual pre-adjustment equilibrium and repeat the benchmark exercise ${ }^{64}$ Results

\footnotetext{
${ }^{64}$ Note that total production of certain ROW industries are less than 50 percent of US consumption. In this case, we set it so that ROW reallocates 90 percent of domestic usage to US producers.
} 
are reported in Table 9, columns (3) and (5). Compared to the benchmark case where the upstreamcaused petitions count only 4.40 percent of total downstream filings, this number almost doubles (8.49 percent) when 50 percent of domestic tasks are offshored and further rises to 13.98 percent in the 90 percent case. However, since petitioning is costly, many injured industries will still choose not to petition and suffer losses, and this renders significant profit losses for US downstream industries: 1.77 and 4.16 percent respectively, while the foreign experiences the opposite. The welfare loss increases as GVC trade becomes pervasive, and rises to 2.63 percent in the 90 percent case. In this setting, welfare correction through a "public interest" mechanism is larger since cascading protection is more likely to happen. In particular, the value of welfare losses corrected by adjusted trade policy are 1.28 and 2.08 percent respectively compared to the 0.49 percent in the benchmark case; similarly, the shares of correction are 69.95 and 79.12 percent respectively compared to 47.38 percent in the benchmark case.

Note that in proposing an adjusted TTB investigation procedure that takes vertical linkages into account, we not only eliminate cascading protection, but also eliminate all upstream protection. To ensure that our calculations are not purely driven by the elimination of the latter, we decompose welfare losses associated with TTBs into four mutually exclusive components: welfare loss directly caused by upstream protection, welfare loss due to downstream protection caused by upstream protection (extensive margin), welfare loss due to higher duties that are obtained by downstream industries caused by upstream protection (intensive margin), and the direct welfare loss caused by downstream protection regardless of upstream protection. Table 10 presents the results. In the benchmark case, direct upstream protection counts for less than half of the total consumer welfare loss, yet this number rises rapidly as GVCs deepen. This is intuitive since as downstream industries use more foreign intermediates, an increase in tariffs leads to higher marginal costs for downstream producers, which eventually hurts final consumers. However, this is not the only story. The extensive and intensive margins also indicate that with the development of GVCs, the welfare loss caused by cascading protection increases as well. In total, cascading protection by itself counts 0.77 to 5.51 percent of the welfare loss (sum of rows three and four divided by row six). Note that in terms of measuring the welfare loss caused by cascading protection, the intensive margin contributes only a small fraction: most of the welfare loss is due to adjustments in the extensive margin.

Overall, our simulation exercise shows that temporary trade protection can cause substantial welfare losses for consumers, and cascading protection accounts a sizable share of it. Moreover, as the world gets increasingly integrated through offshoring, the cascading effect exacerbates the welfare loss. The introduction of a "public interest clause" that takes vertical linkages into account before granting protection can lead to welfare improvement, primarily by curbing upstream protection but also by limiting cascading protection. 


\section{Conclusion}

Influenced by Hoekman and Leidy]s (1992) cascading protection model and Feinberg and Kaplan's (1993) early evidence, this paper provides a simple quantitative trade model with vertical linkages based on Ossa (2014) to guide our empirical specification that tests whether trade protection on upstream goods increases the likelihood of their downstream users' trade remedy petition in the US during 1988-2013. Using the detailed input-output tables and time-varying temporary trade barriers of the US, we find that upstream protection leads to downstream petition for protection. We show that the effect varies depending on input-output pairs' market characteristics such as import penetration of both industries, market size and demand elasticity of the downstream industry, and the importance of the input for the downstream industry in terms of its cost share. Replicating the same analysis for the EU, where trade remedy investigations explicitly take downstream effects into account, we find no evidence for cascading protection. Our empirical test on the model's second prediction confirms that there may be "too many" petitions by upstream industries that have "cascading-protection prone downstream structure." Finally, our numerical solutions of the model suggest that cascading protection causes additional welfare losses.

This paper contributes to the literature by providing the first rigorous and systematic study of vertical linkages in temporary trade barriers. Our results call for a change in trade barrier investigations by giving downstream users a legal standing. The EU and a few other countries have already implemented a "public interest clause" into their anti-dumping regulations in order to make sure that downstream industries and consumers have an active role in investigations. However, the US and the large majority of anti-dumping users have yet to add in this crucial piece of legislation. As explained in detail in this paper, in a world with tight cross-border supply chains, trade policy investigations should consider the downstream effects of protecting key inputs to limit welfare losses. 


\section{References}

Amiti, M. and Konings, J. (2007). Trade liberalization, intermediate inputs, and productivity: Evidence from Indonesia. The American Economic Review, 97(5):1611-1638.

Antràs, P., Chor, D., Fally, T., and Hillberry, R. (2012). Measuring the upstreamness of production and trade flows. American Economic Review Papers and Proceedings, 102(3):412-416.

Atkin, D., Chaudhry, A., Chaudry, S., Khandelwal, A. K., and Verhoogen, E. (2015). Markup and cost dispersion across firms: Direct evidence from producer surveys in Pakistan. The American Economic Review, 105(5):537-544.

Barrot, J.-N. and Sauvagnat, J. (2016). Input specificity and the propagation of idiosyncratic shocks in production networks. The Quarterly Journal of Economics, 131(3):1543-1592.

BEA (1997). 1997 Supplementary Make, Use, and Direct Requirements Tables at the detailed level.

Bernard, A. B., Jensen, J. B., and Schott, P. K. (2006). Survival of the best fit: Exposure to low-wage countries and the (uneven) growth of US manufacturing plants. Journal of International Economics, 68(1):219-237.

Bernard, A. B., Moxnes, A., and Ulltveit-Moe, K. H. (2017). Two-sided heterogeneity and trade. mimeo.

Blanchard, E. J., Bown, C. P., and Johnson, R. C. (2016). Global supply chains and trade policy. National Bureau of Economic Research.

Blonigen, B. (2015). Industrial policy and downstream export performance. The Economic Journal.

Blonigen, B. and Bown, C. P. (2003). Antidumping and retaliation threats. Journal of International Economics, 60(2):249-273.

Blonigen, B. A. and Haynes, S. E. (2002). Antidumping investigations and the pass-through of antidumping duties and exchange rates. The American Economic Review, 92(4):1044-1061.

Blonigen, B. A. and Haynes, S. E. (2010). Antidumping investigations and the pass-through of antidumping duties and exchange rates: Reply. The American Economic Review, 100(3):1283-1284.

Blonigen, B. A. and Park, J.-H. (2004). Dynamic pricing in the presence of antidumping policy: Theory and evidence. The American Economic Review, 94(1):134-154.

Blonigen, B. A. and Prusa, T. J. (2016). Dumping and antidumping duties. In Bagwell, K. and Staiger, R. W., editors, Handbook of Commercial Policy. Elsevier.

Boehm, C., Flaaen, A., and Pandalai-Nayar, N. (2016). Input linkages and the transmission of shocks: Firm-level evidence from the 2011 Tōhoku earthquake. mimeo. 
Boltuck, R. and Litan, R. E. (1991). Down in the dumps: Administration of the unfair trade laws. Brookings Institution Press.

Bown, C. P. (2011). Taking stock of antidumping, safeguards and countervailing duties, 1990-2009. The World Economy, 34(12):1955-1998.

Bown, C. P. (2014). Temporary Trade Barriers Database. The World Bank lavailable at http://econ.worldbank.org/ttbd/], June. [First version published in 2010].

Bown, C. P. and Crowley, M. A. (2013). Import protection, business cycles, and exchange rates: Evidence from the Great Recession. Journal of International Economics, 90(1):50-64.

Brainard, S. L. and Verdier, T. (1997). The political economy of declining industries: Senescent industry collapse revisited. Journal of International Economics, 42(1):221-237.

Broda, C. and Weinstein, D. E. (2006). Globalization and the gains from variety. The Quarterly Journal of Economics, 121(2):541-585.

Carvalho, V. M., Nirei, M., Saito, Y. U., and Tahbaz-Salehi, A. (2016). Supply chain disruptions: Evidence from the Great East Japan earthquake. mimeo.

De Loecker, J., Goldberg, P. K., Khandelwal, A. K., and Pavcnik, N. (2016). Prices, markups, and trade reform. Econometrica, 84(2):445-510.

Dekle, R., Eaton, J., and Kortum, S. (2007). Unbalanced trade. The American Economic Review, $97(2): 351-355$.

Durling, J. P. and Prusa, T. J. (2003). Using safeguard protection to raise domestic rivals' costs. Japan and the World Economy, 15(1):47-68.

Durling, J. P. and Prusa, T. J. (2006). The trade effects associated with an antidumping epidemic: The hot-rolled steel market, 1996-2001. European Journal of Political Economy, 22(3):675-695.

Edmond, C., Midrigan, V., and Xu, D. Y. (2015). Competition, markups, and the gains from international trade. The American Economic Review, 105(10):3183-3221.

Feinberg, R. M. and Kaplan, S. (1993). Fishing downstream: The political economy of effective administered protection. Canadian Journal of Economics, 26(1):150-158.

Finger, J. M., Hall, H. K., and Nelson, D. R. (1982). The political economy of administered protection. The American Economic Review, 72(3):452-466.

Freund, C. and Özden, Ç. (2008). Trade policy and loss aversion. The American Economic Review, 98(4):1675-1691. 
Goldberg, P., Khandelwal, A., Pavcnik, N., and Topalova, P. (2009). Trade liberalization and new imported inputs. The American Economic Review, 99(2):494-500.

Handley, K. (2014). Exporting under trade policy uncertainty: Theory and evidence. Journal of International Economics, 94(1):50-66.

Handley, K. and Limao, N. (2015). Trade and investment under policy uncertainty: Theory and firm evidence. American Economic Journal: Economic Policy, 7(4):189-222.

Hillman, A. L. (1982). Declining industries and political-support protectionist motives. The American Economic Review, 72(5):1180-1187.

Hoekman, B. M. and Leidy, M. P. (1992). Cascading contingent protection. European Economic Review, 36(4):883-892.

Ikenson, D. J. (2011). Economic self-flagellation: How US antidumping policy subverts the National Export Initiative. Cato Institute Trade Policy Analysis, (46).

Irwin, D. A. (2005). The rise of US anti-dumping activity in historical perspective. The World Economy, 28(5):651-668.

ITC, U. S. (2005). Antidumping and Countervailing Duty Handbook. International Trade Commission.

Knetter, M. M. and Prusa, T. J. (2003). Macroeconomic factors and antidumping filings: Evidence from four countries. Journal of International Economics, 61(1):1-17.

Konings, J. and Vandenbussche, H. (2008). Heterogeneous responses of firms to trade protection. Journal of International Economics, 76(2):371-383.

Konings, J. and Vandenbussche, H. (2013). Antidumping protection hurts exporters: Firm-level evidence. Review of World Economics, 149(2):295-320.

Krugman, P. (1980). Scale economies, product differentiation, and the pattern of trade. The American Economic Review, 70(5):950-959.

Krupp, C. M. and Skeath, S. (2002). Evidence on the upstream and downstream impacts of antidumping cases. The North American Journal of Economics and Finance, 13(2):163-178.

Leidy, M. P. and Hoekman, B. M. (1991). Spurious injury as indirect rent seeking: Free trade under the prospect of protection. Economics \& Politics, 3(2):111-137.

Lindsey, B. and Ikenson, D. J. (2003). Antidumping exposed: The devilish details of unfair trade law. Cato Institute, Washington, D.C.

Magee, C. (2002). Declining industries and persistent tariff protection. Review of International Economics, 10(4):749-762. 
Obama, B. H. (2010). Remarks by the President at the Signing of the Manufacturing Enhancement Act of 2010 .

Ossa, R. (2014). Trade wars and trade talks with data. The American Economic Review, 104(12):41044146.

Pierce, J. R. and Schott, P. K. (2009). Concording US Harmonized System categories over time. National Bureau of Economic Research.

Pierce, J. R. and Schott, P. K. (2016). The surprisingly swift decline of US manufacturing employment. The American Economic Review, 106(7):1632-1662.

Prusa, T. J. (1996). The trade effects of US antidumping actions. National Bureau of Economic Research.

Prusa, T. J. (2001). On the spread and impact of anti-dumping. Canadian Journal of Economics/Revue canadienne d'économique, 34(3):591-611.

Prusa, T. J. (2011). USA: Evolving trends in temporary trade barriers. In Bown, C. P., editor, The Great Recession and Import Protection: The Role of Temporary Trade Barriers. CEPR and World Bank.

Schott, P. K. (2008). The relative sophistication of Chinese exports. Economic Policy, 23(53):5-49.

Sleuwaegen, L., Belderbos, R., and Jie-A-Joen, C. (1998). Cascading contingent protection and vertical market structure. International Journal of Industrial Organization, 16(6):697-718.

Staiger, R. W. and Wolak, F. A. (1994). Measuring industry specific protection: Antidumping in the United States. National Bureau of Economic Research.

Takacs, W. E. (1981). Pressures for protectionism: An empirical analysis. Economic Inquiry, 19(4):687-693.

Tovar, P. (2009). The effects of loss aversion on trade policy: Theory and evidence. Journal of International Economics, 78(1):154-167.

Vandenbussche, H. and Viegelahn, C. (2016). Input reallocation within firms. CEPR Discussion Paper 11395.

Vandenbussche, H. and Zanardi, M. (2008). What explains the proliferation of antidumping laws? Economic Policy, 23(53):93-138. 


\section{Tables and Figures}

Table 1: Sector Composition of TTBs

\begin{tabular}{lcc} 
Sector (NAICS3) & Number of investigations & Percent of total \\
\hline \hline Primary Metals (331) & 121 & 25.7 \\
Chemicals (325) & 84 & 17.8 \\
Fabricated Metals (332) & 47 & 10.0 \\
Machinery (333) & 34 & 7.2 \\
Computer and Electronics (334) & 23 & 4.9 \\
Food Manufacturing (311) & 18 & 3.8 \\
Electrical Equipment and Appliances (335) & 18 & 3.8 \\
Transportation Equipment (336) & 17 & 3.6 \\
Nonmetallic Minerals (327) & 14 & 3.0 \\
Plastics and Rubber (326) & 13 & 2.8 \\
Other sectors (15 distinct NAICS3) & 82 & 17.4 \\
\hline Total & 471 & 100.0 \\
\hline
\end{tabular}

Source: Authors' calculations based on the Temporary Trade Barriers Database (Bown, 2014).

Table 2: Correlations

Dep. variable:

(2)

(3)

(4)

(5)

Downstream petition Basic measure Basic duty Affected share Coverage ratio $\quad$ X Elasticity

\begin{tabular}{lccccc}
\hline \hline Marginal effect & $0.537^{*}$ & $1.048^{* * *}$ & $4.573^{* * *}$ & $11.533^{* * *}$ & $1.617 ; 11.171^{* * *}$ \\
& $(0.304)$ & $(0.321)$ & $(1.516)$ & $(4.155)$ & $(2.252) ;(4.043)$ \\
\hline Number of industries & 153 & 153 & 153 & 153 & 152 \\
Number of observations & 3,519 & 3,519 & 3,519 & 3,519 & 3,496 \\
Pseudo $R^{2}$ & 0.07 & 0.07 & 0.07 & 0.07 & 0.07 \\
\hline
\end{tabular}

Notes: Coefficients are average marginal effects of the variables specified for each column. All regressions include industry and year fixed effects. Column (5) interacts affected share by a dummy that equals 1 if the demand elasticity of the industry is higher than the sample mean (10.05). Marginal effect for column (5) is calculated for when the dummy equals 0 and 1 separately. Standard errors clustered by industries in parentheses. ${ }^{* *},{ }^{* *}$, and ${ }^{*}$ denote statistical significance at the 1,5 , and 10 percent levels respectively. 
Table 3: Main Results

Dep. variable:

1988-2013

1997-2013

Downstream petition

(1)

$(2)$

(3)

(4)

\begin{tabular}{lcccc}
\hline \hline$Z_{s} X$ mean affected share & $\begin{array}{c}1.353^{* *} \\
(0.203)\end{array}$ & \multicolumn{3}{c}{$45.665^{* *}$} \\
& & $(68.564)$ & \\
$Z_{s} X$ max. affected share & & $\left(0.077^{* *}\right.$ & & $4.127^{*}$ \\
& & $(0.033)$ & & $(3.000)$ \\
\hline Marginal effect & $0.052^{*}$ & $0.013^{* *}$ & $0.865^{* *}$ & $0.321^{*}$ \\
& $(0.027)$ & $(0.005)$ & $(0.340)$ & $(0.165)$ \\
\hline Increase in pp & 0.702 & 0.515 & 3.460 & 2.761 \\
\hline Number of industries & 140 & 140 & 113 & 113 \\
Number of observations & 3,220 & 3,220 & 1,582 & 1,582 \\
Pseudo $R^{2}$ & 0.07 & 0.07 & 0.08 & 0.08
\end{tabular}

Notes: Coefficients are odd ratios. Marginal effects are average. All regressions include industry and year fixed effects. Standard errors clustered by industries in parentheses. Increase in pp (percentage points) is calculated by multiplying the marginal effect by the standard deviation of the independent variable times $100 . * * * * *$, and $*$ denote statistical significance at the 1,5 , and 10 percent levels respectively. 

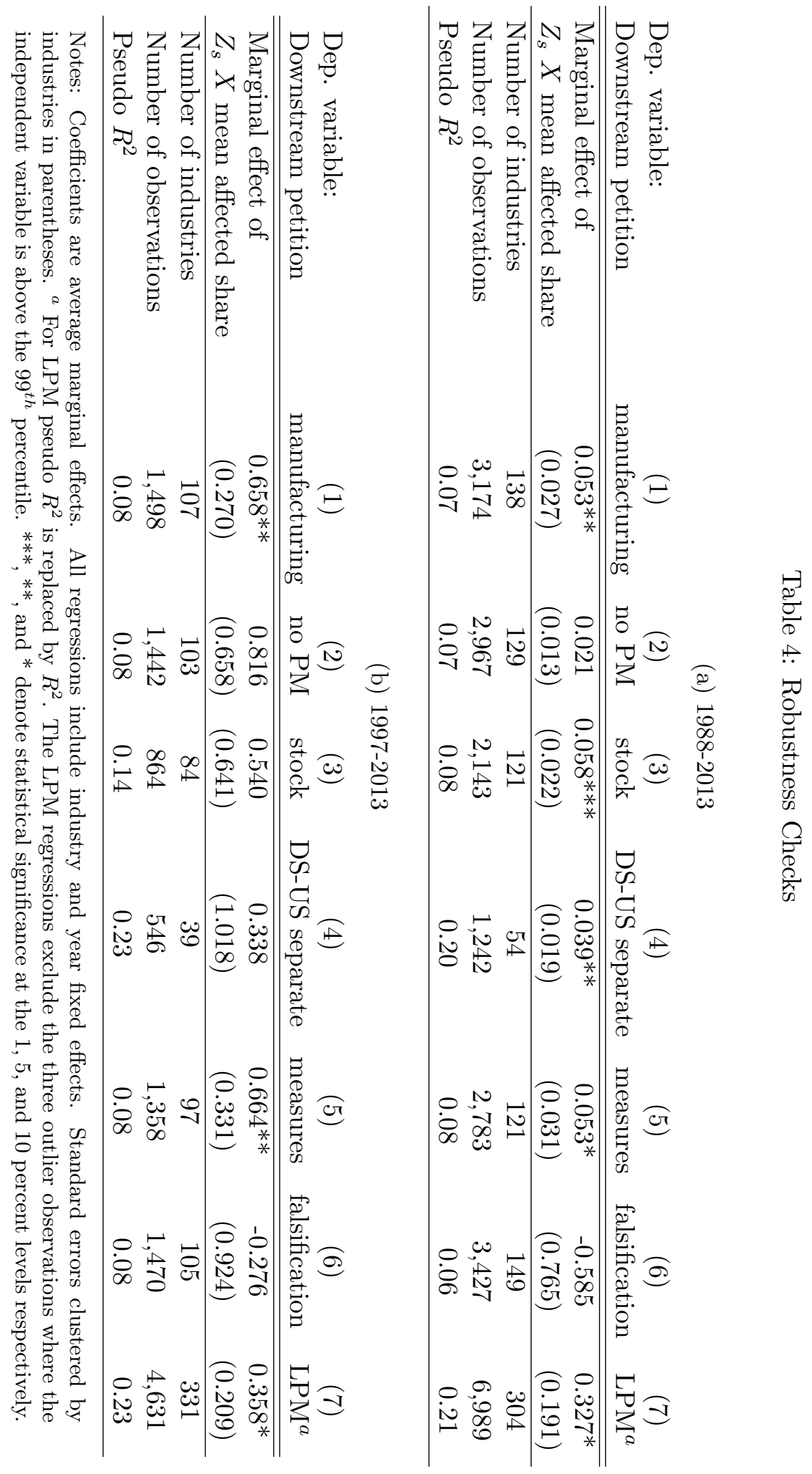
Table 5: Cascading Protection in the EU

\begin{tabular}{lcccc} 
Dep. variable: & \multicolumn{2}{c}{$1988-2012$} & \multicolumn{2}{c}{$1997-2012$} \\
Downstream petition & $(1)$ & $(2)$ & $(3)$ & $(4)$ \\
\hline \hline$Z_{s} X$ mean affected share & 1.000 & \multicolumn{3}{c}{0.994} \\
& $(0.007)$ & & $(0.017)$ & \\
$Z_{s} X$ max. affected share & & 0.999 & & 1.001 \\
& & $(0.004)$ & & $(0.007)$ \\
\hline Number of industries & 121 & 121 & 102 & 102 \\
Number of observations & 2,662 & 2,662 & 1,326 & 1,326 \\
Pseudo $R^{2}$ & 0.07 & 0.07 & 0.09 & 0.09 \\
\hline
\end{tabular}

Notes: Coefficients are odd ratios. All regressions include industry and year fixed effects.

Standard errors clustered by industries in parentheses. 
Table 6: Upstream-Downstream Effects

\begin{tabular}{|c|c|c|c|c|c|}
\hline upstream industry (BEA) & $\begin{array}{l}\text { downstream industry } \\
\qquad(\mathrm{BEA})\end{array}$ & $\begin{array}{c}\text { increase in } \\
\text { petition } \\
\text { likelihood, } \\
\text { 1988-2013 }\end{array}$ & $\begin{array}{c}\text { increase in } \\
\text { petition } \\
\text { likelihood, } \\
\text { 1997-2013 }\end{array}$ & $\begin{array}{c}\text { mean petition } \\
\text { likelihood, } \\
\text { 1988-2013 }\end{array}$ & $\begin{array}{c}\text { mean petition } \\
\text { likelihood, } \\
\text { 1997-2013 }\end{array}$ \\
\hline $\begin{array}{l}\text { Broadwoven fabric mills } \\
\qquad(313210)\end{array}$ & $\begin{array}{l}\text { Textile bag and canvas } \\
\text { mills (314910) }\end{array}$ & 0.03 & 0.66 & 4.17 & 7.14 \\
\hline $\begin{array}{l}\text { Leather and hide tanning } \\
\text { and finishing (316100) }\end{array}$ & $\begin{array}{l}\text { Other leather products } \\
\qquad(316900)\end{array}$ & 0.22 & 4.04 & 4.17 & 7.14 \\
\hline \multirow{3}{*}{ Sawmills (321113) } & Wood preservation (321114) & 0.14 & 0.23 & 8.33 & 7.14 \\
\hline & $\begin{array}{l}\text { Other millwork, including } \\
\text { flooring ( } 321918)\end{array}$ & 0.16 & 2.52 & 12.50 & 14.29 \\
\hline & $\begin{array}{l}\text { Miscellaneous wood } \\
\text { products }(321999)\end{array}$ & 0.22 & 3.20 & 12.50 & 7.14 \\
\hline \multirow{4}{*}{$\begin{array}{l}\text { Paper and paperboard mills } \\
\qquad(3221 \mathrm{~A} 0)\end{array}$} & $\begin{array}{l}\text { Paperboard container } \\
\qquad(322210)\end{array}$ & 0.22 & 2.01 & 4.17 & 7.14 \\
\hline & $\begin{array}{l}\text { Surface-coated paperboard } \\
\qquad(322226)\end{array}$ & 0.01 & 0.65 & 8.33 & 14.29 \\
\hline & $\begin{array}{c}\text { Coated and uncoated paper } \\
\text { bag }(32222 \mathrm{~B})\end{array}$ & 0.02 & 1.43 & 8.33 & 14.29 \\
\hline & $\begin{array}{l}\text { Stationery and related } \\
\text { products }(322233)\end{array}$ & 0.01 & 0.55 & 8.33 & 7.14 \\
\hline \multirow{3}{*}{ Petrochemicals (325110) } & $\begin{array}{l}\text { Other basic organic } \\
\text { chemicals }(325190)\end{array}$ & 0.55 & 7.21 & 62.50 & 64.29 \\
\hline & $\begin{array}{l}\text { Plastics material and resin } \\
\qquad(325211)\end{array}$ & 0.20 & 4.76 & 16.67 & 14.29 \\
\hline & Synthetic rubber (325212) & 0.07 & 0.63 & 12.50 & 7.14 \\
\hline \multirow{3}{*}{$\begin{array}{l}\text { Other basic organic } \\
\text { chemicals }(325190)\end{array}$} & $\begin{array}{l}\text { Plastics material and resin } \\
\qquad(325211)\end{array}$ & 0.17 & 11.79 & 16.67 & 14.29 \\
\hline & Synthetic rubber (325212) & 0.04 & 1.05 & 12.50 & 7.14 \\
\hline & $\begin{array}{l}\text { Noncellulosic organic fiber } \\
\qquad(325222)\end{array}$ & 0.07 & 4.87 & 12.50 & 7.14 \\
\hline \multirow[t]{2}{*}{$\begin{array}{l}\text { Plastics material and resin } \\
\qquad(325211)\end{array}$} & $\begin{array}{c}\text { Plastics packaging } \\
\text { materials, film and sheet } \\
\qquad(326110)\end{array}$ & 0.03 & 2.99 & 16.67 & 21.43 \\
\hline & $\begin{array}{c}\text { Plastics plumbing fixtures } \\
\text { and all other plastics } \\
\text { products (32619A) }\end{array}$ & 0.13 & 5.77 & 12.50 & 7.14 \\
\hline Synthetic rubber (325212) & Tires $(326210)$ & 0.20 & 3.28 & 8.33 & 14.29 \\
\hline $\begin{array}{l}\text { Noncellulosic organic fiber } \\
\qquad(325222)\end{array}$ & $\begin{array}{l}\text { Tire cord and tire fabric } \\
\text { mills (314992) }\end{array}$ & $>0.00$ & 0.78 & 8.33 & 7.14 \\
\hline
\end{tabular}

Other rubber products (326290)
Oil and gas field machinery and equipment (333132)
0.01

0.27

8.33

14.29 
Table 6 - Continued from previous page

\begin{tabular}{|c|c|c|c|c|c|}
\hline upstream industry (BEA) & $\begin{array}{l}\text { downstream industry } \\
\qquad(\mathrm{BEA})\end{array}$ & $\begin{array}{c}\text { increase in } \\
\text { petition } \\
\text { likelihood, } \\
\text { 1988-2013 }\end{array}$ & $\begin{array}{c}\text { increase in } \\
\text { petition } \\
\text { likelihood, } \\
\text { 1997-2013 }\end{array}$ & $\begin{array}{c}\text { mean petition } \\
\text { likelihood, } \\
\text { 1988-2013 }\end{array}$ & $\begin{array}{c}\text { mean petition } \\
\text { likelihood, } \\
\text { 1997-2013 }\end{array}$ \\
\hline \multirow{11}{*}{$\begin{array}{l}\text { Iron and steel mills } \\
\qquad(331111)\end{array}$} & Steel wire drawing (331222) & 0.35 & 9.67 & 66.67 & 64.29 \\
\hline & $\begin{array}{l}\text { Saw blade and handsaw } \\
\qquad(332213)\end{array}$ & 0.02 & 0.37 & 4.17 & 7.14 \\
\hline & $\begin{array}{l}\text { Fabricated structural metal } \\
\qquad(332312)\end{array}$ & 0.01 & 0.70 & 8.33 & 14.29 \\
\hline & Plate work (332313) & 0.01 & $>0.00$ & 4.17 & 7.14 \\
\hline & Sheet metal work (332322) & 0.01 & 0.03 & 4.17 & 7.14 \\
\hline & $\begin{array}{c}\text { Ornamental and } \\
\text { architectural metal work } \\
(332323)\end{array}$ & 0.04 & 0.12 & 8.33 & 14.29 \\
\hline & $\begin{array}{l}\text { Metal tank, heavy gauge } \\
\qquad(332420)\end{array}$ & 0.01 & 0.24 & 4.17 & 7.14 \\
\hline & $\begin{array}{l}\text { Elevator and moving } \\
\text { stairway }(333921)\end{array}$ & 0.01 & 0.38 & 4.17 & 7.14 \\
\hline & $\begin{array}{l}\text { Industrial truck, trailer, } \\
\text { and stacker (333924) }\end{array}$ & 0.07 & 2.35 & 8.33 & 14.29 \\
\hline & $\begin{array}{l}\text { Electric power and specialty } \\
\text { transformer }(335311)\end{array}$ & 0.06 & 1.26 & 4.17 & 7.14 \\
\hline & $\begin{array}{l}\text { Motorcycle, bicycle, and } \\
\text { parts }(336991)\end{array}$ & 0.10 & 1.91 & 8.33 & 7.14 \\
\hline Steel wire drawing (331222) & $\begin{array}{l}\text { Spring and wire products } \\
\qquad(332600)\end{array}$ & 0.05 & 1.59 & 8.33 & 14.29 \\
\hline \multirow{2}{*}{ Primary aluminum (331312) } & $\begin{array}{l}\text { Aluminum sheet, plate, and } \\
\text { foil }(331315)\end{array}$ & 0.52 & 10.50 & 8.33 & 14.29 \\
\hline & $\begin{array}{l}\text { Other aluminum rolling and } \\
\text { drawing }(331319)\end{array}$ & 0.02 & 0.97 & 4.17 & 7.14 \\
\hline $\begin{array}{l}\text { Aluminum sheet, plate, and } \\
\text { foil (331315) }\end{array}$ & $\begin{array}{l}\text { Other aluminum rolling and } \\
\text { drawing }(331319)\end{array}$ & $>0.00$ & 0.13 & 4.17 & 7.14 \\
\hline \multirow{2}{*}{$\begin{array}{l}\text { Primary smelting and } \\
\text { refining of copper (331411) }\end{array}$} & $\begin{array}{l}\text { Other aluminum rolling and } \\
\text { drawing }(331319)\end{array}$ & 0.01 & 0.37 & 4.17 & 7.14 \\
\hline & $\begin{array}{l}\text { Copper rolling, drawing, } \\
\text { and extruding ( } 331421)\end{array}$ & 0.22 & 8.08 & 4.17 & 7.14 \\
\hline \multirow{2}{*}{$\begin{array}{c}\text { Primary nonferrous metal, } \\
\text { except copper and } \\
\text { aluminum (331419) }\end{array}$} & $\begin{array}{l}\text { Nonferrous metal, except } \\
\text { copper and aluminum, } \\
\text { shaping (331491) }\end{array}$ & 0.16 & 3.48 & 8.33 & 7.14 \\
\hline & $\begin{array}{l}\text { Jewelry and silverware } \\
\qquad(339910)\end{array}$ & 2.49 & 38.57 & 4.17 & 7.14 \\
\hline $\begin{array}{l}\text { Spring and wire products } \\
\qquad(332600)\end{array}$ & Mattress (337910) & 0.02 & 0.03 & 8.33 & 14.29 \\
\hline $\begin{array}{c}\text { Turned product and screw, } \\
\text { nut, and bolt }(332720)\end{array}$ & $\begin{array}{l}\text { Military armored vehicles } \\
\text { and tank parts (336992) }\end{array}$ & 0.01 & 0.05 & 4.17 & 7.14 \\
\hline
\end{tabular}


Table 6 - Continued from previous page

\begin{tabular}{|c|c|c|c|c|c|}
\hline upstream industry (BEA) & $\begin{array}{l}\text { downstream industry } \\
\text { (BEA) }\end{array}$ & $\begin{array}{c}\text { increase in } \\
\text { petition } \\
\text { likelihood, } \\
\text { 1988-2013 }\end{array}$ & $\begin{array}{c}\text { increase in } \\
\text { petition } \\
\text { likelihood, } \\
\text { 1997-2013 }\end{array}$ & $\begin{array}{c}\text { mean petition } \\
\text { likelihood, } \\
\text { 1988-2013 }\end{array}$ & $\begin{array}{c}\text { mean petition } \\
\text { likelihood, } \\
1997-2013\end{array}$ \\
\hline $\begin{array}{l}\text { Other engine equipment } \\
\qquad(333618)\end{array}$ & $\begin{array}{c}\text { Lawn and garden } \\
\text { equipment (333112) }\end{array}$ & 0.03 & 0.44 & 4.17 & 7.14 \\
\hline Electron tubes (334411) & $\begin{array}{l}\text { Audio and video equipment } \\
\qquad(334300)\end{array}$ & 0.11 & 21.29 & 4.17 & 7.14 \\
\hline \multirow{2}{*}{$\begin{array}{l}\text { Semiconductors and related } \\
\text { device }(334413)\end{array}$} & $\begin{array}{l}\text { Electronic computer } \\
\qquad(334111)\end{array}$ & 2.45 & 21.32 & 8.33 & 7.14 \\
\hline & $\begin{array}{c}\text { All other electronic } \\
\text { components (33441A) }\end{array}$ & 2.62 & 59.35 & 8.33 & 7.14 \\
\hline \multirow{2}{*}{$\begin{array}{c}\text { All other electronic } \\
\text { components (33441A) }\end{array}$} & $\begin{array}{l}\text { Electronic computer } \\
\qquad(334111)\end{array}$ & 1.04 & 20.77 & 8.33 & 7.14 \\
\hline & $\begin{array}{l}\text { Other computer peripheral } \\
\text { equipment }(334119)\end{array}$ & 1.10 & 44.23 & 16.67 & 7.14 \\
\hline
\end{tabular}

Notes: The sample is restricted to upstream-downstream combinations that are close (cost share $>0.1)$ and that have at least initiated one TTB investigation in 1988-2013. Increase in petition probabilities are calculated by multiplying the marginal effect (from Table 3 columns (1) and (3) (for 1988-2013 and 1997-2013 respectively)) when the downstream industry is not affected by any upstream measure with $Z_{s} *$ (affected share $)_{s w}$ where the (affected share) $)_{s w}$ is IO-specific and the duty levels are evaluated at the observed mean value. Figures in bold indicate that a corresponding downstream initiation within three years of the upstream measure has occurred in the data. 
Table 7: Additional Results

Negative Binomial

Linear

Dep. variable:

(1)

(2)

(3)

(4)

Number of petitions $_{w} \quad 1988-2013 \quad 1997-2013 \quad 1988-2013 \quad 1997-2013$

\begin{tabular}{lcccc}
\hline \hline$D S_{w}$ & $1.01^{*}$ & $1.01^{*}$ & $0.02^{* * *}$ & $0.01^{*}$ \\
& $(0.01)$ & $(0.00)$ & $(0.01)$ & $(0.00)$ \\
$M_{w}$ & $8.40^{* * *}$ & $3.82^{* * *}$ & $2.21^{* *}$ & $0.72^{*}$ \\
& $(5.23)$ & $(1.98)$ & $(0.88)$ & $(0.43)$ \\
\hline Number of observations & 291 & 323 & 291 & 323 \\
\hline
\end{tabular}

Notes: Columns (1) and (2) report IRRs (setting the dispersion parameter to the mean), and columns (3) and (4) show coefficients from a linear specification. Number of observations correspond to the number of upstream industries, and this number is lower for the full sample due to lacking pre-1997 $M_{w}$ for 32 industries. Robust standard errors in parentheses. $* * *, * *$, and ${ }^{*}$ denote statistical significance at the 1,5 , and 10 percent levels respectively.

Table 8: Summary Statistics

\begin{tabular}{lccccc} 
Variable & Obs & Mean & Std. Dev. & Min & Max \\
\hline \hline$\sigma$ & 156 & 8.816 & 9.916 & 1.300 & 65.278 \\
$H$ & 156 & 4.124 & 2.330 & 0.191 & 9.913 \\
$\mu$ & 156 & 0.006 & 0.020 & 0 & 0.200 \\
$\beta$ & 1897 & 0.041 & 0.110 & 0 & 0.984 \\
$T_{i i}$ & 2,184 & 20,627 & 42,493 & 1,000 & 747,044 \\
$T_{j i}$ & 2,184 & 7,610 & 15,189 & 4 & 127,891 \\
$T_{i j}$ & 2,184 & 5,353 & 10,290 & 13 & 97,759 \\
$T_{j j}$ & 2,184 & 49,636 & 93,391 & 0 & 885,272 \\
$t$ & 2,184 & 0.457 & 0.868 & 0 & 4.896 \\
$\Delta G D P$ & 14 & 2.253 & 2.021 & -2.804 & 4.787 \\
\hline
\end{tabular}

Notes: $\beta$ is normalized to sum up to one for each downstream industry, and $\sum \mu_{s}$ and $\mu_{Y}$ are normalized to sum up to one. 
Table 9: Profit, Price and Welfare Adjustment due to TTBs

\begin{tabular}{lcccccc} 
& \multicolumn{2}{c}{ Benchmark } & \multicolumn{2}{c}{ GVC $(50 \%)$} & \multicolumn{2}{c}{ GVC (90\%) } \\
Variables & $(1)$ & $(2)$ & $(3)$ & $(4)$ & $(5)$ & $(6)$ \\
\hline \hline$\#$ of $\mathbb{F}_{1 s}$ & 4.09 & 3.91 & 4.27 & 3.91 & 4.55 & 3.91 \\
$\Delta \Pi_{1 w}$ & $1.67 \%$ & $2.86 \%$ & $1.18 \%$ & $1.35 \%$ & $2.23 \%$ & $0.53 \%$ \\
$\Delta \Pi_{2 w}$ & $-0.26 \%$ & $-0.44 \%$ & $-1.77 \%$ & $2.18 \%$ & $-4.16 \%$ & $2.68 \%$ \\
$\Delta \Pi_{1 s}$ & $-0.57 \%$ & $1.81 \%$ & $-3.43 \%$ & $1.81 \%$ & $-6.42 \%$ & $1.81 \%$ \\
$\Delta \Pi_{2 s}$ & $0.41 \%$ & $-0.43 \%$ & $1.71 \%$ & $-0.43 \%$ & $3.05 \%$ & $-0.43 \%$ \\
$\Delta c_{1 s}$ & $0.89 \%$ & $0.00 \%$ & $2.02 \%$ & $0.00 \%$ & $3.89 \%$ & $0.00 \%$ \\
$\Delta W_{1}$ & $-1.04 \%$ & $-0.55 \%$ & $-1.83 \%$ & $-0.55 \%$ & $-2.63 \%$ & $-0.55 \%$ \\
$\Delta W_{2}$ & $-0.05 \%$ & $0.00 \%$ & $-0.11 \%$ & $0.00 \%$ & $-0.17 \%$ & $0.00 \%$ \\
\hline $\mathbb{F}_{1 s}$ caused by upstream & $4.40 \%$ & $8.49 \%$ & $13.98 \%$ \\
$W$ corr. (value) & $0.49 \%$ & $1.28 \%$ & $2.08 \%$ \\
$W$ corr. (share) & $47.38 \%$ & \multicolumn{2}{c}{$69.95 \%$} & $29.12 \%$ \\
\hline
\end{tabular}

Notes: Rows (2)-(8) report the percentage change in the variable of interest when downstream industries (endogenously) petition and obtain protection; the benchmark case is with observed import penetration rates whereas GVC (50\%) and GVC (90\%) use counterfactual import penetration rates as the US switches 50 and 90 percent of its domestic sourcing to foreign inputs respectively. Columns (1), (3), and (5) represent the case for when both upstream and downstream are protected (i.e. cascading protection), whereas columns (2), (4), and (6) show the results for the counterfactual case without any upstream protection (i.e. "public interest clause" in effect).

Table 10: Decomposition of Welfare Losses

\begin{tabular}{lccc} 
Value & Benchmark & GVC 50\% & GVC 90\% \\
\hline \hline Upstream & $-0.487 \%$ & $-1.226 \%$ & $-1.938 \%$ \\
Downstream & $-0.557 \%$ & $-0.602 \%$ & $-0.695 \%$ \\
Ext. Margin & $-0.006 \%$ & $-0.048 \%$ & $-0.136 \%$ \\
Int. Margin & $-0.002 \%$ & $-0.005 \%$ & $-0.009 \%$ \\
Natural & $-0.550 \%$ & $-0.550 \%$ & $-0.550 \%$ \\
Total & $-1.045 \%$ & $-1.829 \%$ & $-2.632 \%$ \\
\hline
\end{tabular}

Notes: The table decomposes the welfare losses associated with TTBs into four mutually exclusive categories: welfare loss directly caused by upstream protection, welfare loss due to downstream protection caused by upstream protection (extensive margin), welfare loss due to higher duties that are obtained by downstream industries caused by upstream protection (intensive margin), and the direct welfare loss caused by downstream protection regardless of upstream protection (natural). 
Figure 1: US TTBs

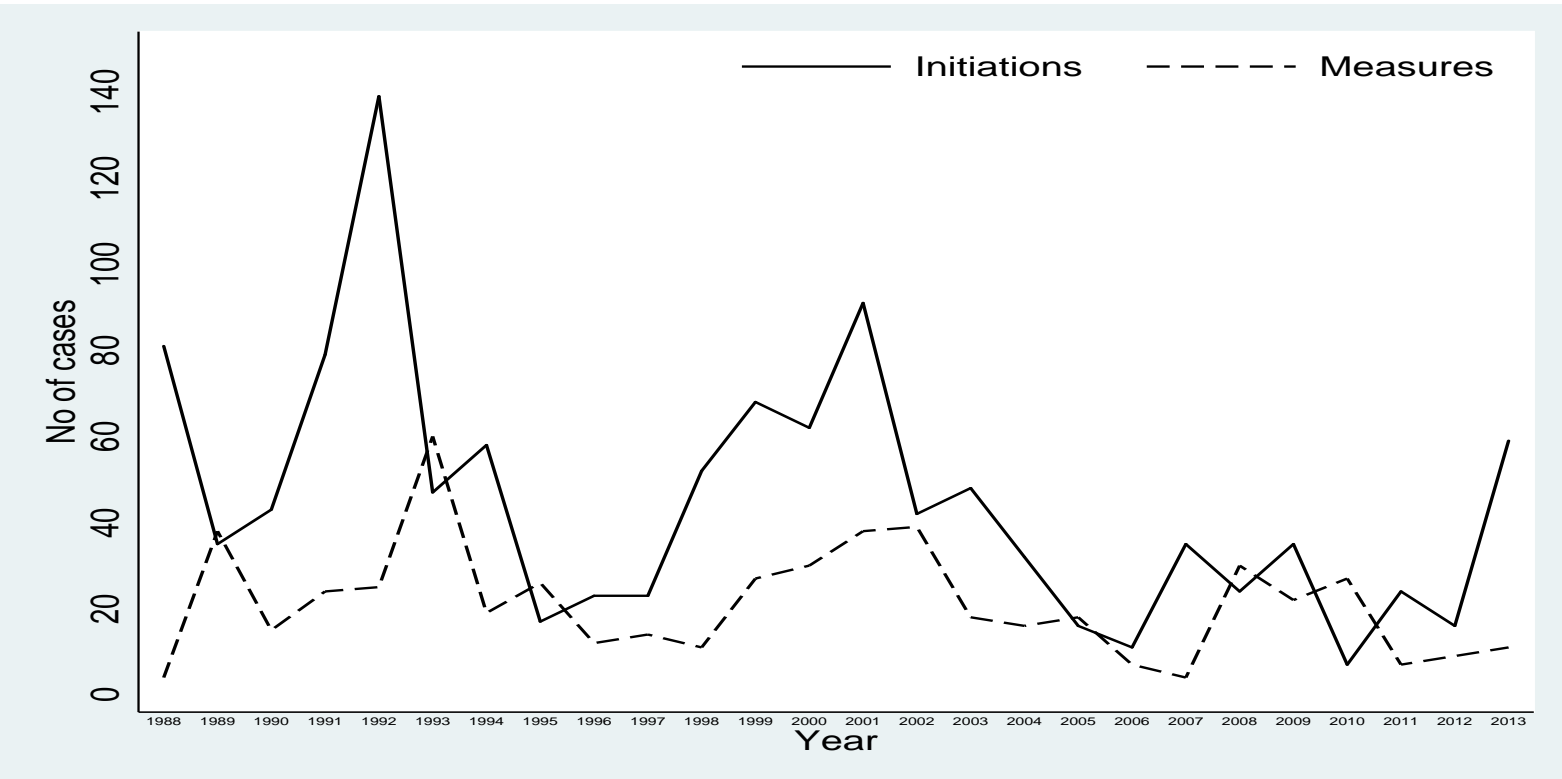

Source: Authors' calculations based on the Temporary Trade Barriers Database (Bown, 2014).

Figure 2: Upstreamness of US TTBs

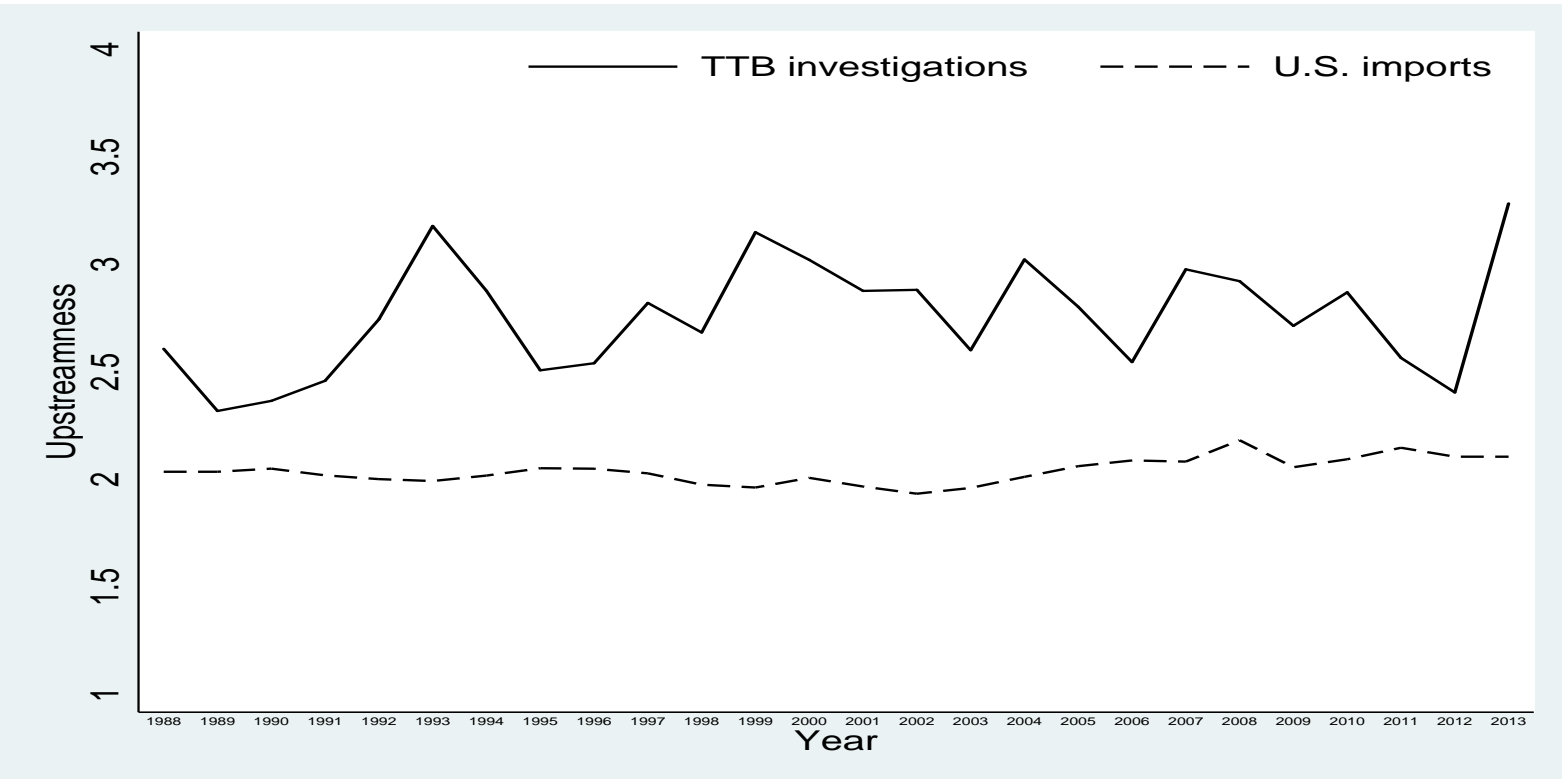

Notes: We use the 1989 and 2012 imports for 1988 and 2013 respectively due to data unavailability.

Source: Authors' calculations based on Antràs et al. (2012), Schott (2008), and the Temporary Trade Barriers Database (Bown, 2014). 
Figure 3: Sector Relationships

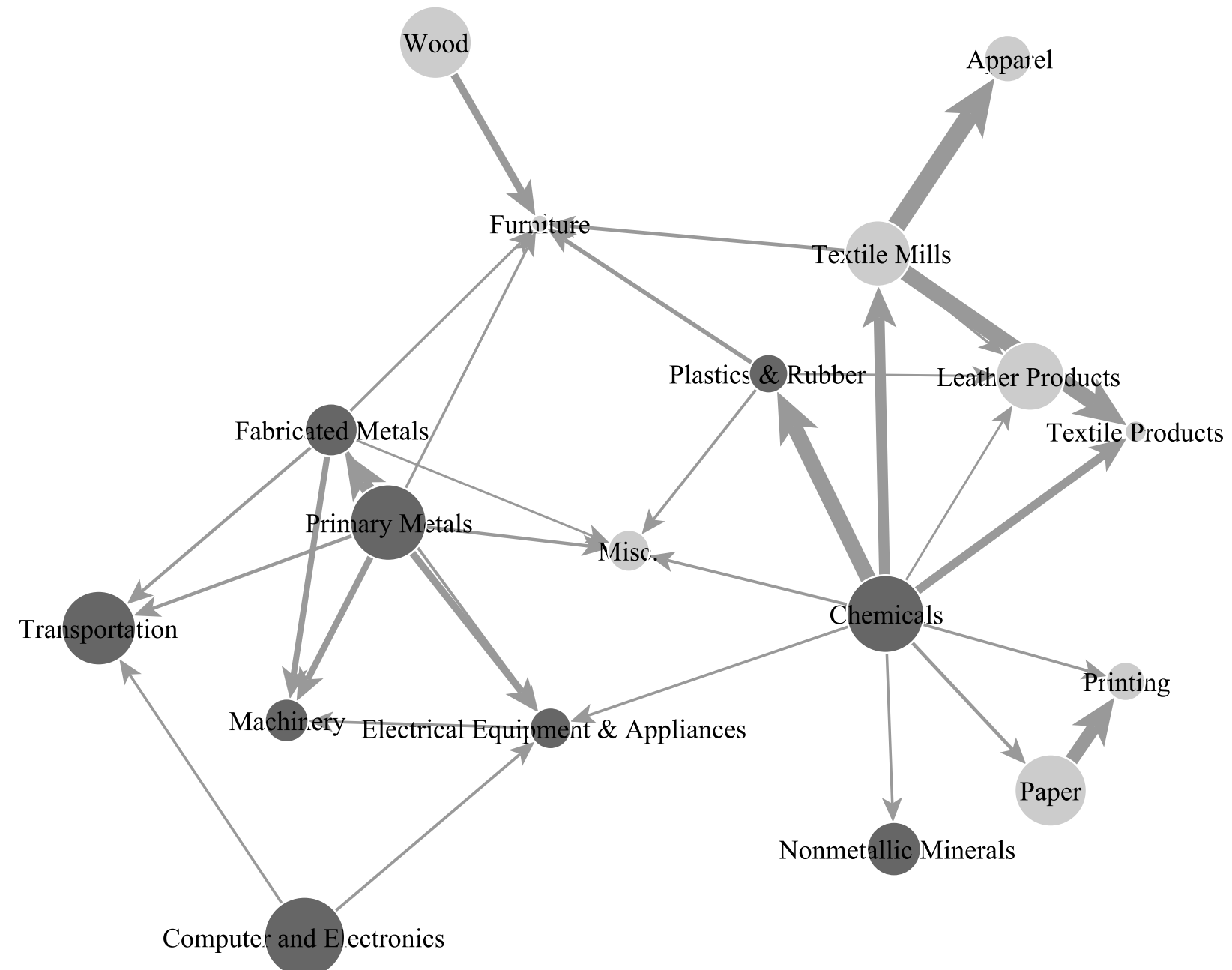

Notes: Nodes indicate NAICS3 sectors and links indicate input to output relationships. The links thicken as cost shares increase (with minimum cost share set at 10 percent for visual clarity). The locations of the nodes are based on the number of links each node has (i.e. centrality indices). The size of the nodes specifies how self-reliant a sector is. The colors indicate target concentration (dark gray: heavy TTB target, light gray: light TTB target). A sector is a heavy target if it's on the top 10 targeted sectors listed in Table 1

Source: Authors' calculations based on the Temporary Trade Barriers Database (Bown, 2014) and the Bureau of Economic Analysis' 1997 Input-Output tables (BEA, 1997) using network visualization software Visone. 


\section{A Appendix}

\section{A.1 Proof of Proposition 1}

We first derive equation (8). By definition of $\frac{\Delta^{2} \Pi_{1 s}}{\Delta \mathbb{P}_{s} \Delta \mathbb{P}_{w}}$, we have:

$\left.\frac{\Delta^{2} \Pi_{1 s}}{\Delta \mathbb{P}_{s} \Delta \mathbb{P}_{w}}=\left[\Pi_{1 s}\left(\mathbb{P}_{w}=1, \mathbb{P}_{s}=1\right)-\Pi_{1 s}\left(\mathbb{P}_{w}=1, \mathbb{P}_{s}=0\right)\right]-\left[\Pi_{1 s}\left(\mathbb{P}_{w}=0, \mathbb{P}_{s}=1\right)-\Pi_{1 s}\left(\mathbb{P}_{w}=0, \mathbb{P}_{s}=0\right)\right]\right]$

Denote $\Pi_{1 j s}$ as domestic industry $s$ profits in market $j$. Since we have a fixed number of firms and income levels, foreign market profits are not affected by domestic protection conditions. Therefore, $\frac{\Delta^{2} \Pi_{1 s}}{\Delta \mathbb{P}_{s} \Delta \mathbb{P}_{w}}$ can be expressed as:

$\frac{\Delta^{2} \Pi_{1 s}}{\Delta \mathbb{P}_{s} \Delta \mathbb{P}_{w}}=\left[\Pi_{11 s}\left(\mathbb{P}_{w}=1, \mathbb{P}_{s}=1\right)-\Pi_{11 s}\left(\mathbb{P}_{w}=1, \mathbb{P}_{s}=0\right)\right]-\left[\Pi_{11 s}\left(\mathbb{P}_{w}=0, \mathbb{P}_{s}=1\right)-\Pi_{11 s}\left(\mathbb{P}_{w}=0, \mathbb{P}_{s}=0\right)\right]$

Because the government grants protection in order to restore firms' domestic profits, the above expression can be simplified to:

$$
\frac{\Delta^{2} \Pi_{1 s}}{\Delta \mathbb{P}_{s} \Delta \mathbb{P}_{w}}=\Pi_{11 s}\left(\mathbb{P}_{w}=0, \mathbb{P}_{s}=0\right)-\Pi_{11 s}\left(\mathbb{P}_{w}=1, \mathbb{P}_{s}=0\right)
$$

Equation 20 suggests that cascading protection exists if and only if upstream protection causes additional profit losses for downstream industries $\left(\frac{\Delta^{2} \Pi_{1 s}}{\Delta \mathbb{P}_{s} \Delta \mathbb{P}_{w}}>0\right)$. Substituting equation 4 into the profit formula (5), equation (20) can be rewritten as:

$$
\frac{\Delta^{2} \Pi_{1 s}}{\Delta \mathbb{P}_{s} \Delta \mathbb{P}_{w}}=\frac{\mu_{s} E_{1}}{\sigma_{s}}\left(M_{s}^{\prime}-M_{s}\right)
$$

where $M_{s}^{\prime}=1-\frac{N_{1 s} p_{1 s}^{1-\sigma_{s}}}{N_{1 s} p_{1 s}^{1-\sigma_{s}}+N_{2 s} p_{2 s}{ }^{1-\sigma_{s}}}$ and $M_{s}=1-\frac{N_{1 s} p_{1 s}^{1-\sigma_{s}}}{N_{1 s} p_{1 s}^{1-\sigma_{s}}+N_{2 s} p_{2 s}{ }^{1-\sigma_{s}}}$ are the import penetration rates of industry $s$ with and without upstream protection; and $p_{1 s}^{\prime}$ and $p_{1 s}$ are the corresponding prices charged by domestic firms.

Note that $M_{s}$ is an increasing function of $p_{1 s}$. Substituting the upstream price index equation (1) into the downstream cost equation (2), we can verify that the unit cost of downstream firms is an increasing function of $t_{12 w}$, which is increasing in upstream protection $\mathbb{P}_{w}$. Because downstream firms charge a constant markup over marginal cost, $p_{1 s}$ also increases with respect to $\mathbb{P}_{w}$. This implies $p_{1 s}^{\prime}>p_{1 s}$ and hence $M_{s}^{\prime}-M_{s}>0$. Therefore $\frac{\Delta^{2} \Pi_{1 s}}{\Delta \mathbb{P}_{s} \Delta \mathbb{P}_{w}}>0$ and cascading protection naturally emerges in our setting.

Next, we derive equation (9). Substituting the expressions of $M_{s}^{\prime}$ and $M_{s}$ into equation (21), $\frac{\Delta^{2} \Pi_{1 s}}{\Delta \mathbb{P}_{s} \Delta \mathbb{P}_{w}}$ can be written as:

$$
\frac{\Delta^{2} \Pi_{1 s}}{\Delta \mathbb{P}_{s} \Delta \mathbb{P}_{w}}=\frac{\mu_{s} E_{1}}{\sigma_{s}}\left(\frac{N_{1 s} p_{1 s}^{1-\sigma_{s}}}{N_{1 s} p_{1 s}^{1-\sigma_{s}}+N_{2 s} p_{2 s}{ }^{1-\sigma_{s}}}-\frac{N_{1 s} p_{1 s}^{\prime 1-\sigma_{s}}}{N_{1 s} p_{1 s}^{\prime 1-\sigma_{s}}+N_{2 s} p_{2 s}{ }^{1-\sigma_{s}}}\right) .
$$

\footnotetext{
${ }^{65}$ We slightly abuse notation as $\frac{\Delta \Pi_{1 s}\left(\mathbb{P}_{w}\right)}{\Delta \mathbb{P}_{s}}$ should be formally written as $\frac{\Delta \Pi_{1 s}\left(\mathbb{P}_{w}, \mathbb{P}_{-w}\right)}{\Delta \mathbb{P}_{s}}$.
} 
We now perform a first-order Taylor approximation for $f \equiv \frac{N_{1 s} p_{1 s}^{1-\sigma_{s}}}{N_{1 s} p_{1 s}^{1-\sigma_{s}}+N_{2 s} p_{2 s}^{1-\sigma_{s}}}$ around $t_{21 w}=0$ (i.e. $\left.\tau_{21 w}=1\right)$ :

$$
\begin{aligned}
f \approx & f\left(p_{1 s}\right)+\left.f^{\prime}\left(p_{1 s}\right) \frac{\partial p_{1 s}}{\partial c_{1 s}} \frac{\partial c_{1 s}}{\partial P_{1 w}} \frac{\partial P_{1 w}}{\partial \tau_{21 w}}\left(\tau_{21 w}^{\prime}-\tau_{21 w}\right)\right|_{\tau_{21 w}=1} \\
& =f\left(p_{1 s}\right)+\left.\frac{\left(1-\sigma_{s}\right)\left(1-M_{s}\right) M_{s}}{p_{1 s}} \frac{\sigma_{s}}{\sigma_{s}-1} \frac{c_{1 s} \beta_{w s}}{P_{1 w}} \frac{P_{1 w} M_{w}}{\tau_{21 w}}\left(\tau_{21 w}^{\prime}-\tau_{21 w}\right)\right|_{\tau_{21 w}=1} \\
& =\frac{N_{1 s} p_{1 s}^{1-\sigma_{s}}}{N_{1 s} p_{1 s}^{1-\sigma_{s}}+N_{2 s} p_{2 s}{ }^{1-\sigma_{s}}}+\left(1-\sigma_{s}\right)\left(1-M_{s}\right) M_{s} \beta_{w s} M_{w} t_{21 w} .
\end{aligned}
$$

Substituting the above back into equation $(22$ ) and rearranging terms, we get equation (9):

$$
\frac{\Delta^{2} \Pi_{1 s}}{\Delta \mathbb{P}_{s} \Delta \mathbb{P}_{w}} \approx \frac{\left(\sigma_{s}-1\right) \mu_{s} E_{1}}{\sigma_{s}}\left(1-M_{s}\right) M_{s} \beta_{w s} M_{w} t_{21 w}
$$

\section{A.2 Proof of Proposition 2}

We decompose the proofs for Proposition 2 into two parts. In Part 1, we show that given upstream protection, a duty imposed on downstream imports increases upstream profits, then in Part 2 we prove Proposition 2 by iteration.

Part 1. $\Pi_{1 w}\left(\mathbb{P}_{w}=1, \mathbb{P}_{s}=1, \mathbb{P}_{-s}\right)-\Pi_{1 w}\left(\mathbb{P}_{w}=1, \mathbb{P}_{s}=0, \mathbb{P}_{-s}\right)>0$ :

To simplify notation, denote $\Delta \Pi_{1 w, s} \equiv \Pi_{1 w}\left(\mathbb{P}_{w}=1, \mathbb{P}_{s}=1, \mathbb{P}_{-s}\right)-\Pi_{1 w}\left(\mathbb{P}_{w}=1, \mathbb{P}_{s}=0, \mathbb{P}_{-s}\right)$. When industry $s$ gets protected, upstream prices are unaffected, and $\Pi_{i s}$ becomes $\Pi_{i s}^{\prime}$. Because the utility function is Cobb-Douglas and income is fixed, protection of $s$ has no impact on downstream industries other than $s$. Substituting for $\Pi_{1 w}$ using the profit equation (5), $\Delta \Pi_{1 w, s}$ can be expressed as:

$$
\begin{gathered}
\Delta \Pi_{1 w, s}=\sum_{j \in\{1,2\}} \frac{N_{1 w}\left(\frac{p_{1 w}}{P_{j w}}\right)^{1-\sigma_{w}}}{\sigma_{w}}\left(\left(\sigma_{s}-1\right) \beta_{w s} \Pi_{j s}^{\prime}+\sum_{k \neq s}\left(\sigma_{k}-1\right) \beta_{w k} \Pi_{j k}-\sum_{k}\left(\sigma_{k}-1\right) \beta_{w k} \Pi_{j k}\right), \\
=\frac{N_{1 w} p_{1 w}^{1-\sigma_{w}}}{\sigma_{w}} \beta_{w s}\left(\sigma_{s}-1\right)\left(\frac{\Pi_{1 s}^{\prime}-\Pi_{1 s}}{P_{1 w}^{1-\sigma_{w}}}+\frac{\Pi_{2 s}^{\prime}-\Pi_{2 s}}{P_{2 w}^{1-\sigma_{w}}}\right) .
\end{gathered}
$$

Using downstream profit function (4), we can verify that:

$$
\begin{aligned}
& \Pi_{1 s}^{\prime}-\Pi_{1 s}>0, \\
& \Pi_{1 s}+\Pi_{2 s}=\Pi_{1 s}^{\prime}+\Pi_{2 s}^{\prime}=\frac{\mu_{s}}{\sigma_{s}}\left(E_{1}+E_{2}\right) .
\end{aligned}
$$

Thus, equation 23 can be rewritten as:

$$
\Delta \Pi_{1 w, s}=\frac{N_{1 w} p_{1 w}^{1-\sigma_{w}}}{\sigma_{w}} \beta_{w s}\left(\sigma_{s}-1\right)\left(\Pi_{1 s}^{\prime}-\Pi_{1 s}\right)\left(\frac{1}{P_{1 w}^{1-\sigma_{w}}}-\frac{1}{P_{2 w}^{1-\sigma_{w}}}\right) .
$$


When $\mathbb{P}_{w}=1$, equation (1) implies $P_{1 w}>P_{2 w} \sqrt{66}$ Together with $\Pi_{1 s}^{\prime}-\Pi_{1 s}>0$ and $\sigma_{w}>1$, we verify that $\Delta \Pi_{1 w, s}>0$.

Part 2. $E\left(\Pi_{1 w}\left(\mathbb{P}_{w}=1\right)\right)>E_{0}\left(\Pi_{1 w}\left(\mathbb{P}_{w}=1\right)\right)$ :

First, we order downstream industries and refer to the $j^{\text {th }}$ industry as $s_{j}$. Industries ordered before $s_{j}$ are denoted as $s_{j}(+)$. Denote the probability of an industry $s$ petitioning for protection as $r_{s}$; the existence of cascading protection therefore implies $r_{s}(1)>r_{s}(0)$, with 1 indicating the presence of upstream protection. Then, $E\left(\Pi_{1 w}\left(\mathbb{P}_{w}=1\right)\right)$ could be expanded as:

$$
\begin{aligned}
E\left(\Pi_{1 w}\left(\mathbb{P}_{w}=1\right)\right) & =\theta r_{s_{1}}(1) \sum_{\left\{\mathbb{P}_{s_{1}(+)}\right\}} \Pi_{1 w}\left(\mathbb{P}_{w}=1, \mathbb{P}_{s_{1}}=1,\left\{\mathbb{P}_{s_{1}(+)}\right\}\right) \operatorname{Pr}\left(\left\{\mathbb{P}_{s_{1}(+)}\right\}\right) \\
& +\left(1-\theta r_{s_{1}}(1)\right) \sum_{\left\{\mathbb{P}_{s_{1}(+)}\right\}} \Pi_{1 w}\left(\mathbb{P}_{w}=1, \mathbb{P}_{s_{1}}=0,\left\{\mathbb{P}_{s_{1}(+)}\right\}\right) \operatorname{Pr}\left(\left\{\mathbb{P}_{s_{1}(+)}\right\}\right),
\end{aligned}
$$

which can be rearranged to:

$$
\begin{aligned}
& E\left(\Pi_{1 w}\left(\mathbb{P}_{w}=1\right)\right)=\theta r_{s_{1}}(0) \sum_{\left\{\mathbb{P}_{s_{1}(+)}\right\}} \Pi_{1 w}\left(1, \mathbb{P}_{s_{1}}=1,\left\{\mathbb{P}_{s_{1}(+)}\right\}\right) \operatorname{Pr}\left(\left\{\mathbb{P}_{s_{1}(+)}\right\}\right) \\
& \quad+\left(1-\theta r_{s_{1}}(0)\right) \sum_{\left\{\mathbb{P}_{s_{1}(+)}\right\}} \Pi_{1 w}\left(1, \mathbb{P}_{s_{1}}=0,\left\{\mathbb{P}_{s_{1}(+)}\right\}\right) \operatorname{Pr}\left(\left\{\mathbb{P}_{s_{1}(+)}\right\}\right) \\
& \quad+\theta\left(r_{s_{1}}(1)-r_{s_{1}}(0)\right) \sum_{\left\{\mathbb{P}_{s_{1}(+)}\right\}}\left[\Pi_{1 w}\left(1, \mathbb{P}_{s_{1}}=1,\left\{\mathbb{P}_{s_{1}(+)}\right\}\right)-\Pi_{1 w}\left(1, \mathbb{P}_{s_{1}}=0,\left\{\mathbb{P}_{s_{1}(+)}\right\}\right)\right] \operatorname{Pr}\left(\left\{\mathbb{P}_{s_{1}(+)}\right\}\right),
\end{aligned}
$$

where we shorthand $\Pi_{1 w}\left(\mathbb{P}_{w}=1, \mathbb{P}_{s_{1}}=1,\left\{\mathbb{P}_{s_{1}(+)}\right\}\right)$ as $\Pi_{1 w}\left(1, \mathbb{P}_{s_{1}},\left\{\mathbb{P}_{s_{1}(+)}\right\}\right)$. Because $\Pi_{1 w}\left(1, \mathbb{P}_{s_{1}}=\right.$ $\left.1,\left\{\mathbb{P}_{s_{1}(+)}\right\}\right)-\Pi_{1 w}\left(1, \mathbb{P}_{s_{1}}=0,\left\{\mathbb{P}_{s_{1}(+)}\right\}\right)>0$ by Part 1 and $r_{s_{1}}(1)-r_{s_{1}}(0)>0$ by cascading protection, we have:

$$
\begin{gathered}
E\left(\Pi_{1 w}\left(\mathbb{P}_{w}=1\right)\right)>\theta r_{s_{1}}(0) \sum_{\left\{\mathbb{P}_{s_{1}(+)}\right\}} \Pi_{1 w}\left(1, \mathbb{P}_{s_{1}}=1,\left\{\mathbb{P}_{s_{1}(+)}\right\}\right) \operatorname{Pr}\left(\left\{\mathbb{P}_{s_{1}(+)}\right\}\right) \\
+\left(1-\theta r_{s_{1}}(0)\right) \sum_{\left\{\mathbb{P}_{s_{1}(+)}\right\}} \Pi_{1 w}\left(1, \mathbb{P}_{s_{1}}=0,\left\{\mathbb{P}_{s_{1}(+)}\right\}\right) \operatorname{Pr}\left(\left\{\mathbb{P}_{s_{1}(+)}\right\}\right) .
\end{gathered}
$$

The right-hand side (RHS) of equation (25) is upstream industry w's expected profit without taking into account the impact of potential cascading protection in downstream industry $s_{1}$. Using the RHS of equation (25) and iterating the same expansion over $s=s_{2}, s=s_{3} \ldots$ until $s=S$, we get $E\left(\Pi_{1 w}\left(\mathbb{P}_{w}=1\right)\right)>E_{0}\left(\Pi_{w}\left(\mathbb{P}_{w}=1\right)\right)$.

\footnotetext{
${ }^{66}$ Notice that we get $P_{1 w}>P_{2 w}$ when $\mathbb{P}_{w}=1$ because we assumed away other trade costs (e.g. transportation fees) in our model for simplicity. If transportation costs of shipping goods $w$ from country 1 to country 2 are asymmetrically high, $P_{1 w}>P_{2 w}$ may not hold even after country 1 imposes trade protection. In a model that contains other type of iceberg trade costs, for $P_{1 w}>P_{2 w}$ to hold when $\mathbb{P}_{w}=1$, the pre-protection trading costs of shipping industry $w$ goods from country 1 to 2 and from 2 to 1 cannot differ too much.
} 
Figure A.1: Extensive Form of the Game (simplified)

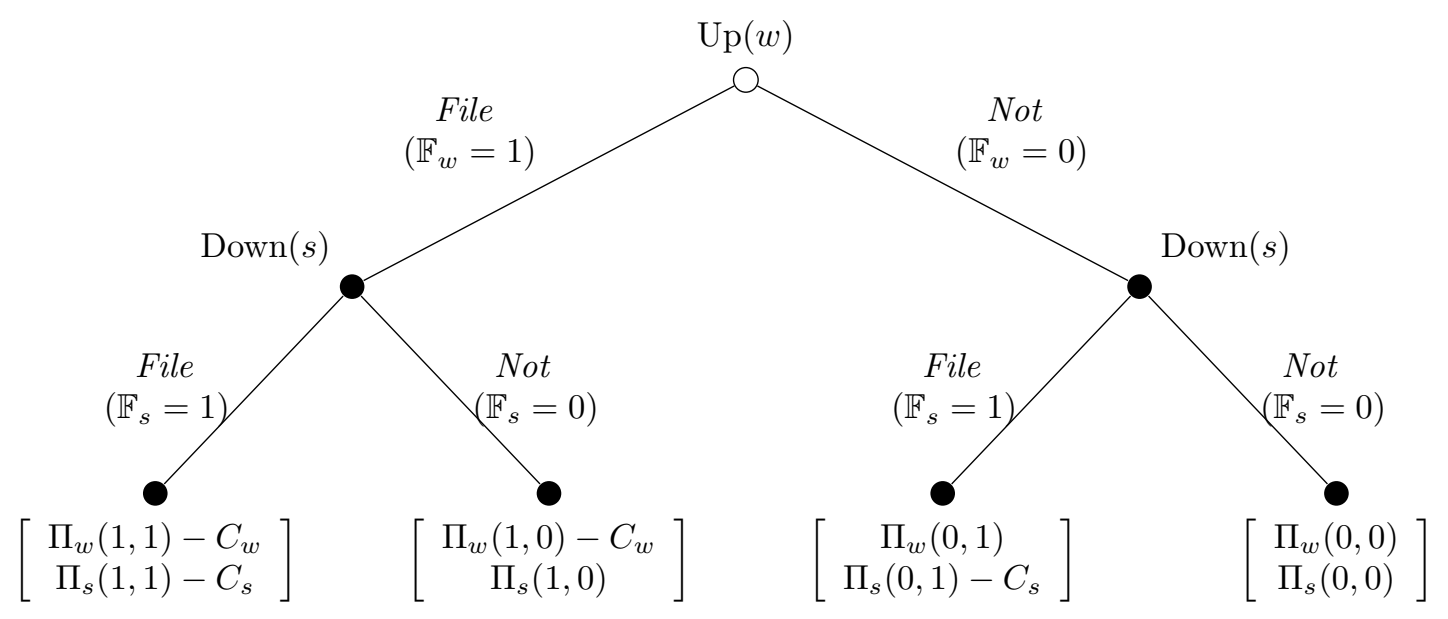

\section{A.3 The Petition Game}

In describing cascading protection, we have a two-stage game in mind. Without loss of generality, consider a simplified case in which $\theta=1$ and there are only two industries (upstream and downstream). The extensive form of the game is depicted in Figure A.1. The game starts at an initial decision node (represented by an open circle), where the upstream industry chooses its petition decision, perfectly accounting for its impact on the decision of the downstream industry. Here, $\theta=1$ implies that the government grants protection to every petitioning industry, so we don't distinguish decision $(\mathbb{F})$ from protection outcomes $(\mathbb{P})$. Then, conditional on upstream industry's move (and eventual protection status), the downstream industry makes its petition decision. Subsequently, the game reaches the terminal node with the relevant payoffs for the two players being realized.

Since we left the petition $\operatorname{cost} C$ unspecified (except that it is non-negative and consists of an i.i.d. shock component), any equilibrium outcome may emerge depending on the level of $C$. This can be best explained by considering two extreme cases. If the downstream industry's petition cost is infinite, it will never seek protection regardless of the upstream industry's move. In this case, upstream industry will file for protection if and only if $\Pi_{w}(1,0)-\Pi_{w}(0,0)>C_{w}$. Since $\Pi_{w}(1,0)-\Pi_{w}(0,0)>0$, there always exists a cut-off $\bar{C}_{w}$ such that the subgame Nash equilibrium is $\left(\mathbb{F}_{w}=1, \mathbb{F}_{s}=0\right)$ if $C_{w}<\bar{C}_{w}$, or $\left(\mathbb{F}_{w}=0, \mathbb{F}_{s}=0\right)$ if $C_{w} \geqslant \bar{C}_{w}$. Similarly, if $C_{s}$ equals zero, the downstream industry will always file for protection. In this case, the subgame Nash equilibrium is $\left(\mathbb{F}_{w}=1, \mathbb{F}_{s}=1\right)$ if $C_{w}$ is sufficiently low, or $\left(\mathbb{F}_{w}=0, \mathbb{F}_{s}=1\right)$ if $C_{w}$ is sufficiently high.

Working out the complete game reveals the importance of considering the intrinsic petition likelihood of industries (which we control for in our empirical analysis), and that observing $\left(\mathbb{F}_{w}=1, \mathbb{F}_{s}=1\right.$ ) as the equilibrium outcome does not necessarily imply the existence of cascading protection. Even though the petition decisions are meant to be the subgame perfect Nash equilibrium of the game, downstream petition can be caused by upstream protection or other factors, such as the intrinsic 
tendency of the industry to seek protection. Note that cascading protection, the subject of this paper, refers to the case where upstream trade protection increases the demand for protection in downstream industries. In other words, we are interested in whether the downstream industry (the second stage of the game) will be more likely to File for protection when the upstream industry has already chosen to File and got protected: i.e. whether $\left[\Pi_{s}(1,1)-C_{s}\right]-\Pi_{w}(1,0)>\left[\Pi_{s}(0,1)-C_{s}\right]-\Pi_{w}(0,0)$ naturally emerges from our model.

\section{A.4 Model Extensions with Discussions}

\section{A.4.1 Multi-country extension}

In this paper, we adopt a two-country model to focus on the interplay between domestic industries. In reality, the large majority of TTBs are applied bilaterally, raising the concern that downstream firms might simply switch suppliers, and thus cascading protection might not hold. Bearing in mind that a US TTB covers, on average, 45 percent of import values, and 50 percent of import volumes (i.e. TTBs tend to target the cheaper varieties) of the targeted products, we proceed in this section to show that cascading protection holds even under an environment with trade diversion 67 In any case, since we assume that protection is granted to restore home firms' domestic profits, cascading protection exists as long as upstream protection causes additional profit losses for downstream industries. This is true as long as the upstream varieties from targeted versus non-targeted countries are not perfect substitutes.

A more interesting extension will be if governments impose duties on targeted countries in order to make domestic firms price-competitive: when protection is imposed, it raises the prices of imported goods to match the prices of their domestic equivalents. In this case, upstream protection leads to a higher "dumping margin," hence higher protection for downstream firms with respect to targeted foreign countries - this increases the downstream firms' petition likelihood. However, upstream protection also benefits non-targeted foreign-country firms. This means that when duties are imposed on targeted countries, some of the gains will accrue to those non-targeted countries, which discourages downstream firms to file for protection. We proceed to examine if cascading protection still arises under this extension.

Consider a world with $J$ countries with Home denoted as country 1 . The rest of our assumptions remain the same. Now, the change in domestic profits of downstream industry $s$ after upstream protection on imports from $j, \Delta \Pi_{1 s} / \Delta \mathbb{P}_{j s}$, becomes:

$$
\frac{\Delta \Pi_{1 s}}{\Delta \mathbb{P}_{j s}}=\frac{\mu_{s} E_{1}}{\sigma_{s}}\left(\frac{N_{1 s} p_{1 s}^{1-\sigma_{s}}}{N_{1 s} p_{1 s}^{1-\sigma_{s}}+N_{j s} p_{1 s}^{1-\sigma_{s}}+\sum_{i \neq 1, j} N_{i s} p_{i s}^{1-\sigma_{s}}}-\frac{N_{1 s} p_{1 s}^{1-\sigma_{s}}}{N_{1 s} p_{1 s}^{1-\sigma_{s}}+N_{j s} p_{j s}^{1-\sigma_{s}}+\sum_{i \neq 1, j} N_{i s} p_{i s}^{1-\sigma_{s}}}\right),
$$

\footnotetext{
${ }^{67} \mathrm{US}$ AD investigations targeted 2.4 countries on average during 1988-2013.
} 
which can be rewritten as:

$$
\frac{\Delta \Pi_{1 s}}{\Delta \mathbb{P}_{j s}}=\underbrace{\left(1-M_{s}\right) \frac{\mu_{s} E_{1}}{\sigma_{s}}\left(\frac{N_{j s} p_{j s}^{1-\sigma_{s}}-N_{j s} p_{1 s}^{1-\sigma_{s}}}{N_{1 s} p_{1 s}^{1-\sigma_{s}}+N_{j s} p_{1 s}^{1-\sigma_{s}}}\right)}_{\text {two-country case }} \underbrace{\left.\frac{N_{1 s} p_{1 s}^{1-\sigma_{s}}+N_{j s} p_{1 s}^{1-\sigma_{s}}}{N_{1 s} p_{1 s}^{1-\sigma_{s}}+N_{j s} p_{1 s}^{1-\sigma_{s}}+\sum_{i \neq 1, j} N_{i s} p_{i s}^{1-\sigma_{s}}}\right)}_{\text {trade diversion }},
$$

where $M_{s}$ is the initial import penetration of industry $s$. When the set $J$ includes only two countries, the last term of the above equation drops out, in this case $\frac{\Delta \Pi_{1 s}}{\Delta \mathbb{P}_{j s}}$ is clearly an increasing function of $p_{1 s}$, hence cascading protection exists. When $J>2$, the last term is smaller than 1: in a multi-country setting, gains from trade protection are shared between the domestic and the non-affected foreign competitors. A larger $\sum_{i \neq 1, j} N_{i s} p_{i s}^{1-\sigma_{s}}$ implies greater trade diversion, and hence lesser incentives for the domestic industry to petition for protection.

Does cascading protection still exist in this extension? When an upstream industry gets protected, import penetration in the downstream industry increases due to rising imports from (i) country $j$ and (ii) other countries ${ }^{68}$ Here, (i) leads to the "injury transmission" effect we discussed in the two-country setting, which incentivizes downstream petition for protection. However, (ii) implies a larger market share for the unaffected foreign competitors prior to downstream petition, hence larger the trade diversion will be once downstream protection on country $j$ is granted. In other words, the existence of trade diversion reduces the likelihood of cascading protection. To see which effect dominates, suppose that upstream protection raises downstream prices from $p_{1 s}$ to $p_{1 s}^{\prime}$. Denote $\Delta p_{1 s} \equiv\left(p_{1 s}^{\prime}-p_{1 s}\right)>0$. After some algebra, the first-order Taylor expansion of $\Delta^{2} \Pi_{1 s} /\left(\Delta \mathbb{P}_{j s} \Delta \mathbb{P}_{h w}\right)$ can be expressed as:

$$
\frac{\Delta^{2} \Pi_{1 s}}{\Delta \mathbb{P}_{j s} \Delta \mathbb{P}_{h w}} \approx D_{1 j s}\left[\left(N_{1 s} p_{1 s}^{1-\sigma_{s}}\right)^{2}-N_{j s} p_{j s}^{1-\sigma_{s}} \sum_{i \neq 1, j} N_{i s} p_{i s}^{1-\sigma_{s}}-\left(\sum_{i \neq 1, j} N_{i s} p_{i s}^{1-\sigma_{s}}\right)^{2}+B_{1 j s}\right],
$$

where both $D_{1 j s}$ and $B_{1 j s}$ are positive ${ }^{69}$ Thus, the sufficient condition for cascading protection to occur is $\left(N_{1 s} p_{1 s}^{1-\sigma_{s}}\right)^{2}-N_{j s} p_{j s}^{1-\sigma_{s}} \sum_{i \neq 1, j} N_{i s} p_{i s}^{1-\sigma_{s}}-\left(\sum_{i \neq 1, j} N_{i s} p_{i s}^{1-\sigma_{s}}\right)^{2}>0$. Intuitively, cascading protection will occur only if the initial market share of non-affected foreign competitors is low enough. This sufficient condition can be written as $\left(1-M_{s}\right)^{2}-M_{j s} M_{s}>0$, where $M_{j s}$ is the initial import penetration of the targeted country $j$.

We check the data to see whether this sufficient statistic holds for each industry-county pair. We use the 1997 import penetration rate data and find that the average (median) sufficient statistic is 0.63 (0.67) with only 0.1 percent of observations showing a negative value. As an additional check we look at sufficient statistics for TTB measures imposed on industry-country pairs in 1998 (closest year to our 1997 import penetration data) and find positive values for all. This reveals that trade diversion is often not enough to offset pains from upstream protection, giving support to the two-country assumption

\footnotetext{
${ }^{68}$ Note that (i) here is formally represented by the first part of the equation labeled as "two-country case," whereas (ii) is represented by the second part of the equation labeled as "trade diversion."

${ }^{69}$ Here, $\quad D_{1 j s}=\frac{\left(\sigma_{s-1}\right) \mu_{s} E_{1} N_{1 s}}{\sigma_{s}}\left[\left(N_{1 s} p_{1 s}^{1-\sigma_{s}}+N_{j s} p_{1 s}^{1-\sigma_{s}}+\sum_{i \neq 1, j} N_{i s} p_{i s}^{1-\sigma_{s}}\right)\left(N_{1 s} p_{1 s}^{1-\sigma_{s}}+N_{j s} p_{j s}^{1-\sigma_{s}}+\right.\right.$ $\left.\left.\sum_{i \neq 1, j} N_{i s} p_{i s}^{1-\sigma_{s}}\right)\right]^{-2} N_{j s} p_{j s}^{1-\sigma_{s}} p_{1 s}^{-\sigma_{s}} \Delta p_{1 s}$ and $B_{1 j s}=\left[\left(N_{j s} p_{1 s}^{1-\sigma_{s}}\right)^{2}+2 N_{j s} N_{1 s} p_{1 s}^{2-2 \sigma_{s}}+2 N_{j s} p_{1 s}^{1-\sigma_{s}} \sum_{i \neq 1, j} N_{i s} p_{i s}^{1-\sigma_{s}}+\right.$ $\left.p_{1 s}^{1-\sigma_{s}} p_{j s}^{\sigma_{s}-1} \sum_{i \neq 1, j} N_{i s} p_{i s}^{1-\sigma_{s}}\left(2 N_{1 s} p_{1 s}^{1-\sigma_{s}}+N_{j s} p_{1 s}^{1-\sigma_{s}}+2 \sum_{i \neq 1, j} N_{i s} p_{i s}^{1-\sigma_{s}}\right)\right]$.
} 
for our study.

\section{A.4.2 Variable markups}

The CES demand adopted in this paper may be a rather strong assumption given the existing studies showing that trade protection positively affects the markups of protected domestic firms (see Atkin et al. (2015), Edmond et al. (2015), and De Loecker et al. (2016)). Again, with a profit-restoring government, cascading protection trivially exists since upstream protection causes downstream profit losses in a variable markup setting as well. Therefore, following the multi-country extension, we discuss the extension with variable markups under the assumption that governments impose duties to raise the prices of imported goods to match the prices of their domestic equivalents.

We adopt the quasi-linear preference setup from Meliz and Ottaviano (2008) to generate endogenous markups. Now, consumer preferences are given by the following utility function:

$$
U_{i}=Y_{i}+\sum X_{i s}
$$

where:

$X_{i s}=\alpha \sum_{j \in(1,2)} \int_{0}^{N_{j s}} x_{j i s}\left(u_{j s}\right) d u_{j s}-(\gamma / 2) \sum_{j \in(1,2)} \int_{0}^{N_{j s}} x_{j i s}^{2}\left(u_{j s}\right) d u_{j s}-(\eta / 2)\left(\sum_{j \in(1,2)} \int_{0}^{N_{j s}} x_{j i s}\left(u_{j s}\right) d u_{j s}\right)^{2}$.

The demand parameters $\alpha, \gamma$, and $\eta$ are all positive and we assume that consumers always consume a positive amount of the numeraire good; country 1 is the Home country and the rest of our assumptions remain the same. The markup $(m k)$ and quantity sold $(q)$ in country 1 industry $s$ are therefore:

$$
\begin{gathered}
m k_{i 1 s}=\left(C_{1 s, D}-c_{i s} \tau_{i 1 s}\right) / 2, \\
q_{i 1 s}=\left(C_{1 s, D}-c_{i s} \tau_{i 1 s}\right) E_{1} / 2 \gamma
\end{gathered}
$$

where $C_{1 s, D}$ is the cutoff marginal cost. Specifically,

$$
C_{1 s, D} \equiv \frac{2 \gamma \alpha+\eta\left[N_{1 s} c_{1 s}+N_{2 s} c_{2 s} \tau_{21 s}\right]}{\eta N_{s}+2 \gamma}
$$

where $N_{s}=N_{1 s}+N_{2 s}$ and $\tau_{21 s}=1+\frac{p_{1 s}-p_{2 s}}{p_{2 s}} \mathbb{P}_{s}$. We assume that $\alpha$ is large enough so that firms in both countries sell positive amounts of goods to the Home market.

The change in domestic downstream industry $s$ profits due to protection on imports from country 2 can be written as:

$$
\frac{\Delta \Pi_{1 s}}{\Delta \mathbb{P}_{s}}=\frac{\mu_{s} E_{1}}{4 \gamma}\left[\left(C_{1 s, D}\left(\mathbb{P}_{s}=1\right)-c_{1 s}\right)^{2}-\left(C_{1 s, D}\left(\mathbb{P}_{s}=0\right)-c_{1 s}\right)^{2}\right]
$$

When there is downstream protection, $C_{1 s, D}$ rises, leading to an increase in the domestic profits of country 1 firms. Denoting markups after downstream protection as $m k^{\prime}, \Delta \Pi_{1 s} / \Delta \mathbb{P}_{s}$ can be rewritten 
as:

$$
\frac{\Delta \Pi_{1 s}}{\Delta \mathbb{P}_{s}}=\Delta m k_{11 s} q_{11 s}+m k_{11 s}^{\prime} \Delta q_{11 s}
$$

The above equation decomposes the incentives for protection into two parts: (i) the increase in profits due to changes in markups based on initial sales, and (ii) the changes in profits due to the rise in sales under the new equilibrium price.

Does cascading protection still exist in this extension? Substituting into the expression of $C_{1 s, D}$ and after some algebra, we can write each part of the right-hand side of equation (26) as follows:

$$
\begin{gathered}
\Delta m k_{11 s}=\frac{\eta N_{2 s}}{\eta N_{s}+2 \gamma} \frac{c_{1 s}-c_{2 s}}{2}, \\
q_{11 s}=\frac{E_{1}}{2 \gamma} \frac{2 \gamma \alpha-2 \gamma c_{1 s}-\eta N_{2 s}\left(c_{1 s}-c_{2 s}\right)}{\eta N_{s}+2 \gamma} \\
m k_{11 s}^{\prime}=\frac{\gamma \alpha-\gamma c_{1 s}}{\eta N_{s}+2 \gamma} \\
\Delta q_{11 s}=\frac{E_{1}}{\gamma} \Delta m k_{11 s} .
\end{gathered}
$$

Whether cascading protection exists or not with variable markups depends on how the above four components change with upstream protection.

When an upstream industry gets protected, the marginal cost of domestic downstream industry $s$ $\left(c_{1 s}\right)$ increases. This entails a larger increase in markups $\left(\Delta m k_{11 s}\right)$ and domestic sale volumes $\left(\Delta q_{11 s}\right)$ if downstream protection is granted ${ }^{70}$ as increased marginal costs are transmitted to higher "dumping margins." Both the increase in markups and domestic sales encourage downstream industries to file for protection. However, the increased marginal cost due to upstream protection also leads to lower initial domestic sale volumes $\left(q_{11 s}\right)$ and lowers the post-downstream-protection markups $\left(m k_{11 s}^{\prime}\right)$ of the domestic downstream firms.71 Therefore, for a given "dumping margin," increased marginal costs always decrease the incentives of downstream industries to file for protection.72 Thus, with variable markups, whether cascading protection exists or not depends on which of the above mentioned forces prevail.

Writing $\Delta \Pi_{1 s} / \Delta \mathbb{P}_{s}$ as a function of $c_{1 s}$ and $c_{2 s}$, we get:

$$
\frac{\Delta \Pi_{1 s}}{\Delta \mathbb{P}_{s}}=\frac{\mu_{s} E_{1}}{4 \gamma} \frac{\eta N_{2 s}}{\left(\eta N_{s}+2 \gamma\right)^{2}}\left(c_{1 s}-c_{2 s}\right)\left[2 \gamma \alpha-2 \gamma c_{1 s}-\eta N_{2 s}\left(c_{1 s}-c_{2 s}\right)\right] .
$$

Now consider an increase in costs $\left(\Delta c_{1 s}\right)$ due to upstream protection. After some algebra, the firstorder Taylor expansion of $\Delta^{2} \Pi_{1 s} /\left(\Delta \mathbb{P}_{s} \Delta c_{1 s}\right)$ can be written as:

\footnotetext{
${ }^{70}$ Note that both $\Delta m k_{11 s}$ and $\Delta q_{11 s}$ are increasing functions of $c_{1 s}$.

${ }^{71}$ Note that $q_{11 s}$ and $m k_{11 s}^{\prime}$ are decreasing functions of $c_{1 s}$.

${ }^{72}$ With a quasi-linear demand function, domestic firms' profits are affected not only by their marginal costs relative to foreign competitors, but also by their absolute levels. High domestic production costs entail lower profit increases given a rise in foreign competitor prices.
} 


$$
\frac{\Delta^{2} \Pi_{1 s}}{\Delta \mathbb{P}_{s} \Delta c_{1 s}} \approx B_{1 s}\left[c_{2 s}+\frac{\gamma\left(\alpha-c_{2 s}\right)}{2 \gamma+\eta N_{2 s}}-c_{1 s}\right]
$$

where $B_{1 s} \equiv \frac{\mu_{s} E_{1}}{2 \gamma} \frac{\eta N_{2 s}\left(\eta N_{2 s}+2 \gamma\right)}{\left(\eta N_{s}+2 \gamma\right)^{2}}>0$. Therefore the sufficient condition for equation 27 to be positive is:

$$
c_{1 s}<c_{2 s}+\frac{\gamma\left(\alpha-c_{2 s}\right)}{2 \gamma+\eta N_{2 s}} .
$$

Notice that the positive sales in market 1 implies $0<c_{2 s}<\alpha$; so $\frac{\gamma\left(\alpha-c_{2 s}\right)}{2 \gamma+\eta N_{2 s}}$ is positive. Therefore equation (28) implies that in order for cascading protection to happen, the cost disadvantage of domestic firms prior to upstream protection cannot be too high. Given $c_{2 s}$, the above inequality is more likely satisfied with a high $\alpha$ and $\lambda$, and a low $\eta N_{2 s}$. Intuitively, cascading protection is more likely to happen if country 1's firms have market power in their domestic market. Unfortunately, equation (27) is difficult to bring to the data as we do not have information on the cost structures of firms. Thus, we stick to our CES framework and the empirical specification derived from it in the main text of the paper. Nevertheless, we do acknowledge the importance of taking into account variable markups, especially when analyzing heterogeneous effects: it sheds light on a plausible albeit rare scenario in which the downstream industry is so uncompetitive to start with that upstream protection could worsen the situation to such a degree that domestic protection will not save the industry - in this case upstream protection would discourage downstream petition.

Note that if there was a significant change in markups, then we should see price hikes by the protected industry. To check whether this is the case, we run the following regression at the industryyear level:

$$
\ln (\text { price index })_{w t}=\alpha+\beta \ln \left(\text { duty }_{w t}\right)+f_{w}+f_{t}+\epsilon_{w t},
$$

where $\alpha$ is a constant, and $f_{w}$ and $f_{t}$ are 6 -digit BEA industry and year fixed effects. We allow the errors $\epsilon_{w t}$ to be correlated over time and thus cluster them at the industry level. We get annual industry level price indices from the BEA that are available for 1998-2011. This regression results in a $\beta$ coefficient of -0.002 with $t$-statistic -0.11 , revealing that there is no significant relationship between higher duties on imported goods and the prices of their domestic substitutes. Using lagged duties or a measure dummy instead produce similar results.73 Even though a formal test for the effect of protection on domestic prices is beyond the scope of our paper, this result gives support to our CES assumption.

\section{A.4.3 Implications of potential retaliations}

A potential concern of assuming Home as the only active country in policy-making is that TTBs imposed by Home can lead to retaliations by the affected country, which might hinder cascading

\footnotetext{
${ }^{73}$ The caveat here is that price levels are calculated at the industry level whereas TTBs are imposed at the more disaggregate product level resulting in random measurement error, biasing the coefficient towards zero.
} 
protection. In this subsection we provide discussions and empirical evidence showing that this is not a major concern for our study.

If we consider that $\mathrm{AD}$ investigations require proof of injury due to increased import penetration, then retaliation is not viable as one country's protection does not increase import penetration rates in the other country - in fact, the import penetration of the downstream industry in the affected country decreases ${ }^{74}$ Thus, an AD measure in country 1 does not provide additional incentives for industries in country 2 to file for protection. Hence, if retaliation exists, incentives for it must lie on some political economy factors. In that case, country 2 can target any industry in country 175

We now discuss the implications of downstream and upstream retaliation separately. First, consider retaliation by country 2 in a downstream industry. Recall that given fixed income and number of firms in each country, protection imposed by one country doesn't affect export profits (see Appendix Section A.1). Thus, $\frac{\Delta^{2} \Pi_{1 s}}{\Delta \mathbb{P}_{s} \Delta \mathbb{P}_{w}}$ does not depend on the protection level in country 2: cascading protection still exists. Next, we consider retaliation by country 2 in an upstream industry $w^{\prime}$. The first-order Taylor approximation of $\frac{\Delta^{2} \Pi_{1 s}}{\Delta \mathbb{P}_{s} \Delta \mathbb{P}_{w}}$ becomes:

$$
\frac{\Delta^{2} \Pi_{1 s}}{\Delta \mathbb{P}_{s} \Delta \mathbb{P}_{w}} \approx \frac{\left(\sigma_{s}-1\right) \mu_{s} E_{1}}{\sigma_{s}} M_{s}\left(1-M_{s}\right)\left(\beta_{w s} M_{1 w} t_{21 w}-\beta_{w^{\prime} s} M_{2 w^{\prime}} t_{12 w^{\prime}}\right) .
$$

In other words, cascading protection will not occur if the country 2 downstream industry cost disadvantages caused by retaliation are larger than the country 1 downstream industry cost disadvantages caused by upstream protection. However, if retaliation is rare to begin with, then retaliation affecting the existence of cascading protection should be an extremely rare event. To check whether retaliation is rare, we pool TTB measures imposed on US products by countries that the US has targeted at least once during 1988-2013 ${ }^{76}$ Then, we run the following regression:

$$
X_{c t}=\alpha+\beta \max _{k \in(1,2,3)} M_{c t-k}+\phi_{c}+\delta_{t}+\epsilon_{c t},
$$

where $X_{c t}$ is a binary variable indicating whether country $c$ has imposed a measure on at least one US HS6 in year $t, M_{c t-k}$ is a dummy indicating whether the US has imposed a TTB on country $c$ goods in year $t-k$, and $\phi_{c}$ and $\delta_{t}$ are country and year fixed effects to control for unobservable country characteristics and macro shocks respectively. Our coefficient of interest is $\beta$ which proxies for the retaliatory effect of a US TTB imposed on goods from $c$ within the last three years. This regression produces a $\beta$ coefficient of 0.02 with a $t$-value of 0.28 , indicating that retaliation is not systematic and seems to be a rare phenomenon. Hence, retaliation that might alter incentives for cascading protection

\footnotetext{
${ }^{74}$ Following the literature, we assume that the other requirement of a successful AD investigation, namely finding "dumping," is rudimentary.

${ }^{75}$ See Blonigen and Bown (2003) for an analysis on the effect of retaliation threats on AD filings.

${ }^{76}$ The subset of these targeted countries that have HS6 level TTB data in the database are: Argentina, Australia, Brazil, Canada, Chile, China, EU, India, Indonesia, Israel, Korea, Malaysia, Mexico, Pakistan, Peru, South Africa, Turkey, and Venezuela. The database includes other US-targeted countries such as Ecuador, Japan, New Zealand, Philippines, Thailand, and Trinidad and Tobago, but we exclude them since they never imposed a bilateral TTB measure on US goods in 1988-2013.
} 
is quite unlikely.

\section{A.5 Exogenous Probability of Obtaining Protection: $\theta$}

We take the probability of being granted protection $(\theta)$ as exogenous because whether a TTB is granted or not largely hinges on the evidence of "material injury" rather than its causes ${ }^{77}$ If TTB investigations do in fact obey by (at least) the rule of establishing the existence of injury, then industries would not petition for protection without some form of injury (as they are requested to provide proof). Thus, we let $\theta$, conditional on petitioning, to be exogenous.

One may still wonder whether the granting authority, given injury, is more likely to approve the evidence (leading to a higher $\theta$ ) under some conditions. We considered four important factors that might influence the granting authority's decision: the existing upstream measures, level of injury, sector characteristics, and lobbying intensity. We now discuss them in turn. First, related to our study, we wondered whether the granting authority, given injury, is more likely to provide protection if there is already an upstream measure. However, injury might be due to upstream protection to begin with, thus there is no obvious reason as to why the authority would consider the existence of input measures. To test whether a downstream industry's likelihood of getting protection depends on existing measures on its inputs, we use the same independent variable that proxies for input cost shocks due to TTBs ${ }^{78}$ but change the dependent variable to a dummy that indicates whether a measure was imposed at the end of an investigation. Note that for these downstream industries in our sample, the mean probability of obtaining protection (given petition) is 57 and 61 percent for 1988-2013 and 1997-2013, respectively. Table A.3 shows the marginal effects from our conditional logit estimation that includes industry and year fixed effects. Like our main results in Table 3 , we do the estimation for two time periods and use the maximum instead of the mean affected share as robustness checks. As expected, marginal effects are not significantly different than zero, giving support to our fixed $\theta$ assumption 79

What about the importance of the level of injury? Note that assuming a positive relationship between the two would mean that cascading protection is even more likely to happen. Thus, our setting could be viewed as a conservative way of modeling cascading protection. Third, characteristics such as a sector's concentration level, economic importance and political power might also influence its granting probability. Though these factors may be important, as long as they are relatively stable over time, an industry-specific $\theta_{s}$ would not change the predictions of our model nor the empirical results. In fact, when we run the binary "successful petition" variable on industry and year fixed effects only, we get an $R^{2}$ of 0.45 , indicating that a large part of successful petition probability depends on non-

\footnotetext{
${ }^{77}$ All TTBs require some sort of evidence for injury (or threat of) to the domestic industry. In practice, as argued by Boltuck and Litan (1991) and Lindsey and Ikenson (2003), neither the petitioners nor the authorities almost never establish a rigorous causal relationship between rising imports and injury suffered by the domestic industry.

${ }^{78}$ Section 4 shows that an increase in this variable raises the likelihood of petitioning by a downstream industry.

${ }^{79} \mathrm{~A}$ caveat in these regressions is that we can only include investigations that have been initiated resulting in a selected sample - an industry might know that it won't be granted protection and thus not petition, which would be omitted from our analysis.
} 
time-varying industry-specific variables and macro shocks. Finally, lobbying intensity might result in a successful petition for protection. Lobbying intensity naturally affects the petition $\operatorname{cost} C$ and if we assume that the cost function is invertible, then $\theta$ becomes a function of $C$. In this case, the industry decides whether to petition or not, and decides its lobbying intensity once it petitions (or equivalently decides its petition cost). As long as we assume that $\theta$ is continuous in $C$, from the envelope theorem we know that cascading protection would still occur. In sum, even if the above mentioned factors might influence the probability of granting protection, they do not alter the existence of cascading protection, which is the main result of this paper. Moreover, it is difficult to provide convincing empirical evidence that $\theta$ crucially depends on the above factors. Hence, we think that an exogenous $\theta$, admittedly an abstraction from reality, is relatively innocuous for this study.

\section{A.6 TTBs and Import Prices}

As explained in Section 2.3, cascading protection depends on the effect of upstream protection on downstream profits. With the CES framework, the effect on downstream profits is at its maximum due to the complete pass-through of upstream duties. Although this is clearly an abstraction from reality, allowing incomplete pass-through will not alter the existence of cascading protection. As Section 2.3 depicts, cascading protection can occur if upstream protection adversely affects downstream profits - this is the case as long as the pass-through is positive. In other words, it is the existence of "transmission of injury," rather than the level of injury, that motivates cascading protection.

Empirically, Blonigen and Haynes (2002, 2010) examine US imports of Canadian iron and steel products in 1989-1995 and find a pass-through rate of around 60 percent for $\mathrm{AD}$ duties. In order to have a sense of the effect of $\mathrm{AD}$ measures on import prices, we run the following regression:

$$
\ln (u v)_{c h t}=\alpha+\beta \ln \left(d u t y_{c h t}\right)+f_{c h}+f_{c t}+f_{s t}+\epsilon_{c h t},
$$

where $\alpha$ is a constant, and $f_{c h}, f_{c t}$, and $f_{s t}$ are country-HS10 (variety), country-year, and industry (HS4)-year fixed effects in order to examine within-variety variation with purging time-varying trading partner and industry shocks. We allow the errors $\epsilon_{c h t}$ to be correlated over time and thus cluster them at the $c h$ level. We calculate unit values using the US import data from Schott (2008) who reports quantities and values 80 The $\beta$ coefficient we get is 0.13 , significant at the 1 percent level, indicating that measures do increase unit values albeit with less than perfect pass-through. Note that lagging the independent variable by one- and two-years also produce positive and statistically significant coefficients, indicating that targeted firms might be letting the price rise gradually. Our main analysis in the text takes this issue into account by having a three-year moving average cost shock. A possible explanation as to why we do not observe a higher pass-through of AD duties (in addition to the usual terms-of-trade explanation which we ignore in this paper for simplicity) is exits-when a country-

\footnotetext{
${ }^{80}$ We restrict the sample to country-products that were targeted at least once by an $\mathrm{AD}$ in the sample period for computational constraints.
} 
product is hit with a TTB measure, it might stop exporting to the US and thus would drop out from our regressions. If switching is costly, then this would entail additional costs to the downstream manufacturer, possibly leading to cascading protection.

\section{A.7 Concordance and Measurement Error}

\section{A.7.1 Concordance in steps}

This section explains the concordance of HTS products to BEA industry codes (based on NAICS6) in detail since the accuracy of this matching procedure is crucial in identifying the correct input-output relationships. In order to achieve maximum precision, we follow the steps below:

1. Convert all HS codes specified for US TTBs to HTS10 level using Schott's import data: This allows us to expand the investigated HS8, HS6, HS4 codes to HTS10 level and have a consistent product level dataset.

2. Match HTS10 to BEA industry codes using the BEA's 1997 concordance table: This results in 69 percent of cases matched with at least one BEA industry code.

3. Concord the HTS10 of the "unmatched" TTB cases overtime using the methodology by Pierce and Schott and rematch them to BEA industry codes using the BEA's 1997 concordance table: Now, 76 percent of cases are matched with at least one BEA industry code.

4. Match the HS8 of the "unmatched" TTB cases to BEA industry codes using the BEA's 1997 concordance table collapsed to the HS8 level: Now, 97 percent of cases are matched with at least one BEA industry code.

5. Match the remaining 33 cases manually using the names of the investigated products.

This procedure allows us to identify all the industries that are targeted by TTB investigations ${ }^{81}$ Note that since an investigation often includes several HTS10 codes, they can be assigned to multiple industries. In fact, the average TTB investigation covers 1.4 industries (median: 1). While the majority (82 percent) of investigations target only a single industry, two investigations stand out as they comprise more than 10 industries: Steel Wheels from China in 2011 (16 industries), and the Steel safeguard (12 industries) in 2001. Table A.1 shows the industries that have petitioned for protection in the sample period, with their respective counts, ex-post likelihood of successful petition (conditional on initiation), upstreamness, 1997 import penetration rates, and average import demand elasticities.

\section{A.7.2 Potential measurement error}

In this paper, inputs and outputs are linked using an IO table which is at the industry level. However, TTBs target products, and thus the concordance done at the industry level leads to measurement

\footnotetext{
${ }^{81}$ The output of this TTBs-to-industries match is available on request.
} 
error. In order to make sure that this error is not systematic, we look at whether the IO-matched TTB investigations make economic sense. Table A.2 shows examples of correct, incorrect, and missed matches. The majority of matches make economic sense, even though some require a product-level IO table to confirm.

It is important to note that there are IO-matched pairs that are not likely to be related (incorrect matches) - for example, silicon metal is matched as an input for manganese metal but this cannot be confirmed in industrial publications. On the other hand, there are also economically viable IOrelationships that are not matched in the data (missed matches). This happens largely because the products are within the same industry. An important example of this is the measures on cut-to-length steel place, and the subsequent $\mathrm{AD}$ initiation on its direct consumer clad steel plate. Thankfully, these two types of measurement error, which affect both the dependent and the independent variables, do not seem to be severe in the data.

\section{A.8 Additional Robustness Checks}

\section{A.8.1 Reduced-form results}

Here, we run simpler reduced-form regressions as a comparison to our main findings. The coefficient of interest is for the input cost shock which we proxy here as the log of last three-years' average $\sum_{w}\left(\beta_{w s} t_{21 w} \mathbb{P}_{w}\right)$. We use the linear probability model (LPM) to run the binary downstream petition variable $\mathbb{F}_{s t}$ on input cost shock and other variables that are deemed to be important factors of petitioning by our model: logged downstream market size $\left(\ln E_{s}\right)$, logged downstream import penetration ratio $\left(\ln M_{s}\right.$ ), and logged elasticity of substitution $\left(\ln \sigma_{s}\right)$. Table A.4 panel (a) shows the results for the LPM with random-effects, while panel (b) has the preferred industry fixed-effects specification. Columns (1) and (2) has the full sample period, and columns (3) and (4) examine the 1997-2013 period only. As we do in our main results, we use the maximum input cost shock instead of the mean as a robustness check in columns (2) and (4).

Panel (a) of Table A.4 shows that the input cost shock is consistently positive and statistically significant in all four columns. As expected, market size and import penetration rates have positive and significant effects on the probability of downstream petition; however, the elasticity of substitution does not seem to be an important factor based on these reduced-form regressions. Note that the randomeffects model might not be the correct specification as there might be factors in the error variable that are correlated with our regressors; one obvious example is the political clout of the downstream industry which might be correlated with market size and the probability of petitioning. Thus, in panel (b) we use industry fixed-effects to control for all inherent downstream industry characteristics. Again, all columns show that the input cost shock is an important predictor of downstream petitions 82

\footnotetext{
${ }^{82}$ Note that the other variables we used in the random-effects specification are dropped since they are collinear with industry fixed-effects.
} 


\section{A.8.2 Multinomial logit specification}

In order to explicitly examine whether input cost shocks have a differential effect on petitions versus measures, we follow Blonigen and Park (2004) and Konings and Vandenbussche (2008) and employ a multinomial logit specification based on a reduced-form of our structural equation. We estimate the effect of an input cost shock on a dependent variable which is " 0 " for non-filing as before, "1" for unsuccessful petitions, and "2" for successful petitions. Note that unlike Blonigen and Park (2004) and Konings and Vandenbussche (2008), who are concerned with the outcome of an investigation, our model predicts that upstream protection causes downstream demand for protection, but not necessarily downstream protection since the probability of protection is fixed and exogenous. In fact, our Appendix Section A.5 shows that the likelihood of obtaining protection $(\theta)$ depends on the existence of "material injury," regardless of whether this injury is caused by input measures or not.

Table A.5 shows the results with controls for industry-specific logged industry size $\left(\ln E_{s}\right)$, import penetration $\left(\ln M_{s}\right)$, and elasticity of substitution $\left(\ln \sigma_{s}\right)$. Columns (1) and (2) use the full sample period, while columns (3) and (4) examine the post-1997 period (we also use the maximum cost shock instead of the mean as a robustness check). The results show that the coefficient on the input cost shock is positive and statistically significant in all columns and crucially for both unsuccessful and successful petitions, with similar magnitudes. Also, changing the base outcome to unsuccessful petitions results in a statistically insignificant coefficient for input cost shocks for successful petitioning, and a negative and statistically significant coefficient for non-filing. These results reveal that input cost shocks do not change the outcome of an investigation but merely cause its petition, as predicted by our model ${ }^{83}$

\footnotetext{
${ }^{83}$ We thank one of the referees for pointing this out.
} 


\section{Appendix Tables and Figures}

Table A.1: Industry Characteristics

\begin{tabular}{|c|c|c|c|c|c|c|}
\hline $\begin{array}{l}\text { BEA } \\
\text { code }\end{array}$ & industry & $\begin{array}{l}\text { no of } \\
\text { cases }\end{array}$ & $\begin{array}{l}\text { likelihood of } \\
\text { protection }\end{array}$ & upstreamness & $\begin{array}{c}\text { import } \\
\text { penetration }\end{array}$ & $\begin{array}{l}\text { demand } \\
\text { elasticity }\end{array}$ \\
\hline 331111 & Iron and steel mills & 76 & 0.80 & 3.36 & 0.18 & 12.22 \\
\hline 325190 & $\begin{array}{c}\text { Other basic organic } \\
\text { chemicals }\end{array}$ & 29 & 0.69 & 3.85 & 0.20 & 8.09 \\
\hline 331222 & Steel wire drawing & 23 & 0.78 & 3.45 & 0.24 & 10.96 \\
\hline 325180 & $\begin{array}{c}\text { Other basic } \\
\text { inorganic chemicals }\end{array}$ & 22 & 0.68 & 3.42 & 0.15 & 6.28 \\
\hline 332910 & $\begin{array}{l}\text { Metal valve } \\
\text { manufacturing }\end{array}$ & 16 & 0.75 & 2.54 & 0.20 & 2.84 \\
\hline 331419 & $\begin{array}{l}\text { Primary nonferrous } \\
\text { metal, except copper } \\
\text { and aluminum }\end{array}$ & 13 & 0.85 & 3.42 & 0.60 & 9.14 \\
\hline 336300 & Motor vehicle parts & 11 & 0.64 & 2.30 & 0.22 & 6.31 \\
\hline 325130 & $\begin{array}{l}\text { Synthetic dye and } \\
\text { pigments }\end{array}$ & 10 & 0.50 & 3.52 & 0.27 & 12.56 \\
\hline 332991 & $\begin{array}{l}\text { Ball and roller } \\
\text { bearing }\end{array}$ & 9 & 0.89 & 3.15 & 0.25 & 4.59 \\
\hline $33361 \mathrm{~A}$ & $\begin{array}{c}\text { Speed changers and } \\
\text { mechanical power } \\
\text { transmission } \\
\text { equipment }\end{array}$ & 9 & 0.78 & 2.75 & 0.38 & 1.84 \\
\hline 331112 & $\begin{array}{l}\text { Ferroalloy and } \\
\text { related products }\end{array}$ & 7 & 0.86 & 3.36 & 0.56 & 4.50 \\
\hline 114100 & Fishing & 7 & 0.71 & 2.21 & 0.83 & 19.08 \\
\hline 325211 & $\begin{array}{l}\text { Plastics material and } \\
\text { resin }\end{array}$ & 6 & 1.00 & 3.57 & 0.12 & 5.22 \\
\hline $3221 \mathrm{~A} 0$ & $\begin{array}{c}\text { Paper and } \\
\text { paperboard mills }\end{array}$ & 6 & 1.00 & 3.03 & 0.14 & 17.24 \\
\hline 332999 & $\begin{array}{l}\text { Miscellaneous } \\
\text { fabricated metal } \\
\text { products }\end{array}$ & 6 & 0.83 & 2.64 & 0.28 & 7.69 \\
\hline 325998 & $\begin{array}{l}\text { Other miscellaneous } \\
\text { chemical products }\end{array}$ & 6 & 0.67 & 2.88 & 0.11 & 8.38 \\
\hline 332720 & $\begin{array}{l}\text { Turned product and } \\
\text { screw, nut, and bolt }\end{array}$ & 6 & 0.50 & 2.96 & 0.12 & 3.68 \\
\hline $112 \mathrm{~A} 00$ & $\begin{array}{l}\text { Animal production, } \\
\text { except cattle and } \\
\text { poultry and eggs }\end{array}$ & 5 & 1.00 & 2.58 & 0.07 & 20.47 \\
\hline 333415 & $\begin{array}{c}\mathrm{AC}, \text { refrigeration, } \\
\text { and forced air } \\
\text { heating }\end{array}$ & 5 & 1.00 & 2.12 & 0.13 & 10.52 \\
\hline
\end{tabular}


Table A.1 - Continued from previous page

\begin{tabular}{|c|c|c|c|c|c|c|}
\hline $\begin{array}{l}\text { BEA } \\
\text { code }\end{array}$ & industry & $\begin{array}{l}\text { no of } \\
\text { cases }\end{array}$ & $\begin{array}{l}\text { likelihood of } \\
\text { protection }\end{array}$ & upstreamness & $\begin{array}{c}\text { import } \\
\text { penetration }\end{array}$ & $\begin{array}{l}\text { demand } \\
\text { elasticity }\end{array}$ \\
\hline 311420 & $\begin{array}{l}\text { Fruit and vegetable } \\
\text { canning and drying }\end{array}$ & 5 & 1.00 & 1.44 & 0.08 & 11.34 \\
\hline 311410 & Frozen food & 5 & 0.80 & 1.28 & 0.05 & 12.73 \\
\hline 339994 & $\begin{array}{c}\text { Broom, brush, and } \\
\text { mop }\end{array}$ & 5 & 0.60 & 1.81 & 0.24 & 12.31 \\
\hline 111200 & $\begin{array}{l}\text { Vegetable and melon } \\
\text { farming }\end{array}$ & 5 & 0.60 & 1.36 & 0.14 & 7.96 \\
\hline 31499A & $\begin{array}{l}\text { Other miscellaneous } \\
\text { textile product mills }\end{array}$ & 5 & 0.40 & 2.12 & 0.17 & 28.92 \\
\hline 327310 & Cement & 4 & 1.00 & 2.99 & 0.12 & 4.28 \\
\hline 334413 & $\begin{array}{l}\text { Semiconductors and } \\
\text { related device }\end{array}$ & 4 & 1.00 & 2.91 & 0.36 & 7.46 \\
\hline 326110 & $\begin{array}{l}\text { Plastics packaging } \\
\text { materials, film and } \\
\text { sheet }\end{array}$ & 4 & 1.00 & 2.79 & 0.07 & 3.73 \\
\hline 325400 & $\begin{array}{c}\text { Pharmaceutical and } \\
\text { medicine }\end{array}$ & 4 & 1.00 & 2.19 & 0.28 & 9.73 \\
\hline 337127 & $\begin{array}{l}\text { Institutional } \\
\text { furniture }\end{array}$ & 4 & 1.00 & 1.09 & 0.26 & 2.68 \\
\hline 326290 & $\begin{array}{l}\text { Other rubber } \\
\text { products }\end{array}$ & 4 & 0.75 & 2.55 & 0.14 & 6.40 \\
\hline 334119 & $\begin{array}{l}\text { Other computer } \\
\text { peripheral } \\
\text { equipment }\end{array}$ & 4 & 0.75 & 1.69 & 0.65 & 7.86 \\
\hline 325212 & Synthetic rubber & 4 & 0.50 & 3.05 & 0.14 & 3.56 \\
\hline 333111 & $\begin{array}{c}\text { Farm machinery and } \\
\text { equipment }\end{array}$ & 4 & 0.50 & 1.36 & 0.26 & 7.88 \\
\hline 325311 & Nitrogenous fertilizer & 3 & 1.00 & 3.76 & 0.25 & 15.08 \\
\hline 331510 & $\begin{array}{l}\text { Ferrous metal } \\
\text { foundries }\end{array}$ & 3 & 1.00 & 3.13 & 0.04 & 7.58 \\
\hline 325222 & $\begin{array}{c}\text { Noncellulosic organic } \\
\text { fiber }\end{array}$ & 3 & 1.00 & 3.11 & 0.11 & 12.40 \\
\hline 321918 & $\begin{array}{l}\text { Other millwork, } \\
\text { including flooring }\end{array}$ & 3 & 1.00 & 2.43 & 0.11 & 4.48 \\
\hline 32619A & $\begin{array}{l}\text { Plastics plumbing } \\
\text { fixtures and all other } \\
\text { plastics products }\end{array}$ & 3 & 1.00 & 2.42 & 0.09 & 3.19 \\
\hline 33399A & $\begin{array}{c}\text { Scales, balances, and } \\
\text { misc. general } \\
\text { purpose machinery }\end{array}$ & 3 & 1.00 & 1.62 & 0.56 & 12.49 \\
\hline 315200 & Cut and sew apparel & 3 & 1.00 & 1.46 & 0.52 & 13.63 \\
\hline 333611 & $\begin{array}{l}\text { Turbine and turbine } \\
\text { generator set units }\end{array}$ & 3 & 1.00 & 1.44 & 0.25 & 26.75 \\
\hline
\end{tabular}

Continued on next page 
Table A.1 - Continued from previous page

\begin{tabular}{|c|c|c|c|c|c|c|}
\hline $\begin{array}{l}\text { BEA } \\
\text { code }\end{array}$ & industry & $\begin{array}{l}\text { no of } \\
\text { cases }\end{array}$ & $\begin{array}{l}\text { likelihood of } \\
\text { protection }\end{array}$ & upstreamness & $\begin{array}{c}\text { import } \\
\text { penetration }\end{array}$ & $\begin{array}{l}\text { demand } \\
\text { elasticity }\end{array}$ \\
\hline $33451 \mathrm{~A}$ & $\begin{array}{l}\text { Watch, clock, and } \\
\text { other measuring and } \\
\text { controlling device }\end{array}$ & 3 & 1.00 & 1.38 & 0.48 & 5.50 \\
\hline 336110 & $\begin{array}{l}\text { Automobile and } \\
\text { light truck }\end{array}$ & 3 & 1.00 & 1.00 & 0.32 & 24.94 \\
\hline 335312 & Motor and generator & 3 & 0.67 & 2.34 & 0.28 & 7.42 \\
\hline 321999 & $\begin{array}{l}\text { Miscellaneous wood } \\
\text { products }\end{array}$ & 3 & 0.67 & 2.23 & 0.30 & 4.71 \\
\hline 327112 & $\begin{array}{l}\text { Vitreous china and } \\
\text { earthenware articles }\end{array}$ & 3 & 0.67 & 1.73 & 0.63 & 3.69 \\
\hline 333120 & $\begin{array}{l}\text { Construction } \\
\text { machinery }\end{array}$ & 3 & 0.67 & 1.29 & 0.27 & 23.74 \\
\hline 336214 & $\begin{array}{l}\text { Travel trailer and } \\
\text { camper }\end{array}$ & 3 & 0.67 & 1.26 & 0.02 & 28.97 \\
\hline 335211 & $\begin{array}{l}\text { Electric housewares } \\
\text { and household fan }\end{array}$ & 3 & 0.67 & 1.20 & 0.58 & 3.50 \\
\hline $2122 \mathrm{~A} 0$ & $\begin{array}{l}\text { Gold, silver, and } \\
\text { other metal ore } \\
\text { mining }\end{array}$ & 2 & 1.00 & 4.02 & 1.00 & 12.14 \\
\hline 327125 & $\begin{array}{c}\text { Nonclay refractory } \\
\text { Secondary }\end{array}$ & 2 & 1.00 & 3.46 & 0.16 & 2.28 \\
\hline 331492 & $\begin{array}{l}\text { processing of other } \\
\text { nonferrous }\end{array}$ & 2 & 1.00 & 3.40 & 0.19 & 15.74 \\
\hline 331491 & $\begin{array}{l}\text { Nonferrous metal, } \\
\text { except copper and } \\
\text { aluminum, shaping }\end{array}$ & 2 & 1.00 & 3.40 & 0.11 & 4.00 \\
\hline 331315 & $\begin{array}{l}\text { Aluminum sheet, } \\
\text { plate, and foil }\end{array}$ & 2 & 1.00 & 3.14 & 0.09 & 9.28 \\
\hline 339991 & $\begin{array}{l}\text { Gasket, packing, and } \\
\text { sealing device }\end{array}$ & 2 & 1.00 & 3.13 & 0.21 & 2.65 \\
\hline 327910 & Abrasive products & 2 & 1.00 & 3.03 & 0.17 & 4.37 \\
\hline 321113 & Sawmills & 2 & 1.00 & 3.01 & 0.24 & 21.31 \\
\hline 321114 & Wood preservation & 2 & 1.00 & 3.01 & 0.01 & 2.03 \\
\hline $33441 \mathrm{~A}$ & $\begin{array}{l}\text { All other electronic } \\
\text { components }\end{array}$ & 2 & 1.00 & 2.90 & 0.47 & 5.01 \\
\hline 325992 & $\begin{array}{l}\text { Photographic film } \\
\text { and chemicals }\end{array}$ & 2 & 1.00 & 2.88 & 0.21 & 5.53 \\
\hline 313320 & Fabric coating mills & 2 & 1.00 & 2.82 & 0.17 & 3.44 \\
\hline 322226 & $\begin{array}{l}\text { Surface-coated } \\
\text { paperboard }\end{array}$ & 2 & 1.00 & 2.64 & 0.27 & 2.16 \\
\hline 326220 & $\begin{array}{l}\text { Rubber and plastics } \\
\text { hose and belting }\end{array}$ & 2 & 1.00 & 2.62 & 0.17 & 7.47 \\
\hline $32121 \mathrm{~A}$ & Veneer and plywood & 2 & 1.00 & 2.60 & 0.14 & 6.18 \\
\hline
\end{tabular}


Table A.1 - Continued from previous page

\begin{tabular}{|c|c|c|c|c|c|c|}
\hline $\begin{array}{l}\text { BEA } \\
\text { code }\end{array}$ & industry & $\begin{array}{l}\text { no of } \\
\text { cases }\end{array}$ & $\begin{array}{l}\text { likelihood of } \\
\text { protection }\end{array}$ & upstreamness & $\begin{array}{c}\text { import } \\
\text { penetration }\end{array}$ & $\begin{array}{l}\text { demand } \\
\text { elasticity }\end{array}$ \\
\hline 332500 & Hardware & 2 & 1.00 & 2.55 & 0.22 & 4.32 \\
\hline $32721 \mathrm{~A}$ & $\begin{array}{l}\text { Glass and glass } \\
\text { products, except } \\
\text { glass containers }\end{array}$ & 2 & 1.00 & 2.55 & 0.16 & 8.24 \\
\hline 332212 & Hand and edge tool & 2 & 1.00 & 2.27 & 0.23 & 1.92 \\
\hline 333618 & $\begin{array}{l}\text { Other engine } \\
\text { equipment }\end{array}$ & 2 & 1.00 & 2.26 & 0.22 & 7.60 \\
\hline 322233 & $\begin{array}{l}\text { Stationery and } \\
\text { related products }\end{array}$ & 2 & 1.00 & 2.10 & 0.21 & 2.48 \\
\hline 339940 & $\begin{array}{l}\text { Office supplies, } \\
\text { except paper }\end{array}$ & 2 & 1.00 & 1.98 & 0.26 & 2.38 \\
\hline 326210 & Tire & 2 & 1.00 & 1.94 & 0.20 & 9.63 \\
\hline 334513 & $\begin{array}{c}\text { Industrial process } \\
\text { variable instruments }\end{array}$ & 2 & 1.00 & 1.81 & 0.32 & 3.01 \\
\hline 333132 & $\begin{array}{l}\text { Oil and gas field } \\
\text { machinery and } \\
\text { equipment }\end{array}$ & 2 & 1.00 & 1.76 & 0.12 & 22.60 \\
\hline 327113 & $\begin{array}{l}\text { Porcelain electrical } \\
\text { supply }\end{array}$ & 2 & 1.00 & 1.73 & 0.18 & 1.43 \\
\hline 333924 & $\begin{array}{l}\text { Industrial truck, } \\
\text { trailer, and stacker }\end{array}$ & 2 & 1.00 & 1.60 & 0.31 & 21.73 \\
\hline 333922 & $\begin{array}{c}\text { Conveyor and } \\
\text { conveying equipment }\end{array}$ & 2 & 1.00 & 1.60 & 0.12 & 22.14 \\
\hline 333513 & $\begin{array}{l}\text { Metal forming } \\
\text { machine tool }\end{array}$ & 2 & 1.00 & 1.41 & 0.53 & 25.62 \\
\hline 334515 & $\begin{array}{l}\text { Electricity and signal } \\
\text { testing instruments }\end{array}$ & 2 & 1.00 & 1.38 & 0.22 & 1.67 \\
\hline 333313 & Office machinery & 2 & 1.00 & 1.35 & 0.51 & 16.68 \\
\hline 336991 & $\begin{array}{c}\text { Motorcycle, bicycle, } \\
\text { and parts }\end{array}$ & 2 & 1.00 & 1.22 & 0.51 & 10.84 \\
\hline 336120 & Heavy duty truck & 2 & 1.00 & 1.12 & 0.19 & 35.73 \\
\hline 334111 & Electronic computer & 2 & 1.00 & 1.04 & 0.13 & 5.46 \\
\hline $32222 \mathrm{~B}$ & $\begin{array}{c}\text { Coated and } \\
\text { uncoated paper bag }\end{array}$ & 2 & 1.00 & . & 0.21 & 2.80 \\
\hline 112100 & $\begin{array}{c}\text { Cattle ranching and } \\
\text { farming }\end{array}$ & 2 & 0.50 & 2.94 & 0.02 & . \\
\hline 332600 & $\begin{array}{l}\text { Spring and wire } \\
\text { products }\end{array}$ & 2 & 0.50 & 2.74 & 0.14 & 4.76 \\
\hline 332323 & $\begin{array}{l}\text { Ornamental and } \\
\text { architectural metal } \\
\text { work }\end{array}$ & 2 & 0.50 & 2.48 & 0.01 & 5.86 \\
\hline 314992 & $\begin{array}{l}\text { Tire cord and tire } \\
\text { fabric mills }\end{array}$ & 2 & 0.50 & 2.12 & 0.16 & 16.65 \\
\hline
\end{tabular}

Continued on next page 
Table A.1 - Continued from previous page

\begin{tabular}{|c|c|c|c|c|c|c|}
\hline $\begin{array}{l}\text { BEA } \\
\text { code }\end{array}$ & industry & $\begin{array}{l}\text { no of } \\
\text { cases }\end{array}$ & $\begin{array}{l}\text { likelihood of } \\
\text { protection }\end{array}$ & upstreamness & $\begin{array}{c}\text { import } \\
\text { penetration }\end{array}$ & $\begin{array}{l}\text { demand } \\
\text { elasticity }\end{array}$ \\
\hline 311611 & $\begin{array}{c}\text { Animal, except } \\
\text { poultry, slaughtering }\end{array}$ & 2 & 0.50 & 1.70 & 0.06 & 18.37 \\
\hline 333293 & $\begin{array}{l}\text { Printing machinery } \\
\text { and equipment }\end{array}$ & 2 & 0.50 & 1.58 & 0.48 & 8.48 \\
\hline $1113 \mathrm{~A} 0$ & Fruit farming & 2 & 0.50 & 1.51 & 0.40 & 12.88 \\
\hline 333220 & $\begin{array}{l}\text { Plastics and rubber } \\
\text { industry machinery }\end{array}$ & 2 & 0.50 & 1.47 & 0.46 & 48.05 \\
\hline 333112 & $\begin{array}{l}\text { Lawn and garden } \\
\text { equipment }\end{array}$ & 2 & 0.50 & 1.21 & 0.04 & 8.24 \\
\hline 339992 & Musical instrument & 2 & 0.50 & 1.15 & 0.51 & 4.56 \\
\hline 335221 & $\begin{array}{l}\text { Household cooking } \\
\text { appliance }\end{array}$ & 2 & 0.50 & 1.09 & 0.34 & 7.72 \\
\hline 337910 & Mattress & 2 & 0.50 & 1.03 & 0.01 & 3.12 \\
\hline $113 \mathrm{~A} 00$ & $\begin{array}{c}\text { Forest nurseries, } \\
\text { forest products, and } \\
\text { timber tracts }\end{array}$ & 2 & 0.00 & 4.60 & 0.19 & 4.68 \\
\hline 332312 & $\begin{array}{c}\text { Fabricated } \\
\text { structural metal }\end{array}$ & 2 & 0.00 & 2.64 & 0.03 & 7.32 \\
\hline 332313 & Plate work & 2 & 0.00 & 2.64 & 0.00 & 2.80 \\
\hline 331312 & $\begin{array}{l}\text { Primary aluminum } \\
\text { production }\end{array}$ & 1 & 1.00 & 3.81 & 0.26 & 14.50 \\
\hline 335991 & $\begin{array}{c}\text { Carbon and graphite } \\
\text { products }\end{array}$ & 1 & 1.00 & 3.75 & 0.21 & 2.79 \\
\hline 331421 & $\begin{array}{l}\text { Copper rolling, } \\
\text { drawing, and } \\
\text { extruding }\end{array}$ & 1 & 1.00 & 3.61 & 0.15 & 6.16 \\
\hline 327992 & $\begin{array}{l}\text { Ground or treated } \\
\text { minerals and earths }\end{array}$ & 1 & 1.00 & 3.49 & 0.09 & 4.60 \\
\hline 1111B0 & Grain farming & 1 & 1.00 & 3.40 & 0.03 & 5.18 \\
\hline 333515 & $\begin{array}{l}\text { Cutting tool and } \\
\text { machine tool } \\
\text { accessory }\end{array}$ & 1 & 1.00 & 3.16 & 0.17 & 4.18 \\
\hline 334612 & $\begin{array}{c}\text { Audio and video } \\
\text { media reproduction }\end{array}$ & 1 & 1.00 & 3.15 & 0.09 & 4.27 \\
\hline 334611 & $\begin{array}{l}\text { Software } \\
\text { reproducing }\end{array}$ & 1 & 1.00 & 3.15 & 0.01 & 1.50 \\
\hline 325221 & $\begin{array}{c}\text { Cellulosic organic } \\
\text { fiber }\end{array}$ & 1 & 1.00 & 3.11 & 0.15 & 10.15 \\
\hline 325920 & Explosives & 1 & 1.00 & 2.88 & 0.12 & 7.52 \\
\hline 313100 & $\begin{array}{l}\text { Fiber, yarn, and } \\
\text { thread mills }\end{array}$ & 1 & 1.00 & 2.77 & 0.06 & 6.93 \\
\hline
\end{tabular}

Continued on next page 
Table A.1 - Continued from previous page

\begin{tabular}{|c|c|c|c|c|c|c|}
\hline $\begin{array}{l}\text { BEA } \\
\text { code }\end{array}$ & industry & $\begin{array}{l}\text { no of } \\
\text { cases }\end{array}$ & $\begin{array}{l}\text { likelihood of } \\
\text { protection }\end{array}$ & upstreamness & $\begin{array}{c}\text { import } \\
\text { penetration }\end{array}$ & $\begin{array}{l}\text { demand } \\
\text { elasticity }\end{array}$ \\
\hline 212320 & $\begin{array}{l}\text { Sand, gravel, clay, } \\
\text { and refractory } \\
\text { mining }\end{array}$ & 1 & 1.00 & 2.76 & 0.01 & 6.06 \\
\hline 322210 & $\begin{array}{l}\text { Paperboard } \\
\text { container }\end{array}$ & 1 & 1.00 & 2.75 & 0.01 & 3.47 \\
\hline 335314 & $\begin{array}{c}\text { Relay and industrial } \\
\text { control }\end{array}$ & 1 & 1.00 & 2.73 & 0.25 & 1.89 \\
\hline 332998 & $\begin{array}{l}\text { Enameled iron and } \\
\text { metal sanitary ware }\end{array}$ & 1 & 1.00 & 2.64 & 0.10 & 3.05 \\
\hline 332430 & $\begin{array}{l}\text { Metal can, box, and } \\
\text { other container }\end{array}$ & 1 & 1.00 & 2.63 & 0.03 & 2.82 \\
\hline 334512 & $\begin{array}{c}\text { Automatic } \\
\text { environmental } \\
\text { control }\end{array}$ & 1 & 1.00 & 2.58 & 0.14 & 7.95 \\
\hline 323118 & $\begin{array}{l}\text { Blankbook and } \\
\text { looseleaf binder }\end{array}$ & 1 & 1.00 & 2.57 & 0.19 & 2.87 \\
\hline 334613 & $\begin{array}{l}\text { Magnetic and optical } \\
\text { recording media }\end{array}$ & 1 & 1.00 & 2.43 & 0.36 & 35.34 \\
\hline 336413 & $\begin{array}{l}\text { Other aircraft parts } \\
\text { and equipment }\end{array}$ & 1 & 1.00 & 2.43 & 0.30 & 13.43 \\
\hline 335930 & Wiring device & 1 & 1.00 & 2.42 & 0.20 & 4.24 \\
\hline 332996 & $\begin{array}{c}\text { Fabricated pipe and } \\
\text { pipe fitting }\end{array}$ & 1 & 1.00 & 2.39 & 0.02 & 2.52 \\
\hline 313220 & $\begin{array}{l}\text { Narrow fabric mills } \\
\text { and schiffli } \\
\text { embroidery }\end{array}$ & 1 & 1.00 & 2.30 & 0.22 & 6.47 \\
\hline 332213 & $\begin{array}{l}\text { Saw blade and } \\
\text { handsaw }\end{array}$ & 1 & 1.00 & 2.27 & 0.18 & 4.66 \\
\hline 314910 & $\begin{array}{l}\text { Textile bag and } \\
\text { canvas mills }\end{array}$ & 1 & 1.00 & 2.10 & 0.14 & 8.33 \\
\hline 333131 & $\begin{array}{l}\text { Mining machinery } \\
\text { and equipment }\end{array}$ & 1 & 1.00 & 1.76 & 0.25 & 18.78 \\
\hline 332420 & $\begin{array}{l}\text { Metal tank, heavy } \\
\text { gauge }\end{array}$ & 1 & 1.00 & 1.75 & 0.04 & 2.89 \\
\hline 333921 & $\begin{array}{c}\text { Elevator and moving } \\
\text { stairway }\end{array}$ & 1 & 1.00 & 1.60 & 0.12 & 13.62 \\
\hline 333923 & $\begin{array}{c}\text { Overhead cranes, } \\
\text { hoists, and monorail } \\
\text { systems }\end{array}$ & 1 & 1.00 & 1.60 & 0.12 & 11.47 \\
\hline 333298 & $\begin{array}{c}\text { All other industrial } \\
\text { machinery }\end{array}$ & 1 & 1.00 & 1.58 & 0.25 & 18.93 \\
\hline 316900 & $\begin{array}{l}\text { Other leather } \\
\text { products }\end{array}$ & 1 & 1.00 & 1.50 & 0.71 & 5.46 \\
\hline
\end{tabular}


Table A.1 - Continued from previous page

\begin{tabular}{|c|c|c|c|c|c|c|}
\hline $\begin{array}{l}\text { BEA } \\
\text { code }\end{array}$ & industry & $\begin{array}{l}\text { no of } \\
\text { cases }\end{array}$ & $\begin{array}{l}\text { likelihood of } \\
\text { protection }\end{array}$ & upstreamness & $\begin{array}{c}\text { import } \\
\text { penetration }\end{array}$ & $\begin{array}{l}\text { demand } \\
\text { elasticity }\end{array}$ \\
\hline 335311 & $\begin{array}{c}\text { Electric power and } \\
\text { specialty transformer }\end{array}$ & 1 & 1.00 & 1.50 & 0.18 & 19.93 \\
\hline 337215 & $\begin{array}{c}\text { Showcases, } \\
\text { partitions, shelving, } \\
\text { and lockers }\end{array}$ & 1 & 1.00 & 1.47 & 0.04 & 2.30 \\
\hline 33999A & $\begin{array}{c}\text { Buttons, pins, and } \\
\text { all other } \\
\text { miscellaneous } \\
\text { products }\end{array}$ & 1 & 1.00 & 1.44 & 0.35 & 3.62 \\
\hline 339112 & $\begin{array}{l}\text { Surgical and medical } \\
\text { instrument }\end{array}$ & 1 & 1.00 & 1.44 & 0.18 & 22.89 \\
\hline 333512 & $\begin{array}{l}\text { Metal cutting } \\
\text { machine tool }\end{array}$ & 1 & 1.00 & 1.41 & 0.52 & 39.25 \\
\hline 334210 & Telephone apparatus & 1 & 1.00 & 1.35 & 0.25 & 7.37 \\
\hline 111400 & $\begin{array}{c}\text { Greenhouse and } \\
\text { nursery production }\end{array}$ & 1 & 1.00 & 1.35 & 0.10 & 4.74 \\
\hline 334516 & $\begin{array}{l}\text { Analytical } \\
\text { laboratory } \\
\text { instrument }\end{array}$ & 1 & 1.00 & 1.31 & 0.27 & 4.23 \\
\hline 333912 & $\begin{array}{l}\text { Air and gas } \\
\text { compressor }\end{array}$ & 1 & 1.00 & 1.29 & 0.29 & 10.51 \\
\hline 314120 & $\begin{array}{l}\text { Curtain and linen } \\
\text { mills }\end{array}$ & 1 & 1.00 & 1.24 & 0.20 & 4.26 \\
\hline 336999 & $\begin{array}{l}\text { All other } \\
\text { transportation } \\
\text { equipment }\end{array}$ & 1 & 1.00 & 1.22 & 0.07 & 66.67 \\
\hline 311823 & Dry pasta & 1 & 1.00 & 1.18 & 0.14 & 30.12 \\
\hline 339910 & $\begin{array}{l}\text { Jewelry and } \\
\text { silverware }\end{array}$ & 1 & 1.00 & 1.14 & 0.50 & 9.20 \\
\hline 334300 & $\begin{array}{c}\text { Audio and video } \\
\text { equipment }\end{array}$ & 1 & 1.00 & 1.13 & 0.77 & 10.36 \\
\hline 333991 & $\begin{array}{c}\text { Power-driven } \\
\text { handtool }\end{array}$ & 1 & 1.00 & 1.13 & 0.34 & 1.93 \\
\hline 337124 & $\begin{array}{l}\text { Metal household } \\
\text { furniture }\end{array}$ & 1 & 1.00 & 1.10 & 0.31 & 3.20 \\
\hline 336992 & $\begin{array}{c}\text { Military armored } \\
\text { vehicles and tank } \\
\text { parts }\end{array}$ & 1 & 1.00 & 1.07 & 0.09 & 4.50 \\
\hline 335224 & $\begin{array}{c}\text { Household laundry } \\
\text { equipment }\end{array}$ & 1 & 1.00 & 1.06 & 0.10 & 5.87 \\
\hline 335222 & $\begin{array}{l}\text { Household } \\
\text { refrigerator and } \\
\text { home freezer }\end{array}$ & 1 & 1.00 & 1.05 & 0.10 & 9.67 \\
\hline
\end{tabular}


Table A.1 - Continued from previous page

\begin{tabular}{|c|c|c|c|c|c|c|}
\hline $\begin{array}{l}\text { BEA } \\
\text { code }\end{array}$ & industry & $\begin{array}{l}\text { no of } \\
\text { cases }\end{array}$ & $\begin{array}{l}\text { likelihood of } \\
\text { protection }\end{array}$ & upstreamness & $\begin{array}{c}\text { import } \\
\text { penetration }\end{array}$ & $\begin{array}{l}\text { demand } \\
\text { elasticity }\end{array}$ \\
\hline 337122 & $\begin{array}{l}\text { Nonupholstered } \\
\text { wood household } \\
\text { furniture }\end{array}$ & 1 & 1.00 & 1.01 & 0.32 & 3.18 \\
\hline 211000 & $\begin{array}{l}\text { Oil and gas } \\
\text { extraction }\end{array}$ & 1 & 0.00 & 3.35 & 0.44 & 10.94 \\
\hline 325120 & Industrial gas & 1 & 0.00 & 3.23 & 0.02 & 5.74 \\
\hline 331319 & $\begin{array}{l}\text { Other aluminum } \\
\text { rolling and drawing }\end{array}$ & 1 & 0.00 & 3.14 & 0.25 & 18.78 \\
\hline 212310 & $\begin{array}{l}\text { Stone mining and } \\
\text { quarrying }\end{array}$ & 1 & 0.00 & 2.77 & 0.02 & 13.18 \\
\hline & Other & & & & & \\
\hline 335929 & $\begin{array}{l}\text { communication and } \\
\text { energy wire }\end{array}$ & 1 & 0.00 & 2.74 & 0.20 & 2.63 \\
\hline 336412 & $\begin{array}{l}\text { Aircraft engine and } \\
\text { engine parts }\end{array}$ & 1 & 0.00 & 2.69 & 0.38 & 21.52 \\
\hline 333996 & $\begin{array}{l}\text { Fluid power pump } \\
\text { and motor }\end{array}$ & 1 & 0.00 & 2.62 & 0.19 & 2.29 \\
\hline 333995 & $\begin{array}{c}\text { Fluid power cylinder } \\
\text { and actuator }\end{array}$ & 1 & 0.00 & 2.62 & 0.13 & 2.23 \\
\hline 313240 & Knit fabric mills & 1 & 0.00 & 2.53 & 0.10 & 7.08 \\
\hline 311221 & Wet corn milling & 1 & 0.00 & 2.52 & 0.05 & 4.18 \\
\hline 332322 & Sheet metal work & 1 & 0.00 & 2.48 & 0.00 & 6.43 \\
\hline 334411 & Electron tube & 1 & 0.00 & 2.40 & 0.35 & 14.80 \\
\hline 335313 & $\begin{array}{c}\text { Switchgear and } \\
\text { switchboard } \\
\text { apparatus }\end{array}$ & 1 & 0.00 & 2.05 & 0.13 & 20.70 \\
\hline 335120 & Lighting fixture & 1 & 0.00 & 2.02 & 0.24 & 2.09 \\
\hline 335911 & Storage battery & 1 & 0.00 & 1.98 & 0.31 & 3.95 \\
\hline 334514 & $\begin{array}{c}\text { Totalizing fluid } \\
\text { meters and counting } \\
\text { devices }\end{array}$ & 1 & 0.00 & 1.97 & 0.20 & 2.30 \\
\hline 311700 & $\begin{array}{l}\text { Seafood product } \\
\text { preparation and } \\
\text { packaging }\end{array}$ & 1 & 0.00 & 1.82 & 0.14 & 13.85 \\
\hline 311612 & $\begin{array}{l}\text { Meat processed from } \\
\text { carcasses }\end{array}$ & 1 & 0.00 & 1.70 & 0.02 & 7.80 \\
\hline 311942 & Spice and extract & 1 & 0.00 & 1.55 & 0.10 & 7.52 \\
\hline 311615 & Poultry processing & 1 & 0.00 & 1.50 & 0.00 & 2.43 \\
\hline 311511 & Fluid milk & 1 & 0.00 & 1.47 & 0.00 & 20.38 \\
\hline 333911 & $\begin{array}{c}\text { Pump and pumping } \\
\text { equipment }\end{array}$ & 1 & 0.00 & 1.44 & 0.17 & 1.80 \\
\hline
\end{tabular}

Continued on next page 
Table A.1 - Continued from previous page

\begin{tabular}{|c|c|c|c|c|c|c|}
\hline $\begin{array}{l}\text { BEA } \\
\text { code }\end{array}$ & industry & $\begin{array}{l}\text { no of } \\
\text { cases }\end{array}$ & $\begin{array}{l}\text { likelihood of } \\
\text { protection }\end{array}$ & upstreamness & $\begin{array}{c}\text { import } \\
\text { penetration }\end{array}$ & $\begin{array}{l}\text { demand } \\
\text { elasticity }\end{array}$ \\
\hline 333319 & $\begin{array}{c}\text { Other commercial } \\
\text { and service industry } \\
\text { machinery }\end{array}$ & 1 & 0.00 & 1.29 & 0.05 & 12.59 \\
\hline 311911 & $\begin{array}{l}\text { Roasted nuts and } \\
\text { peanut butter }\end{array}$ & 1 & 0.00 & 1.19 & 0.16 & 24.08 \\
\hline $31181 \mathrm{~A}$ & $\begin{array}{l}\text { Bread and bakery } \\
\text { products, except } \\
\text { frozen }\end{array}$ & 1 & 0.00 & 1.18 & 0.02 & 23.17 \\
\hline 335912 & Primary battery & 1 & 0.00 & 1.12 & 0.16 & 5.69 \\
\hline
\end{tabular}

Source: Authors' calculations based on the Temporary Trade Barriers Database (Bown 2014). Upstreamness is based on Antràs et al. (2012), import penetration rates (imports/(output - exports + imports)) are based on BEA (1997), and import demand elasticities are calculated using Broda and Weinstein 2006. 
Table A.2: Examples of Correct, Incorrect, and Missed Matches

Measures on input

Initiation on output

\section{A. Correct matches}

Ball bearings (1988)

Minivans (1989)

Limousines (1991)

Cold-rolled carbon steel sheet (1993)

Bicycles (1995)

Roofing nails (1996)

\begin{tabular}{cc}
\hline Manganese metal (1995) & Stainless steel products (1996, 1997, 1998) \\
\hline Hot-rolled carbon steel flat products (1999) & $\begin{array}{l}\text { Steel wire rope (2000) } \\
\text { Steel safeguard (2001) }\end{array}$ \\
\hline PET (2001) & Polyethylene retail carrier bags (2003) \\
\hline Steel safeguard (2002) & Hand trucks (2003) \\
& Steel wire strand (2003) \\
\hline Carboxymethylcellulose (2004) & Commodity matchbooks (2008) \\
\hline Graphite electrodes (2008) & Residential washers (2012) \\
\hline Aluminum extrusions (2010) & \\
Copper pipe and tube (2010) & \\
Galvanized steel wire (2011) &
\end{tabular}

\section{B. Incorrect matches}

Sulfanilic acid (1992)

Aramid fiber (1993)

Saccharin (2002)

PET resin (2004)

\section{Missed matches}

Stainless steel wire rod (1993)

Stainless steel bar (1994)

Steel reinforcing bars (1996)

Cut-to-length carbon steel plate (1993) Clad steel plate (1995)

Notes: Years in parentheses are the imposition and initiation years for inputs and outputs respectively. Inputs and outputs are matched according to the information provided by the ITC publications. This list is not exhaustive for any of the three categories.

Source: The ITC publications and the Temporary Trade Barriers Database (Bown, 2014). 
Table A.3: Likelihood of Obtaining Protection

\begin{tabular}{lcccc} 
& \multicolumn{2}{c}{$1988-2013$} & \multicolumn{2}{c}{$1997-2013$} \\
Dep. variable: & $(1)$ & $(2)$ & $(3)$ & $(4)$ \\
Final measure imposed & mean & max. & mean & max. \\
\hline \hline Marginal effect & -0.383 & -0.371 & -0.789 & -0.505 \\
& $(0.861)$ & $(0.556)$ & $(1.088)$ & $(0.691)$ \\
\hline Number of industries & 52 & 52 & 34 & 34 \\
Number of observations & 217 & 217 & 120 & 120 \\
Pseudo $R^{2}$ & 0.29 & 0.29 & 0.37 & 0.37 \\
\hline
\end{tabular}

Notes: Coefficients are average marginal effects. All regressions include industry and year fixed effects. Standard errors clustered by industries in parentheses.

Table A.4: Reduced-form Results (LPM)

(a) Random-effects

\begin{tabular}{lcccc} 
& \multicolumn{2}{c}{$1988-2013$} & \multicolumn{2}{c}{$1997-2013$} \\
Dep. variable: & $(1)$ & $(2)$ & $(3)$ & $(4)$ \\
Downstream petition & mean & max. & mean & max. \\
\hline \hline ln input cost shock ${ }_{s t}$ & $1.393^{* *}$ & $0.540^{* *}$ & $1.778^{* * *}$ & $0.648^{* * *}$ \\
& $(0.592)$ & $(0.233)$ & $(0.649)$ & $(0.271)$ \\
$\ln E_{s}$ & $0.026^{* * *}$ & $0.026^{* * *}$ & $0.022^{* * *}$ & $0.022^{* * *}$ \\
& $(0.008)$ & $(0.008)$ & $(0.008)$ & $(0.008)$ \\
$\ln M_{s}$ & $0.013^{* * *}$ & $0.013^{* * *}$ & $0.011^{* * *}$ & $0.011^{* * *}$ \\
& $(0.003)$ & $(0.003)$ & $(0.002)$ & $(0.002)$ \\
$\ln \sigma_{s}$ & 0.001 & 0.001 & -0.001 & -0.001 \\
& $(0.004)$ & $(0.004)$ & $(0.004)$ & $(0.004)$ \\
\hline Number of industries & 303 & 303 & 331 & 331 \\
Number of observations & 6,969 & 6,969 & 4,634 & 4,634 \\
\hline
\end{tabular}

(b) Fixed-effects

1988-2013

1997-2013

Dep. variable:

$(2)$

(3)

Downstream petition mean $\max$. mean $\max$.

\begin{tabular}{lcccc}
\hline \hline ln input cost shock & $1.104^{* *}$ & $0.445^{* *}$ & $1.549^{* *}$ & $0.587^{* *}$ \\
& $(0.490)$ & $(0.197)$ & $(0.627)$ & $(0.264)$ \\
\hline Number of industries & 303 & 303 & 331 & 331 \\
Number of observations & 6,969 & 6,969 & 4,634 & 4,634 \\
\hline
\end{tabular}

Notes: All regressions include year fixed effects. Panel (b) has industry fixed-effects. Standard errors clustered by industries in parentheses. ***, **, and * denote statistical significance at the 1, 5, and 10 percent levels respectively. 
Table A.5: Multinomial Logistic Regression

Dep. variable:

1988-2013

$1997-2013$

No-petition: 0; Unsuccessful petition: 1;

(1)

(2)

(3)

(4)

Successful petition: 2

mean max.

mean

$\max$.

\begin{tabular}{lcccc}
\hline \hline Determinants of unsuccessful petitions & & & & \\
\hline $\ln$ input cost shock $s t$ & $32.05^{* * *}$ & $12.27^{* *}$ & $28.95^{* * *}$ & $9.77^{* *}$ \\
& $(10.27)$ & $(5.15)$ & $(9.29)$ & $(3.83)$ \\
$\ln E_{s}$ & $0.431^{* * *}$ & $0.423^{* * *}$ & $0.423^{* * *}$ & $0.415^{* * *}$ \\
& $(0.102)$ & $(0.103)$ & $(0.134)$ & $(0.132)$ \\
$\ln M_{s}$ & $0.249^{* * *}$ & $0.253^{* * *}$ & $0.275^{* * *}$ & $0.276^{* * *}$ \\
& $(0.087)$ & $(0.087)$ & $(0.107)$ & $(0.107)$ \\
$\ln \sigma_{s}$ & 0.159 & 0.155 & 0.151 & 0.149 \\
& $(0.113)$ & $(0.113)$ & $(0.131)$ & $(0.130)$ \\
\hline Determinants of successful petitions & & & & \\
\hline $\ln$ input cost shock ${ }_{s t}$ & $31.20^{* *}$ & $12.90^{* *}$ & $25.31^{* *}$ & $8.59^{*}$ \\
& $(13.37)$ & $(5.79)$ & $(12.07)$ & $(4.63)$ \\
$\ln E_{s}$ & $0.567^{* * *}$ & $0.560^{* * *}$ & $0.462^{* * *}$ & $0.458^{* * *}$ \\
& $(0.145)$ & $(0.146)$ & $(0.145)$ & $(0.143)$ \\
$\ln M_{s}$ & $0.405^{* * *}$ & $0.410^{* * *}$ & $0.346^{* * *}$ & $0.347^{* * *}$ \\
& $(0.094)$ & $(0.093)$ & $(0.075)$ & $(0.075)$ \\
$\ln \sigma_{s}$ & -0.170 & -0.171 & $-0.228^{*}$ & $-0.228^{*}$ \\
& $(0.131)$ & $(0.131)$ & $(0.134)$ & $(0.134)$ \\
\hline Number of industries & 303 & 303 & 331 & 331 \\
Number of observations & 6,969 & 6,969 & 4,634 & 4,634 \\
\hline & 0.11 & 0.11 & 0.11 & 0.10 \\
\hline
\end{tabular}

Notes: All regressions include year fixed effects. Standard errors clustered by industries in parentheses.

$* * *, * *$, and $*$ denote statistical significance at the 1,5 , and 10 percent levels respectively. 